\title{
OPTIMIZATION OF CHAR FOR NOx REMOVAL
}

\section{FINAL REPORT}

June 30, 1995-June 29, 1998

by

J. Phillips, L. R. Radovic, B. Xia and J. A. Menendez

The Pennsylvania State University

University Park, PA 16802

September 1999

DE-FG22-95PC95225--04 


\section{DISCLAIMER}

This report was prepared as an account of work sponsored by an agency of the United States Government. Neither the United States Government nor any agency thereof, nor any of their employees, makes any warranty, express or implied, or assumes any legal liability or responsibility for the accuracy, completeness, or usefulness of any information, apparatus, product, or process disclosed, or represents that its use would not infringe privately owned rights. Reference herein to any specific commercial product, process, or service by trade name, trademark, manufacturer, or otherwise does not necessarily constitute or imply endorsement, recommendation, or favoring by the United States Government or any agency thereof. The views and opinions of authors expressed herein do not necessarily state or reflect those of the United States Government or any agency thereof. 
DISCLAIMER ……............................................................................ ii

ABSTRACT .................................................................................... iii

LIST OF FIGURES ………………........................................................... vii

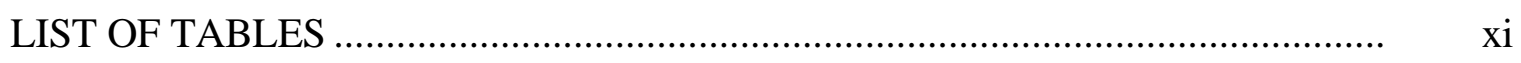

Chapter 1. INTRODUCTION ............................................................................

Chapter 2. EXPERIMENTAL TECHNIQUES AND PROCEDURES....................... 6

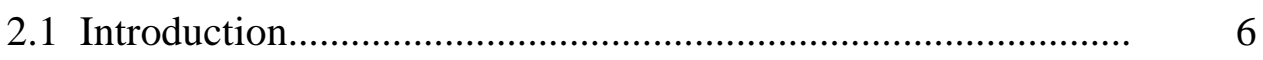

2.2 Sample Preparation....................................................................

2.3 Physical Characterization........................................................... 8

2.4 Chemical Surface Characterization............................................... 9

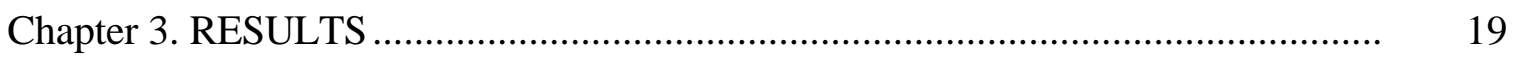

3.1 Physical Properties ................................................................... 19

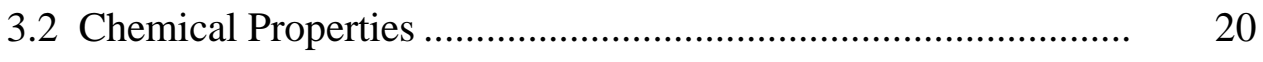

3.3 Electrochemical Properties.......................................................... 21

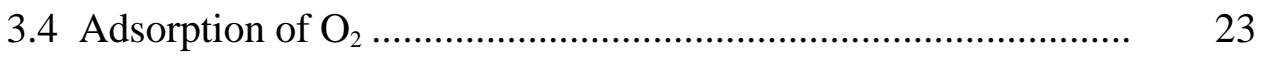

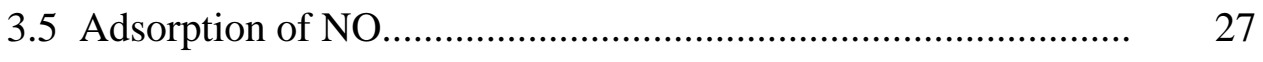

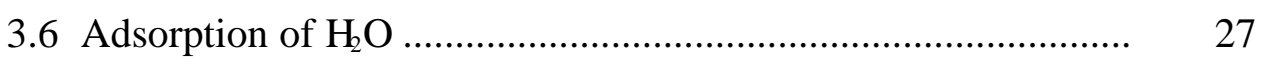

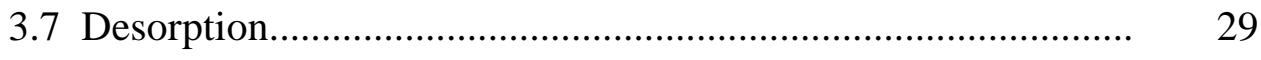




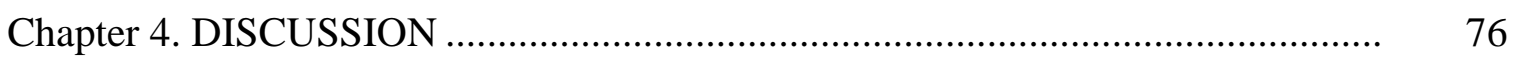

4.1 Effect of Chemical Treatments ................................................. 76

4.2 Surface Stabilization Model............................................................ 77

4.3 NO Selective Adsorption .......................................................... 84

4.4 Carbon Basicity.................................................................. 84

4.5 Carbon Hydrophobicity............................................................. 86

4.6 Low Temperature Generation of Basic Carbon Surfaces

By Hydrogen Spillover........................................................... 93

Chapter 5. CONCLUSIONS .......................................................................... 101

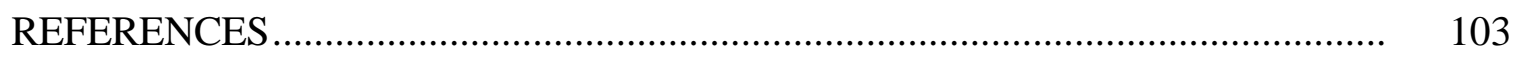




\section{ABSTRACT}

Work performed for this study demonstrates that the temperature of treatment and the identity of the treatment gas both strongly impact the surface chemistry of activated carbon. Two commercial activated carbons were treated in either $\mathrm{N}_{2}$ or $\mathrm{H}_{2}$ at different temperatures up to $2600^{\circ} \mathrm{C}$. Several techniques - including microcalorimetry, point of zero charge measurements, thermal desorption - were used to provide insight into important aspects of the chemical surface properties. The results show that activated carbons treated at high temperatures $\left(\mathrm{ca} .950^{\circ} \mathrm{C}\right)$ in hydrogen will not react with oxygen and water at ambient temperatures; moreover, surfaces created in this fashion have stable properties in ambient conditions for many months. In contrast, the same carbons treated in an inert gas (e.g., $\mathrm{N}_{2}$ ) will react strongly with oxygen and water at ambient temperatures. In the presence of platinum (or any other noble metal), stable basic carbons, which will not adsorb oxygen in ambient laboratory conditions, can be created via a relatively low-temperature process. Treatment at higher temperatures $\left(>1500^{\circ} \mathrm{C}\right)$ produced increasingly stable surfaces in either $\mathrm{N}_{2}$ or $\mathrm{H}_{2}$.

A structural model is proposed. To wit: Treatment at high temperatures in any gas will lead to the desorption of oxygen surface functionalities in the form of $\mathrm{CO}$ and/or $\mathrm{CO}_{2}$. Absent any atom rearrangement, the desorption of these species will leave highly unsaturated carbon atoms ("dangling carbons") on the surface, which can easily adsorb $\mathrm{O}_{2}$ and $\mathrm{H}_{2} \mathrm{O}$. In an inert gas these "dangling carbons" will remain, but hydrogen treatments will remove these species and leave the surface with less energetic sites, which can only adsorb $\mathrm{O}_{2}$ at elevated temperatures. Specifically, hydrogen reacts with any 
highly unsaturated carbons in the surface to form methane.

At temperatures greater than $1500^{\circ} \mathrm{C}$ (e.g., $1800^{\circ} \mathrm{C}, 2600^{\circ} \mathrm{C}$ ), structural annealing takes place and the consequent growth in the size of graphene layers eliminates the highly energetic dangling carbon sites. The basicity of the surface originates from two types of Lewis base sites: the localized electron pairs at the edges of the graphene layers and the delocalized $\pi$ electrons on the basal planes.

A hydrogen spillover mechanism was proposed here to explain the lowtemperature process for the stable basic carbon. The role played by platinum (or any noble metal) is to produce atomic hydrogen, which spills over onto the carbon surface. This atomic hydrogen hydrogasifies the most reactive, unsaturated carbon atoms at far lower temperatures than molecular hydrogen, thus leading to surface stabilization at relatively low temperatures. 


\section{LIST OF FIGURES}

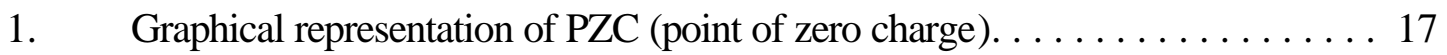

2. Cut-away side-view of microcalorimeter system $\ldots \ldots \ldots \ldots \ldots \ldots \ldots$

3. Representative x-ray diffractograms for activated carbon $\mathrm{H} 950$ and carbons after heat treatments at $1800^{\circ} \mathrm{C}(\mathrm{H} 950 / 1800)$ and $2600^{\circ} \mathrm{C}$

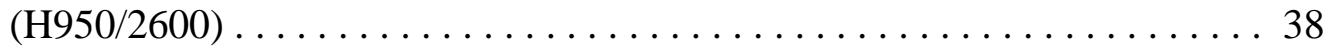

4. Mass titration curves for as received and surface-treated carbons . . . . . . . 39

5. Changes in the point of zero charge of $\mathrm{H} 950$ and H500/PtC upon

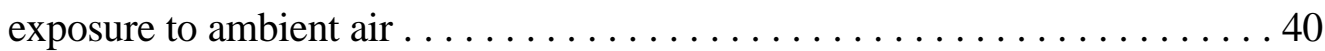

6. Variations in the point of zero charge $(\mathrm{PZC})$ with treatment temperature (in $\left.\mathrm{H}_{2}\right)$ for asreceived Norit $\mathrm{C}$ carbon $(\boldsymbol{\Delta})$ and for surface-modified carbon samples in the presence of a Pt catalyst: $\mathbf{\square}$, Norit $\mathrm{C}$ mixed with commercial activated carbon $\quad$ containing $\quad 1 \% \quad \mathrm{Pt}$ catalyst (in a ratio of $1 ; 2$ ); $\mathrm{O}$, Norit $\mathrm{C}$ treated in a different boat-downstream; commercial activated carbon containing $1 \% \mathrm{Pt}$, previously exposed to concentrated nitric acid at $60^{\circ} \mathrm{C}$ for $64 \mathrm{~h} \ldots \ldots \ldots \ldots \ldots \ldots$

7. Differential heats of oxygen adsorption as a function of surface coverage for surface-treated $\mathrm{Nc}$ activated carbons at $25^{\circ} \mathrm{C} \ldots \ldots \ldots \ldots . \ldots . \ldots 42$

8. Oxygen adsorption isotherms at $25^{\circ} \mathrm{C}$ for surface-treated $\mathrm{Nc}$ activated

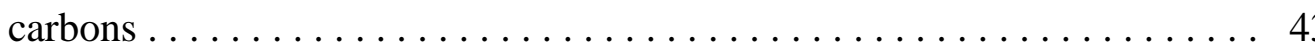

9a. Differential heats of $\mathrm{O}_{2}$ adsorption at 25 and $150^{\circ} \mathrm{C}$ as a function of surface coverage for as-received and acid-washed (aw) $\mathrm{H}_{2}$-treated activated carbons. . . . . . . . . . . . . . . . . . . . . . . . . . . . . . . . . . 44

9b. $\mathrm{O}_{2}$ adsorption isotherms at 25 and $150^{\circ} \mathrm{C}$ as a function of surface coverage for as-received and acid-washed (aw) $\mathrm{H}_{2}$-treated activated carbons. . . . . . . . . 45

10a. Differential heats of $\mathrm{O}_{2}$ adsorption at 25 and $150^{\circ} \mathrm{C}$ as a function of surface coverage for as-received and acid-washed (aw) $\mathrm{N}_{2}$-treated

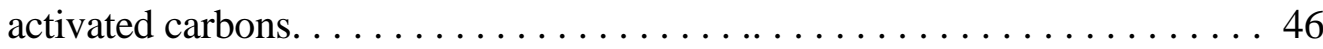

10b. $\mathrm{O}_{2}$ adsorption isotherms at 25 and $150^{\circ} \mathrm{C}$ as a function of surface coverage for as-received and acid-washed (aw) $\mathrm{N}_{2}$-treated activated carbons. 
11a. Plots of the normalized adsorption parameter vs. surface coverage for $\mathrm{O}_{2}$ adsorption at $25^{\circ} \mathrm{C}$ for surface treated activated carbon $\mathrm{Nc} \ldots \ldots \ldots \ldots . . .48$

11b. Plots of the normalized adsorption parameter vs. surface coverage for $\mathrm{O}_{2}$ adsorption at $150^{\circ} \mathrm{C}$ for surface treated activated carbon $\mathrm{Nc}$. . . . . . . . . . 49

12a. Heats of $\mathrm{O}_{2}$ adsorption as a function of surface coverage at $25^{\circ} \mathrm{C}$ on as-received and surface-treated carbons. . . . . . . . . . . . . . . 50

12b. $\mathrm{O}_{2}$ adsorption isotherms at $25^{\circ} \mathrm{C}$ on as-received and surface-treated carbons. . . 51

13a . Heats of $\mathrm{O}_{2}$ adsorption on $\mathrm{N}_{2}$-treated BPL carbon at $25^{\circ} \mathrm{C}$ and $150^{\circ} \mathrm{C} \ldots \ldots 52$

13b. $\mathrm{O}_{2}$ adsorption isotherms on $\mathrm{N}_{2}$-treated BPL carbon at $25^{\circ} \mathrm{C}$ and $150^{\circ} \mathrm{C} \ldots \ldots 53$

14a. Heats of $\mathrm{O}_{2}$ adsorption on $\mathrm{H}_{2}$-treated $\mathrm{BPL}$ carbon at $25^{\circ} \mathrm{C}$ and $150^{\circ} \mathrm{C} \ldots \ldots 54$

14b. $\mathrm{O}_{2}$ adsorption isotherms on $\mathrm{H}_{2}$-treated $\mathrm{BPL}$ carbon at $25^{\circ} \mathrm{C}$ and $150^{\circ} \mathrm{C} \ldots \ldots 5$

15a. Heats of adsorption of $\mathrm{NO}$ and $\mathrm{O}_{2}$ as a function of surface coverage at $25^{\circ} \mathrm{C}$ for

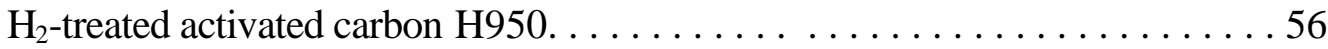

15b. $\mathrm{O}_{2}$ and $\mathrm{NO}$ adsorption isotherms at $25^{\circ} \mathrm{C}$ for $\mathrm{H}_{2}$-treated activated carbon H950 . . . . . . . . . . . . . . . . . . . . . . . . . . . . . . . . . . 57

16a. Heats of adsorption of $\mathrm{NO}$ and $\mathrm{O}_{2}$ as a function of surface coverage at $25^{\circ} \mathrm{C}$ for $\mathrm{N}_{2}$-treated activated carbon $\mathrm{N} 950 \ldots \ldots \ldots \ldots \ldots \ldots$

16b. $\mathrm{O}_{2}$ and $\mathrm{NO}$ adsorption isotherms at $25^{\circ} \mathrm{C}$ for $\mathrm{N}_{2}$-treated activated carbon

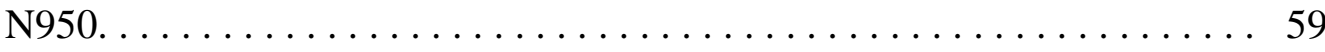

17. Plot of heat and the normalized adsorption parameter vs. surface coverage for NO

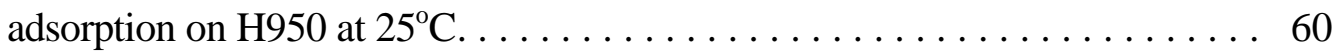

18. Plot of heat and the normalized adsorption parameter vs. surface coverage for NO

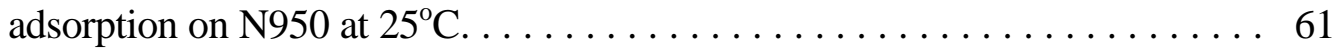

19a. Water vapor adsorption isotherms at $70^{\circ} \mathrm{C}$ for activated carbon $\mathrm{Nc}$ and carbons treated in $\mathrm{N}_{2}$ (N950) and in $\mathrm{H}_{2}(\mathrm{H} 950) \ldots \ldots \ldots \ldots \ldots \ldots \ldots \ldots \ldots \ldots \ldots \ldots \ldots$ 
19b. Heats of water vapor adsorption as a function of surface coverage at $70^{\circ} \mathrm{C}$ on activated carbon $\mathrm{Nc}$ and carbons treated in $\mathrm{N}_{2}$ (N950) and in $\mathrm{H}_{2}(\mathrm{H} 950) \ldots .63$

19c. Heats of water vapor adsorption as a function of relative pressure at $70^{\circ} \mathrm{C}$ on activated carbon $\mathrm{Nc}$ and carbons treated in $\mathrm{N}_{2}$ (N950) and in $\mathrm{H}_{2}(\mathrm{H} 950) \ldots . .64$

20a. Water vapor adsorption isotherms at $70^{\circ} \mathrm{C}$ on $\mathrm{N} 950$ and $\mathrm{O}_{2}$-exposed $\mathrm{N} 950 \ldots 65$

20b. Heats of water vapor adsorption as a function of surface coverage at $70^{\circ} \mathrm{C}$ on $\mathrm{N} 950$ and $\mathrm{O}_{2}$-exposed $\mathrm{N} 950 \ldots \ldots \ldots \ldots \ldots \ldots \ldots \ldots \ldots \ldots \ldots \ldots \ldots \ldots \ldots \ldots \ldots \ldots \ldots$

20c. Heats of water vapor adsorption as a function of relative pressure at $70^{\circ} \mathrm{C}$ on $\mathrm{N} 950$

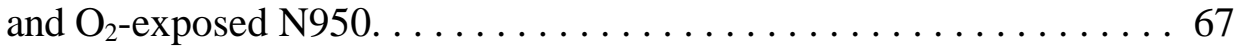

21a. Water vapor adsorption isotherms at $70^{\circ} \mathrm{C}$ on $\mathrm{H} 950$ and $\mathrm{O}_{2}$-exposed $\mathrm{H} 950$. . 68

21b. Heats of water vapor adsorption as a function of surface coverage at $70^{\circ} \mathrm{C}$ on $\mathrm{H} 950$

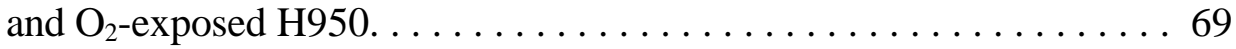

21c. Heats of water vapor adsorption as a function of relative pressure at $70^{\circ} \mathrm{C}$ on $\mathrm{H} 950$

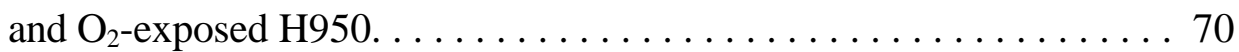

22. Temperature programmed desorption spectra for the as-recieved activated carbon

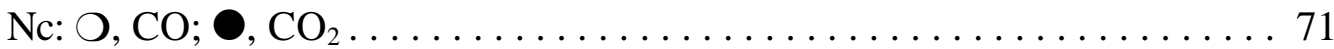

23. Temperature programmed desorption spectra for $\mathrm{N} 950$ obtained after $\mathrm{O}_{2}$ adsorption calorimetry experiment at $25^{\circ} \mathrm{C} . \mathrm{O}, \mathrm{CO} ; \mathrm{O}, \mathrm{CO}_{2} \ldots \ldots \ldots 72$

24. Temperature programmed desorption spectra for N950(aw) obtained after $\mathrm{O}_{2}$ adsorption calorimetry experiment at $25^{\circ} \mathrm{C} . \mathrm{O}, \mathrm{CO} ; \mathrm{O}, \mathrm{CO}_{2} \ldots \ldots \ldots 73$

25. Temperature programmed desorption spectra for N950 obtained after $\mathrm{O}_{2}$ adsorption calorimetry experiment at $150^{\circ} \mathrm{C} . \mathrm{O}, \mathrm{CO} ; \mathrm{O}, \mathrm{CO}_{2} \ldots \ldots \ldots .74$

26. Temperature programmed desorption spectra for N950(aw) obtained after $\mathrm{O}_{2}$ adsorption calorimetry experiment at $150^{\circ} \mathrm{C} . \mathrm{O}, \mathrm{CO} ; \mathrm{O}, \mathrm{CO}_{2} \ldots \ldots 75$

27. Proposed model for the stabilization of carbon surfaces upon heat treatment $(\Delta)$ in $\mathrm{N}_{2}$ (inert gas) and $\mathrm{H}_{2}$. For simplicity and illustrative purposes, only two types of oxygen surface groups (pyrone and lactone) and two types of carbon active sites are shown. These two types are in the order of increasing stability: (i) type I, "dangling carbon" sites (with only one nearest neighbor basal plane carbon); (ii) 
type II, divalent in-plane $\sigma$ pairs, Ar- $\bigcirc *$ (where $*$ represents a localized $\pi$ electron). Structure B is formed in $\mathrm{N}_{2}$, while structures C, D, E and F are formed in $\mathrm{H}_{2} \ldots \ldots \ldots \ldots \ldots \ldots$. . . . . . . . . . . . . . . . . . . . . 97

28. Mass spectrometric analysis of gases evolved upon in situ exposure of sample N950 to $\mathrm{O}_{2}$ at room temperature $\left(5 \% \mathrm{O}_{2}\right.$ in $\mathrm{He}$ at $\left.1 \mathrm{~atm}\right) \ldots \ldots \ldots \ldots . \ldots 9$

29. Proposed model for the adsorption of $\mathrm{O}_{2}$ at carbon active sites of different nature and stability: (a) low-temperature adsorption on highly energetic sites of type I ("dangling carbon"); (b) high-temperature adsorption on less energetic sites of type II (divalent in-plane $\sigma$ pairs) . . . . . . . . . . . . . . . . . . . . . . . . . . 99

30. Graphical representation of the hydrogen spillover model. ............ 100 


\section{LIST OF TABLES}

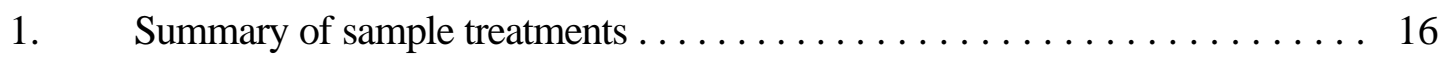

2. Summary of textural properties of as-received and surface-

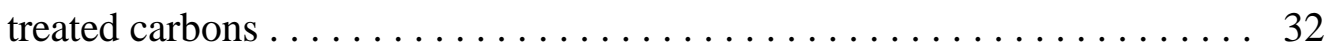

3. Structural parameters for selected carbons (in $\AA$ ) $\ldots \ldots \ldots \ldots \ldots \ldots \ldots$

4. Chemical analyses of as-received and chemically modified

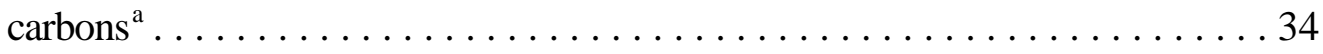

5. Chemical analyses of as-received and chemically modified

carbons (in which oxygen was determined directly)................ 35

6. Electrochemical properties of as-received and surface-treated

carbons ................................... 36

7. Amounts of $\mathrm{CO}, \mathrm{CO}_{2}$ and $\mathrm{O}_{2}$ calculated from TPD experiments

and of $\mathrm{O}_{2}$ adsorbed in the calorimetry experiments . . . . . . . . . . 37 


\section{Chapter 1}

\section{INTRODUCTION}

Activated carbons are well known to be excellent and versatile adsorbents and catalyst supports due to features such as highly microporous structure, inertness, good mechanical properties, high surface area, and especially variable internal surface structure and properties [1-3]. They are widely used to remove a broad spectrum of dissolved organic [4-5] and inorganic species [6-7] from both gas and liquid streams.

Among these special features of activated carbon, the high surface area and the surface chemical nature are most important for its adsorption properties. The surface of activated carbon consists primarily of basal planes as well as edges of graphitic planes which form the sides of microcrystallites. The basal planes are relatively uniform in nature and no functional groups are expected; therefore, the adsorption process on this type of surface would occur mainly as a result of physical van der Waals interaction [8]. The edges of microcrystallites contain a wide variety of functional groups and, therefore, are heterogeneous in nature. According to the affinity of the proton, these functional groups are usually characterized as acidic surface oxides (e.g., carboxyl, lactone, phenol structures) or basic surface oxides (e.g., pyrone and chromene structures) [9-12]. The population of surface functional groups largely determines the adsorption properties of the activated carbon, especially for polar or polarizable molecules [13]. Although the surface sites associated with functional groups constitute only a 
small portion of the total surface area, variations in their chemical nature may produce a marked change in the adsorption capacity and selectivity of the carbon for particular molecules.

Most studies of carbon surface chemistry have focused on acidic surface oxides. Only recently has there been a shift in emphasis to the study of carbon with basic and/or hydrophobic surface properties [14-16]. The interest arises from the need to generate basic surfaces for certain applications. For example, the adsorption affinity of phenolic compounds increases with increasing basicity of the carbon surface [17-19]. The presence of basic surface groups on carbon has also been found to increase the $\mathrm{SO}_{2}$ adsorption of activated carbon [20, 21]. Finally, it was found that basic carbons are more stable when stored in the environment in the presence of moisture. Acidic activated carbons often lose their adsorption capacity (the "aging effect") after long storage in the presence of moisture. Since the aging effect has been ascribed to a gradual surface oxidation [22, 23], and it is known that carbons with basic property are much more resistant to surface oxidation, it has been generally accepted that carbons with basic surface properties are much more resistant to aging [24-26]. Removal of aromatic compounds (e.g., phenol) from aqueous streams also requires hydrophobic surface properties. Indeed, adsorption sites on hydrophilic (i.e., acidic) surface can be at least partially blocked by water. Therefore, it is of great application value to prepare carbons with basic and/or hydrophobic surface properties.

By the careful control of the pretreatment condition, many research groups have tried to tailor carbon surface chemistry [27-30]. It is well documented that acid sites are associated with oxygen-containing functional groups. Thus, surface acidity is generated on the surface by 
carbon oxidation using a chemical or plasma treatment. Pre-oxidation of the carbon with nitric acid, $\mathrm{H}_{2} \mathrm{O}_{2}, \mathrm{O}_{3}$, or oxygen plasma is known to increase the number of acidic groups on the surface [31-34]. The character of "basic" sites on carbon surfaces is apparently more complex. Indeed, basic surface properties are due not only to the presence of some basic surface functional groups $[15,16]$ (e.g., chromene and pyrone-type structure), but also to the oxygenfree Lewis base sites on the basal planes, i.e., within the graphene layers that constitute the carbon crystallites [14]. Thus, different strategies are employed to create basic carbons. One common method is to expose the carbon to a high temperature $(>975 \mathrm{~K})$ in inert gas and thus remove the oxygen-containing groups. For example, activated carbons are known to acquire a basic character upon high temperature heat treatment in an inert atmosphere and subsequent exposure to air below $200^{\circ} \mathrm{C}$ [35]. Another way is to treat the carbon with special gases to introduce some basic surface oxides on the carbon or to saturate the carbon active sites by other atoms. Treatments with either ammonia [36, 37] or chorine $[26,38,39]$ have been shown to be effective methods to generate basic carbons. The former, carried out typically at 400$900^{\circ} \mathrm{C}$, removes the acidic oxygen-containing groups and also introduces basic nitrogencontaining groups onto the carbon surface; the latter can result in the formation of covalent bonds with carbon active sites, thus inhibiting carbon reactivity [40]. Early studies by Walker and coworkers has also suggested that $\mathrm{H}_{2}$ treatment could minimize the $\mathrm{O}_{2}$ chemisorption on the carbon surface, and thus maintain the carbon surface in a hydrophobic state [25]. The effectiveness of this approach has been confirmed more recently [26, 41]. However, these $\mathrm{H}_{2}-$ treated carbon were not characterized in any detail in the literature, and the types of site 
responsible for such basic property were not identified. Most prior work focused on heat treatment induced changes in the quantity of carbon active sites, rather than on the changes in their nature.

In this thesis it is demonstrated that the surface chemistry of high surface area activated carbons can be dramatically impacted by the temperature or the identity of the gas employed. Specifically, calorimetric studies show that high temperature $\left(950^{\circ} \mathrm{C}\right)$ treatments in inert atmosphere (e.g., nitrogen) can produce surfaces capable of strongly bonding significant quantities of oxygen at $298 \mathrm{~K}$. In contrast, treatment of the same carbon in hydrogen can create surface which will not bond oxygen at $300 \mathrm{~K}$. Other tests, such as point of zero charge measurements, also show dramatic changes. This profound change in surface chemistry is linked to modifications in the structure of the edge sites. These differences arise from variations in the nature of oxygen groups and carbon gasification processes as a function of the gas employed in pretreatment. In short, high temperature treatment in any gas leads to oxygen group removal as $\mathrm{CO}$ or $\mathrm{CO}_{2}$. It can readily be shown that this should leave some edge carbon atoms with only one or two bonds to the remaining structure. Such "dangling carbons" clearly will be active for adsorption. Treatment in an inert gas leaves the surface in this condition. In contrast, hydrogen treatment result in an additional process: gasification of weakly bond carbon atoms to form $\mathrm{CH}_{4}$. No "dangling carbons" capable of strong adsorption remain after a high temperature hydrogen treatment. This results in a profound difference in the surface chemistry of high temperature nitrogen-treated and hydrogen-treated surfaces. To wit: High temperature hydrogen treatments remove both oxygen groups and the "dangling carbons" that are created 
during the devolatilization of the carbon oxides. In contrast, high temperature treatment in nitrogen (or other inert gases) removes oxygen groups, but does not remove the "dangling carbons". 


\section{Chapter 2}

\section{EXPERIMENTAL TECHNIQUES AND PROCEDURES}

\subsection{Introduction}

To characterize the chemical surface properties of activated carbon, we used multiple techniques, including elemental analysis, point of zero charge measurement, temperature programmed desorption, and microcalorimetry. In particular, microcalorimetry is the most effective technique to count and differentiate the active sites on carbon surfaces.

\subsection{Sample Preparation}

\subsubsection{Nitrogen and hydrogen treated carbon}

A commercial activated carbon, Norit C-granular, prepared from a wood precursor by phosphoric acid activation (Nc), was used as the starting material for this study. Before any treatment, the sample was ground to $<0.21 \mathrm{~mm}$ (70 mesh). Since the activated carbons from natural sources all have some metal impurities, a demineralization process is desirable to remove all these possible impurities. Thus, the carbon sample was treated with $5 \mathrm{~N} \mathrm{HCl}$ at $60^{\circ} \mathrm{C}$ for $3 \mathrm{~h}$ and then washed with distilled-deionized water until no chloride ions appeared in the distillate solution. These samples were indicated by (aw). Another activated carbon, Calgon BPL, was also chosen as the starting material.

In most of the experiments, the as-received carbon or the demineralized carbon was subjected to a high temperature treatment, either in hydrogen or in an inert gas (e.g., nitrogen). 
Table 1 is a list of all samples treated, giving the treatment conditions used (gaseous atmosphere, time, and temperature). Typically $4 \mathrm{~g}$ of $\mathrm{Nc}$ were heated to $950^{\circ} \mathrm{C}$ in ultra-highpurity $\mathrm{N}_{2}$ or $\mathrm{H}_{2}$ at $25^{\circ} \mathrm{C} / \mathrm{min}$. The gas flow rate was controlled at $150 \mathrm{~mL} / \mathrm{min}$. After holding at $950^{\circ} \mathrm{C}$ for 3 hours, the sample was cooled to room temperature and stored either in ambient air

or in an environment that was free of oxygen. The treated samples were labeled as N950 for $\mathrm{N}_{2}$-treated, or $\mathrm{H} 950$ for $\mathrm{H}_{2}$-treated. Similarly, we made $\mathrm{N} 500$ by heating the $\mathrm{Nc}$ in $\mathrm{N}_{2}$ at $500^{\circ} \mathrm{C}$; we made $\mathrm{H} 800, \mathrm{H} 650$ and $\mathrm{H} 500$ by heating the $\mathrm{Nc}$ in $\mathrm{H}_{2}$ at $800^{\circ} \mathrm{C}, 650{ }^{\circ} \mathrm{C}$ and $500^{\circ} \mathrm{C}$. Sample N950/H650 was obtained by hydrogen treatment followed by $950^{\circ} \mathrm{C}$ nitrogen treatment. To acquire information regarding structural and surface chemical effects at even higher temperatures, Nc, N950 and H950 samples were further heated in a graphite furnace in an inert atmosphere until either $1800^{\circ} \mathrm{C}$ or $2600^{\circ} \mathrm{C}$.

\subsubsection{Low-temperature generation of basic carbon surface}

Two different carbons were employed in the experiments described below, an Norit C-Granular $(\mathbb{N c})$, described above, and a carbon-supported catalyst Alfa Aesar, JohnsonMatthey, Stk\#38343, containing 1 wt\% platinum in highly dispersed form (PtC). The particle sizes of the carbons were very different (PtC: 4 x 8 mesh, $\mathrm{Nc}<70$ mesh), allowing them to be separated by sieving at the completion of all treatments and prior to any characterization tests.

Samples were prepared in quartz boats placed within a quartz reactor $(5 \mathrm{~cm}$, i.d.) the same way as above (see Table 1). The PZC of the surface of this carbon $(\mathrm{PtC})$ as it arrived from the supplier showed it to be basic, with a value of 9.8. 
H150/PtC, H350/PtC, H425/PtC and H500/PtC listed in Table 1 are mixtures. In each case (except when indicated) the mixtures consisted of 1 part Nc and 2 parts (by mass) PtC. The mixtures were treated in $\mathrm{H}_{2}$ at $150,350,425$, and $500^{\circ} \mathrm{C}$ as noted. After treatment the two carbons were separated by sieving in all cases.

There was also one study conducted ("unmixed") in which the two carbons were present in the furnace together, but not all were intimately mixed. Three quartz boats, each $4 \mathrm{~cm}$ long, were used. The furthest upstream contained only $\mathrm{Nc}$, the middle boat contained a 2:1 mixture of PtC and Nc, and the third boat also contained only Nc. Each boat was separated from the others by a $5 \mathrm{~mm}$ gap. These carbons were treated at $500^{\circ} \mathrm{C}$ in flowing hydrogen (approximately $100 \mathrm{~cm}^{3} / \mathrm{min}$, equivalent to a velocity of about $5 \mathrm{~cm} / \mathrm{min}$ ) using the usual procedure.

\subsection{Physical Characterization}

\subsubsection{Surface area and porosity measurement}

The surface area and porosity measurements were carried out using physical adsorption of $\mathrm{N}_{2}$ at $-196^{\circ} \mathrm{C}$ and $\mathrm{CO}_{2}$ at $0^{\circ} \mathrm{C}$ in the Autosorb-6 volumetric system (Quantachrome Corporation). The surface areas were calculated from $\mathrm{N}_{2}$ adsorption data using the BET equation [42]. The micropore and mesopore volumes were obtained using DubininRadushkevich equation [43] and standard T-method, respectively [44].

\subsubsection{True density measurement}


True density was estimated with helium in a commercial picnometer (Accupic 1330, Micrometrics). The picnometer measures the volume of the particles excluding pores smaller than He atoms. Given the mass of the sample, the density is easily calculated. It is important to note that helium density excludes only closed porosity. Sometimes "true" densities are measured with water or other fluids, and these typically exclude a larger fraction of micropores.

\subsubsection{X-Ray diffraction (XRD)}

An XRD technique was used to study carbon structural features after treatments at very high temperature. The high-temperature samples used for these experiments were prepared in a graphite furnace in an inert atmosphere. Once the maximum treatment temperature was reached $\left(1800\right.$ or $\left.2600^{\circ} \mathrm{C}\right)$, it was maintained for $30 \mathrm{~min}$. The XRD analysis were carried out with a Philips MPD diffractometer. Structural parameters $\mathrm{L}_{\mathrm{c}}$ and $\mathrm{L}_{\mathrm{a}}$, roughly corresponding to crystallite height and width, were estimated from the (002) and (10) peaks [45-47]; the dspacing between the graphene layers was determined from the (002) diffraction peak.

\subsection{Chemical Surface Characterization}

\subsubsection{Elemental analysis}

The composition of the treated carbon samples was also obtained because trace impurities might play a significant role in the surface chemical properties. The elemental analysis was carried out by using a LECO CHN-600 instrument. The oxygen content was estimated by difference. Before the elemental analysis, all the samples were dried and demineralized. 
Since the Norit C-granular carbon is prepared from a wood precursor by phosphoric acid activation, the phosphorus contents were determined by using a Leeman Labs PS3000UV inductively coupled plasma emission spectrophotometer (ICP). Before the ICP analysis, all the sample were dried in vacuum.

\subsubsection{Point of zero charge (PZC) measurement}

One method to evaluate the electronic properties of carbon surfaces is by measuring the point of zero charge (PZC) $[48,49]$. The $\mathrm{PZC}$ is the value of $\mathrm{pH}$ required to give a solid surface zero net surface charge . In this work, the PZC of each sample was determined using a modified version of a method proposed by Noh and Schwarz [48]. A 10 wt $\%$ carbon slurry was prepared by mixing particles of carbon $(<0.21 \mathrm{~nm})$ with distilled-deionized water in a plastic bottle sealed under $\mathrm{N}_{2}$. The $\mathrm{pH}$ of the slurry was measured after shaking it for 24 hours. Some distilled-deionized water was subsequently added, and the previous procedure was repeated for slurries of $8,6,4,2$, and $1 \mathrm{wt} \%$. A plot of equilibrium $\mathrm{pH}$ vs solid weight fraction yields a curve and the equilibrium $\mathrm{pH}$ at the plateau of the curve corresponds to the PZC (Figure 1).

\subsubsection{Temperature programmed desorption (TPD)}


In temperature programmed desorption, a sample is heated in an inert gas environment (e.g., He, $\mathrm{N}_{2}$ ), in order to desorb species or decompose functional groups. The amount of gas desorbed as a function of temperature is an indication of both the adsorption strength and the concentration of species originally present [50-52]. In this study, the TPD spectra were obtained in a commercial steady-state transient kinetics apparatus (SSITKA 2000, Altamira Instruments) operated as a conventional fixed-bed reactor connected to a quadrupole mass spectrometer. Helium at $40 \mathrm{~mL} / \mathrm{min}$ was used as the carrier gas. The heating profile was controlled linearly at $10^{\circ} \mathrm{C} / \mathrm{min}$ to $1100^{\circ} \mathrm{C}$. The TPD studies of all the samples were carried out after the microcalorimetric study, so that the oxygen adsorbed and desorbed could be roughly correlated. This procedure also allowed us to establish a correlation between the heats of oxygen adsorption and the forms of desorbed oxygen (e.g., $\mathrm{CO}, \mathrm{CO}_{2}$ ).

\subsubsection{Microcalorimetry}

Instrument. Microcalorimetry techniques have an excellent potential for providing unprecedented insight into the structure and surface chemistry of high surface area materials, such as acid catalysts [53], supported metal catalysts [54], as well as carbons [55-57]. They can provide precise information concerning the concentration and nature of the active sites existing on carbon surfaces.

The microcalorimeter used in this work was designed, built and developed under the direction of Dr. Jonathan Phillips. Earlier reports from this lab describe an instrument which can be built with readily available equipment $[54,57,58]$. However, the instrument described earlier 
suffered from several limitations. Specifically, it could only be operated near room temperature. Thus, we developed a new design which enabled operation at temperatures as high as $200^{\circ} \mathrm{C}$. This permits the study of activated adsorption and ensures that the adsorbed phase is in equilibrium with the gas phase in many cases[59, 60].

The instrument described here (Figure 2) is not only far less expensive than commercial systems, it also has some features that are not found in those systems. For example, the dose volume is at the same temperature as the sample cell/thermopile sandwich. Also, the dose volume consists of two precision Baratron pressure gauges. Thus, pressure readings are available at every instant of time. This provides detailed information regarding the kinetics of adsorption.

This instrument is designed to allow for (1) in situ sample preparation either in vacuum or flowing gas at temperature as high as $1100^{\circ} \mathrm{C}$, (2) transfer of powder samples (as much as 8 $\mathrm{cm}^{3}$ ) under vacuum to the sample cell, (3) adsorption with thoroughly equilibrated gas, (4) precise determination of the amount of gas adsorbed, and (5) precise determination of the heat released at temperature ranging from 25 to $200^{\circ} \mathrm{C}$.

Samples are prepared in a quartz tube, placed in a tube furnace located outside the precisely temperature-controlled convection oven (Despatch, LND 1-42-3) containing the microcalorimeter. Gas from the gas handling system can be passed through the microcalorimeter and then over the sample, or the sample can be treated under a vacuum of $1 \times 10^{-6}$ torr. Following completion of the pre-treatment, the sample is transferred to the sample cell simply by tilting the convection oven to an angle of about $30-45^{\circ}$ relative to horizontal. The cradle holding 
the oven is so designed that the tilting and transfer process can be done by a single individual (Figure 2).

Gas is introduced to the sample in two steps. First, it is metered into the dose volume from the gas handling/vacuum system using a needle valve. The dose volume, which is entirely at the predetermined operating temperature, consists of two high temperature Baratron gauge heads (Model 615AD-MKS Instruments) and the tubing which connects them to (i) the vacuum/gas system and (ii) the sample cell. After a brief period of time (ca. 2 min), during which the gas equilibrates to the system, the second step is performed; gas is allowed into the sample chamber. The dose size can be adjusted so that 15 or more doses are needed to saturate the sample. The adsorption isotherms are obtained by plotting the uptake vs. equilibrium pressure at each dose.

For each dosing process, the adsorption heat released is measured by the thermopiles around the sample cell. Thus, a ballistic curve ( heat output vs time) is obtained at the same time. Integrating the area under these ballistic curves gives the quasi-differential heat of adsorption. A plot of differential heat vs adsorption amount can differentiate the active sites on the carbon surface.

To get a qualitative measure of relative adsorption rates, it is standard practice in our laboratory to normalize kinetic data from the pressure gauge. First, all pressure curves were normalized to read between one (the initial dose pressure) and zero (the final/equilibrium pressure reached). Second, the normalized adsorption time was obtained as the amount of time it takes for the pressure to drop to 0.1 on the normalized scale. Finally, the normalized 
adsorption parameter (NAP) for each dose was computed by dividing the normalized adsorption time for each dose by the normalized adsorption time of the first dose. A plot of NAP vs coverage yields a reasonable qualitative model of gradual changes in adsorption kinetics, reflecting both chemisorption and mass transfer processes.

Measurements. In contrast to the samples prepared for all the other characterization tests, the samples studied here were not exposed to ambient air until the analysis was completed. Using $\mathrm{Nc}, \mathrm{Nc}(\mathrm{aw})$ and BPL as starting samples, the different samples (N950, N500, H950, H500, N950(aw), H950(aw), BPL-n950, BPL-H950 etc, as well as a physical mixture of 7 parts (by mass) of $\mathrm{Nc}$ and 1 part of $\mathrm{PtC}$ in $\mathrm{H}_{2}$ at $500^{\circ} \mathrm{C}$ ) were prepared in situ following the same procedures described earlier, followed by cooling in the same gas to room temperature. Then the samples were gravity-transferred (avoiding air exposure) to the sample cell; they were successively evacuated for $20 \mathrm{~h}$ at $10^{-6}$ torr. Known microdoses of $\mathrm{O}_{2}$ were then introduced. The heat and pressure data were then collected simultaneously.

In ancillary experiments, adsorption of NO on N950 and H950 was also measured by using the same microcalorimeter and the same procedure, except that NO was the dosing gas.

By adding a branch line for a water container to the vacuum/gas handling line, this calorimeter was modified for measuring water adsorption properties of activated carbons. The oven was controlled at $70^{\circ} \mathrm{C}$, as was the pretreatment furnace. All the gas handling lines (outside the oven) where water vapor can reach were wrapped with heating tape, and the temperature was controlled below $60^{\circ} \mathrm{C}$. The temperature of the water outside the calorimeter 
was deliberately maintained at $10^{\circ} \mathrm{C}$ lower than that of the calorimeter to ensure that no condensation would take place inside any part of the calorimeter itself. By carefully controlling the temperature everywhere and controlling the dosing pressure, known microdoses of water vapor were then introduced sequentially. Prior to the adsorption runs, the water was distilled, deionized and degassed. Other measurements and procedures were the same as described above. 
Table 1. Summary of sample treatments.

\begin{tabular}{|c|c|c|}
\hline sample code & starting material & treatment \\
\hline N500 & $\mathrm{Nc}$ & $\mathrm{N}_{2}, 3 \mathrm{~h}, 500^{\circ} \mathrm{C}$ \\
\hline N950 & $\mathrm{Nc}$ & $\mathrm{N}_{2}, 3 \mathrm{~h}, 950^{\circ} \mathrm{C}$ \\
\hline $\mathrm{H} 150$ & $\mathrm{Nc}$ & $\mathrm{H}_{2}, 3 \mathrm{~h}, 150^{\circ} \mathrm{C}$ \\
\hline $\mathrm{H} 350$ & $\mathrm{Nc}$ & $\mathrm{H}_{2}, 3 \mathrm{~h}, 350^{\circ} \mathrm{C}$ \\
\hline $\mathrm{H} 450$ & $\mathrm{Nc}$ & $\mathrm{H}_{2}, 3 \mathrm{~h}, 450^{\circ} \mathrm{C}$ \\
\hline H500 & $\mathrm{Nc}$ & $\mathrm{H}_{2}, 3 \mathrm{~h}, 500^{\circ} \mathrm{C}$ \\
\hline H650 & $\mathrm{Nc}$ & $\mathrm{H}_{2}, 3 \mathrm{~h}, 650^{\circ} \mathrm{C}$ \\
\hline $\mathrm{H} 800$ & $\mathrm{Nc}$ & $\mathrm{H}_{2}, 3 \mathrm{~h}, 800^{\circ} \mathrm{C}$ \\
\hline H950 & $\mathrm{Nc}$ & $\mathrm{H}_{2}, 3 \mathrm{~h}, 950^{\circ} \mathrm{C}$ \\
\hline N950/H650 & $\mathrm{Nc}$ & $\mathrm{N}_{2}, 3 \mathrm{~h}, 950^{\circ} \mathrm{C}$, then $\mathrm{H}_{2}, 3 \mathrm{~h}, 650^{\circ} \mathrm{C}$ \\
\hline $\mathrm{H} 150 / \mathrm{Ptc}$ & Nc mixed with $\mathrm{PtC}$ & $\mathrm{H}_{2}, 3 \mathrm{~h}, 150^{\circ} \mathrm{C}$ \\
\hline $\mathrm{H} 350 / \mathrm{PtC}$ & Nc mixed with PtC & $\mathrm{H}_{2}, 3 \mathrm{~h}, 350^{\circ} \mathrm{C}$ \\
\hline $\mathrm{H} 425 / \mathrm{Ptc}$ & Nc mixed with $\mathrm{PtC}$ & $\mathrm{H}_{2}, 3 \mathrm{~h}, 425^{\circ} \mathrm{C}$ \\
\hline $\mathrm{H} 500 / \mathrm{Ptc}$ & Nc mixed with PtC & $\mathrm{H}_{2}, 3 \mathrm{~h}, 500^{\circ} \mathrm{C}$ \\
\hline $\mathrm{H} 500 / \mathrm{PtC}^{\mathrm{a}}$ & Nc mixed with PtC & $\mathrm{H}_{2}, 3 \mathrm{~h}, 500^{\circ} \mathrm{C}$ \\
\hline $\mathrm{H} 500 / \mathrm{PtC}^{\mathrm{b}}$ & Nc mixed with PtC & $\mathrm{H}_{2}, 3 \mathrm{~h}, 500^{\circ} \mathrm{C}$ \\
\hline $\mathrm{H} 500 / \mathrm{PtC}^{\mathrm{c}}$ & Nc mixed with $\mathrm{PtC}$ & $\mathrm{H}_{2}, 3 \mathrm{~h}, 500^{\circ} \mathrm{C}$ \\
\hline N950(aw) & $\mathrm{Nc}(\mathrm{aw})$ & $\mathrm{N}_{2}, 3 \mathrm{~h}, 950^{\circ} \mathrm{C}$ \\
\hline H950(aw) & $\mathrm{Nc}(\mathrm{aw})$ & $\mathrm{H}_{2}, 3 \mathrm{~h}, 950^{\circ} \mathrm{C}$ \\
\hline $\mathrm{Nc} / 1800$ & $\mathrm{Nc}$ & $\mathrm{N}_{2}, 30 \mathrm{~min}, 1800^{\circ} \mathrm{C}$ \\
\hline N950/1800 & N950 & $\mathrm{N}_{2}, 30 \mathrm{~min}, 1800^{\circ} \mathrm{C}$ \\
\hline H950/1800 & H950 & $\mathrm{N}_{2}, 30 \mathrm{~min}, 1800^{\circ} \mathrm{C}$ \\
\hline $\mathrm{Nc} / 2600$ & $\mathrm{Nc}$ & $\mathrm{N}_{2}, 30 \mathrm{~min}, 2600^{\circ} \mathrm{C}$ \\
\hline N950/2600 & N950 & $\mathrm{N}_{2}, 30 \mathrm{~min}, 2600^{\circ} \mathrm{C}$ \\
\hline $\mathrm{H} 950 / 2600$ & H950 & $\mathrm{N}_{2}, 30 \mathrm{~min}, 2600^{\circ} \mathrm{C}$ \\
\hline BPL-N950 & BPL & $\mathrm{N}_{2}, 3 \mathrm{~h}, 950^{\circ} \mathrm{C}$ \\
\hline BPL-H950 & BPL & $\mathrm{H}_{2}, 3 \mathrm{~h}, 950^{\circ} \mathrm{C}$ \\
\hline
\end{tabular}

PtC: commercial activated carbon-supported catalyst containing $1 \mathrm{wt} \% \mathrm{Pt}$;

Nc, BPL: commercial activated carbons; aw = acid wash .

${ }^{a}$ With PtC reused twice. ${ }^{b}$ With PtC reused three times. ${ }^{c} \mathrm{PtC}: \mathrm{Nc}=1: 2$ by mass.

Note: for all the samples prepared from Nc, prefix Nc- is omitted. 

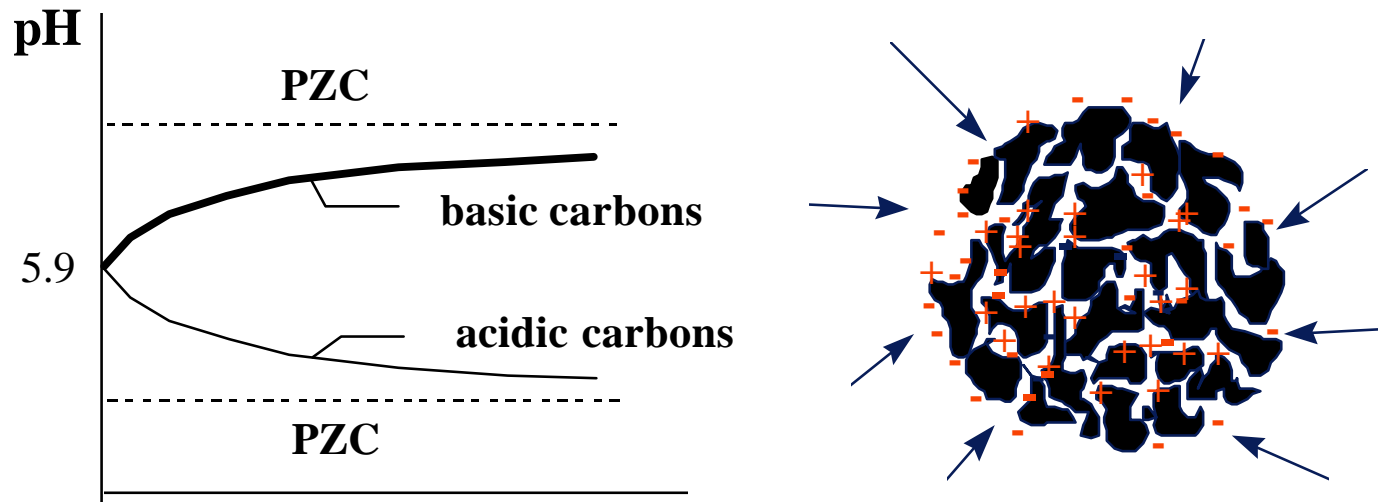

wt \% solid

Figure 1. Graphical representation of PZC (point of zero charge). 


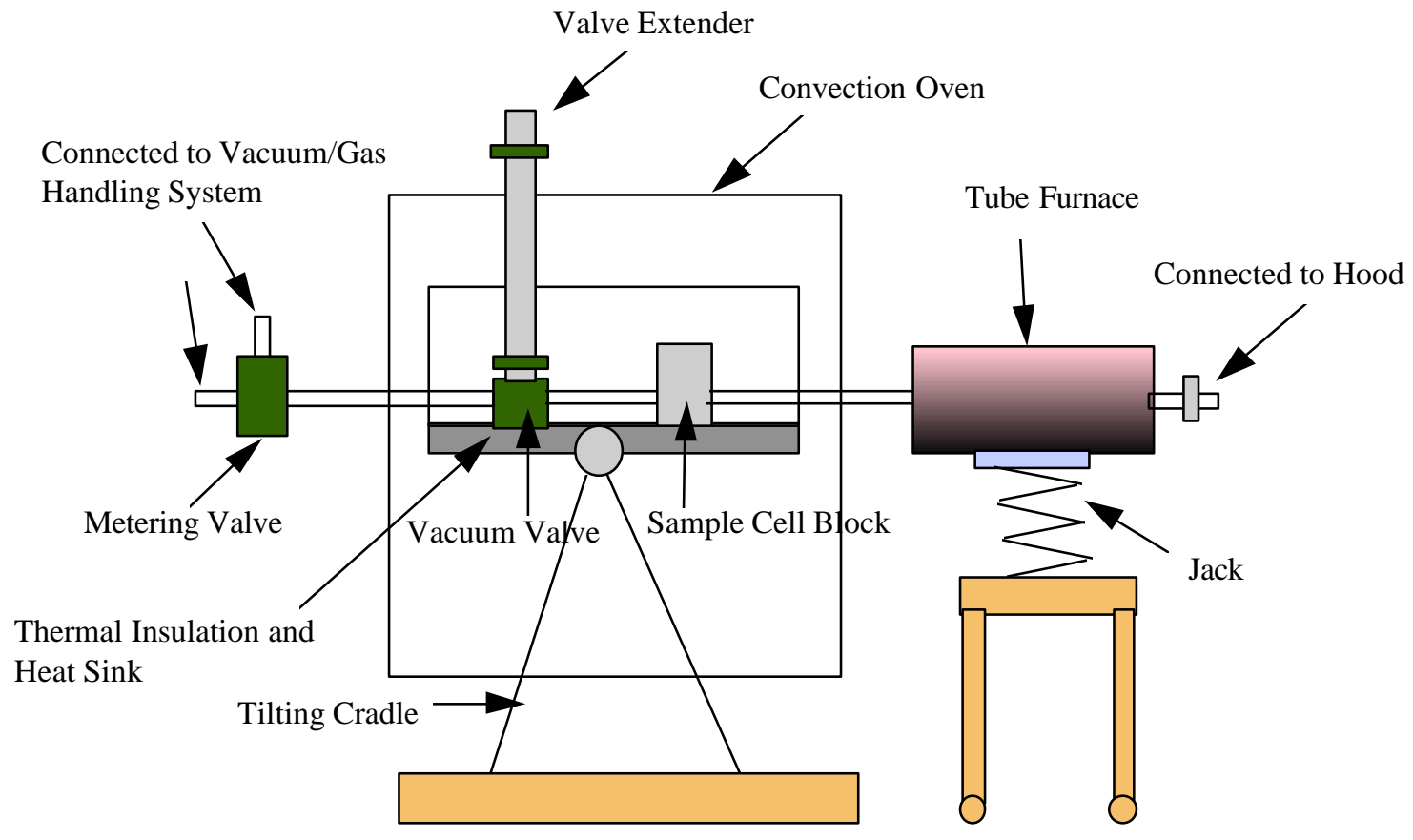

Figure 2. Cut-away (a) side-view (b) top-view of microcalorimeter system. 


\section{Chapter 3}

\section{RESULTS}

\subsection{Physical Properties}

Table 2 shows that the treatments used in this study produce relatively minor changes in the physical (textural) properties of as-received Nc carbons and BPL carbons. The surface areas and pore volumes of $\mathrm{Nc}$ generally decrease slightly, while He density increases after treatments in $\mathrm{N}_{2}$ or $\mathrm{H}_{2}$. Removal of abundant oxygen-containing functional groups from carbon Nc (Table 4), which contains well developed mesoporosity, apparently causes a structure rearrangement that results in only a small loss of its microporosity. However, the results are opposite for BPL: The surface areas and pore volume increase slightly; in the absence of significant mesoporosity, removal of the much less abundant oxygen apparently exposes some additional micropore surface.

Acid washing, on the other hand, did result in small but consistent decreases in the BET surface area, concomitant increases in the mesopore volume, as well as very significant decreases in the volume of narrow micropores (Table 2). This last finding is somewhat puzzling, but its origin (or confirmation) was not investigated further. The XRD results (Table 3) showed no significant structural changes as long as the treatment temperature did not exceed $950^{\circ} \mathrm{C}$. At higher heat treatment temperatures, as expected, this nongraphitizable material clearly became more ordered. This is illustrated in Figure 3 and is reflected in the following facts [61]: (a) At $2600^{\circ} \mathrm{C}$ there are at least two types of (002) reflections; a very sharp peak superimposed on 
the broader peak is indicative of localized graphite-like character in the predominantly amorphous (turbostratic) material. (b) The values of $\mathrm{L}_{\mathrm{c}}, \mathrm{L}_{\mathrm{a}}$ and $d_{002}$ obtained from the broad part of the double peaks change with treatment temperature. Specifically, the $\mathrm{L}_{c}$ and $\mathrm{L}_{\mathrm{a}}$ values reflect a gradual increase in size of the graphene layers once treatment temperatures higher than $950^{\circ} \mathrm{C}$ are employed, while the concomitant decrease in $d_{002}$ indicates a gradual aligning of the graphene layers. Finally, no major difference in structural changes is evident between $\mathrm{N}_{2}$ - and $\mathrm{H}_{2}$-treated samples; a small but consistent increase in $\mathrm{L}_{a} / \mathrm{L}_{\mathrm{c}}$ ratio is observed, especially after $\mathrm{H}_{2}$ treatment.

\subsection{Chemical Properties}

Table 4 contains the data on elemental analysis and mass loss for the as-received and treated carbon samples. The starting activated carbon $\mathrm{Nc}$ has a relatively high oxygen content due to the presence of a large number of oxygen-containing surface groups. Below $1000^{\circ} \mathrm{C}$, $\mathrm{H}_{2}$-treatment is more effective than $\mathrm{N}_{2}$-treatment in reducing the affinity of activated carbon for $\mathrm{O}_{2}$ adsorption for either as-received or acid-washed activated carbon Nc (Table 4 ). The ratio $\mathrm{O} / \mathrm{C}$ decreases as the severity of treatment increase for both $\mathrm{N}_{2}$ and $\mathrm{H}_{2}$. As for the weight loss, the sample after $\mathrm{H}_{2}$-treatment lost much more weight than after $\mathrm{N}_{2}$-treatment at the same temperature. It is also obvious that the higher the treatment temperature, the more weight the sample lost.

The $\mathrm{N}_{2}$-treated sample clearly contained significant oxygen, whereas the $\mathrm{H}_{2}$-treated sample had virtually none. This indicates that the $\mathrm{H}_{2}$-treated samples resist reoxidation, at least 
at ambient conditions. The chemical analysis indicates another apparent anomaly: H950 has an even lower $\mathrm{H} / \mathrm{C}$ ratio than the $\mathrm{N} 950$ sample. In fact, as the severity of $\mathrm{H}_{2}$ treatment increases, the $\mathrm{H} / \mathrm{C}$ ratio in the carbon decreases. This means that high temperature treatment $\left(>500^{\circ} \mathrm{C}\right)$ will remove hydrogen from the surface, and hydrogen does not re-adsorb on high temperature $\mathrm{H}_{2}$ treated carbon.

Chemical analysis of Nc, N950, H950 in Table 5, in which oxygen content was determined directly, is consistent with Table 4 . This indicates that the method to obtain oxygen content by difference is suitable here, and there is no significant impurity except the elements shown in the table. In addition, it is clear that the oxygen content on BPL carbon is much lower than that on Nc. This could explain the different surface properties of these two carbons following similar treatments.

\subsection{Electrochemical Properties}

Figure 4 and Table 6 summarize the electrochemical properties of the samples. The low values of PZC for the as-received $\mathrm{Nc}$ are indicative of the presence of acidic surface groups. After $\mathrm{N}_{2-}$ and $\mathrm{H}_{2}$-treatments, the PZC values become higher. Indeed, for $\mathrm{H}_{2}$-treated samples, the surface turned from acidic to basic. For example, after exposing sample N950(aw) to ambient air, its PZC is much lower (6.1) than that of H950(aw) (8.6). From Table 6, it is also clear that as the severity of the $\mathrm{H}_{2}$-treatment increases, the PZC value of the carbon increases. 
Measurement of PZC as a function of time (Figure 5) shows that $\mathrm{H}_{2}$-treatment results in the creation of a stable basic surface. It is evident that the PZC value of H950 decreases marginally over a period of 30 days and than is virtually unchanged over the next 150 days.

It was also found that the chemical character of the treated Nc samples was profoundly impacted by the mixing process with $\mathrm{PtC}$. The PZC values of Nc separated from the mixture by sieving are remarkable(Table 6 and Figure 6 ). After treatment at $500^{\circ} \mathrm{C}$ the $\mathrm{PZC}$ was 9.0 , which is as high as that for sample H950 and far higher than that of H500 (5.6). Even after reducing the relative fraction of $\mathrm{PtC}$, from $2 \mathrm{PtC}$ : $1 \mathrm{Nc}$ to $1 \mathrm{PtC}: 2 \mathrm{Nc}$, a virtually identical PZC value (8.8) was obtained. Stability tests also indicate that the surfaces of $\mathrm{Nc}$ treated in the mixtures are stable. As shown in Figure 5, there was very little change in the PZC of the $\mathrm{Nc}$ removed from the $\mathrm{Nc} / \mathrm{PtC}$ mix and exposed to ambient laboratory conditions for months. In fact, it is virtually as stable as the H950 sample.

The PZC values of each of the batches of Nc carbon from the unmixed experiment were also measured. The Nc carbon in the upstream boat had a PZC value of 7.0, while the PZC value of the Nc in the downstream boat was 7.5 (Figure 6) and the PZC of the Nc in the middle boat ( after separation from $\mathrm{PtC}$ ) was 9.0. For comparison, the $\mathrm{PZC}$ of $\mathrm{Nc}$ treated at the same position as the middle boat (with no platinum present at all) was 5.6. It is clear (and indeed remarkable!) that the presence of platinum increases the PZC value even if the metal is not intimately mixed with the carbon.

The PZC of BPL (7.1) indicates that its surface does not have many acidic groups, which is consistent with its low oxygen content. Both BPL-N950 and BPL-H950 are basic due 
to further reduction of surface oxygen at high temperature. However, the PZC of BPL-H950 is higher.

\subsection{Adsorption of $\mathrm{O}_{2}$}

Nc carbon. Figures 7 and 8 summarize the microcalorimetry data. As expected, the clean carbon surface (N950) with an abundance of free carbon active sites chemisorbs $\mathrm{O}_{2}$ the most; indeed, when allowance is made for uncertainties in the area occupied by an adsorbed oxygen atom and in the true total surface area of the carbon, it is concluded that the uptake at the highest pressure corresponds to a large fraction of the carbon surface area. Also, when $\mathrm{H}_{2}$ replaces $\mathrm{N}_{2}$ in the $950^{\circ} \mathrm{C}$ treatment, the subsequent $\mathrm{O}_{2}$ uptake is drastically suppressed. This uptake decreases monotonically with increasing severity of $\mathrm{H}_{2}$ treatment, and is in agreement with the elemental analysis data (Table 4 ).The differential heats of adsorption (Figure 7) follow the same trend: the clean carbon surface (N950) possesses the greatest number of high-energy sites $(>100 \mathrm{kcal} / \mathrm{mol})$. As the severity of treatment in $\mathrm{H}_{2}$ increases, the number of sites stabilized by hydrogen increases and/or the high-energy sites are increasingly removed by carbon hydrogasification (see the mass loss data of Table1).

Figure 9 summarizes the $\mathrm{O}_{2}$ chemisorption results on $\mathrm{H}_{2}$-treated samples at elevated temperature. As expected from studies on other carbon materials [62-67], adsorption is seen to be a kinetically controlled process. Very little oxygen chemisorbs at room temperature, whereas the uptake at $150^{\circ} \mathrm{C}$ is quite significant. Suppression of adsorption by acid washing appears to be more pronounced at the higher adsorption temperature as well. Another notable fact is that all the adsorption takes place with heats of ca. $80 \mathrm{kcal} / \mathrm{mol}$ or less (Figure 9a). 
Finally, it is important to note the monotonic rise in coverage with $\mathrm{O}_{2}$ pressure (Figure 9b). In contrast to the behavior of partially stabilized carbon samples, there is no evidence of a pressure reversal in any of the isotherms for samples treated in $\mathrm{H}_{2}$ at $950^{\circ} \mathrm{C}$.

In contrast to the $\mathrm{H}_{2}$-treated samples, $\mathrm{N}_{2}$-treated activated carbons adsorb significant amounts of $\mathrm{O}_{2}$ even at room temperature and they exhibit very similar low-coverage adsorption behavior at 25 and $150^{\circ} \mathrm{C}$ (Figure 10b). In agreement with the results of Figure $10 \mathrm{~b}, \mathrm{O}_{2}$ at low surface coverage is seen to probe sites of similar energy at 25 and $150^{\circ} \mathrm{C}$ (Figure 10a). Notable is also the fact that the heat of adsorption on the N950 samples is far greater than that on the H950 samples (Figure 10a). On the other hand, the effect of acid washing is quite similar for the $\mathrm{H}_{2}$ - and $\mathrm{N}_{2}$-treated samples: greater suppression is evident at the higher adsorption temperature (Figure 10b). Also there are some sites on $\mathrm{N}_{2}$-treated carbons that only adsorb $\mathrm{O}_{2}$ at elevated temperatures (activated adsorption). Finally, as illustrated in Figure 10b, a consistent pressure reversal (negative slope) is evident at very low pressures in the isotherm of all $\mathrm{N}_{2}$-treated samples.

Plots of NAP vs. surface coverage (Figure 11) show qualitative adsorption kinetics, reflecting both chemisorption and mass transfer processes. The rate of $\mathrm{O}_{2}$ chemisorption on high energy sites (which are most abundant in sample N950 and least abundant in sample H950) is high and constant. Subsequent to the coverage of these sites, adsorption on the less energetic sites becomes progressively slower and the NAP increases exponentially. In the final stages of adsorption, as the physisorption regime is approached, the adsorption rates increase, as expected. Physisorption is known to be a very rapid process [68]. Thus, the time for pressure 
to equilibrate, only in physisorption doses, reflects the time it takes for mass transfer to produce equilibrium throughout the bed, including within pores. Chemisorption is far slower than physisorption. Qualitatively, for chemisorption doses, kinetics is clearly dominated by adsorption rates and not by mass transfer. Finally, it is interesting to observe a reasonable correspondence between the energetics of adsorption (Figures 9a and 10a) and the adsorption kinetics (Figure 11). For example, the high energy sites in sample N950 are covered by ca. 300 $\mu \mathrm{mol} \mathrm{O}_{2} / \mathrm{g}$ carbon (Figure 10a); the chemisorption rate on these sites is seen to be relatively constant and to start to increase only beyond $\sim 300 \mu \mathrm{mol} \mathrm{O}_{2} / \mathrm{g}$ carbon (Figure 11a).

A calorimetric study of a mixture $(1 \mathrm{PtC}: 7 \mathrm{Nc})$ was performed after treatment in hydrogen at $500^{\circ} \mathrm{C}$. As shown in Figure 12, this sample adsorbed far less oxygen (per gram of Nc) than the H500 sample. Moreover, approximately 50\% of the oxygen that was adsorbed probably adsorbed on the platinum surface. (The PZC and other measures of Nc properties from mixed samples were performed after separation by sieving. In contrast, this was not feasible for calorimetric experiments.) Once the adsorption on the platinum component was subtracted, it was found that the amount of oxygen adsorbed, on a gram carbon basis, was virtually identical with the amount adsorbed on the H950 sample. Thus, the calorimetric study verified that the Nc prepared in a mix is stable and adsorbs far less oxygen than H500.

In sum, the important differences detected calorimetrically between N950 and H950 samples are (a) the far greater amount of oxygen adsorption on N950, (b) the higher heats of adsorption on N950, (c) the pressure reversal (due to CO evolution) on N950, and (d) the fact 
that virtually all oxygen adsorption is activated on H950. On the other side, the nature of activated adsorption (heats, rates, quantity) on $\mathrm{N}_{2}$-and $\mathrm{H}_{2}$-treated samples is very similar.

BPL carbon. Oxygen adsorption on BPL carbon follows the same trend as that on Nc carbon. As shown in Figures 13 and 14, there are distinct differences in the amounts and heats of adsorption as a function of the gas employed during high temperature treatment. It is evident both from the heats (Figures 13a and 14a) and the uptakes (Figures $13 \mathrm{~b}$ and $14 \mathrm{~b}$ ) at $25^{\circ} \mathrm{C}$ that the $\mathrm{N}_{2}$-treated sample adsorbs considerably more oxygen with higher heats than the $\mathrm{H}_{2}$-treated sample. This same difference is found when adsorption is carried out at $150^{\circ} \mathrm{C}$. These results show that the $\mathrm{N}_{2}$-treated sample contains a greater concentration of active sites than does the $\mathrm{H}_{2}$-treated sample.

It must be noted that, the heats and amounts of oxygen adsorption on the BPL sample are considerably less than those observed for Nc sample. On the Nc sample heats greater than $100 \mathrm{kcal} / \mathrm{mol}$ were recorded even up to $300 \mu$ mols/ g carbon. On BPL the highest heat was only about $80 \mathrm{kcal} / \mathrm{mol} \mathrm{O}_{2}$. On the other hand, the $\mathrm{H}_{2}$-treated BPL and $\mathrm{Nc}$ carbons are qualitatively similar. For example, in both cases very little oxygen adsorbs at $25^{\circ} \mathrm{C}$ and the heat of adsorption is extremely low. Also, on both high temperature hydrogen treated samples the amount adsorbed is far greater at $150^{\circ} \mathrm{C}$ than at $25^{\circ} \mathrm{C}$. The reasons for these differences are not entirely clear, but they were not analyzed further in this study. 


\subsection{Adsorption of NO}

As shown above, sample $\mathrm{H} 950$ does not adsorb oxygen at $25^{\circ} \mathrm{C}$. Yet, it may adsorb $\mathrm{NO}$ at $25^{\circ} \mathrm{C}$ because NO is more reactive in many cases than oxygen [69]. Preliminary tests show that $\mathrm{H}_{2}$-treated activated carbon will selectively adsorb NO. As shown in Figure 15, the amount of $\mathrm{NO}$ adsorbed on the $\mathrm{H}_{2}$-treated sample is significant at $25^{\circ} \mathrm{C}$, whereas the amount of oxygen adsorbed on the same material is almost negligible. There are some surprises in these results which suggest the need for further study. For example, the measured heats of adsorption follow a non-equilibrium pattern. As discussed elsewhere, this can be explained if a linear free energy relationship is not assumed [60]. More NO than oxygen adsorbed on $\mathrm{N}_{2}$-treated samples as well (Figure 16). Still, the relative selectivity was not as great as that found for the $\mathrm{H}_{2}$-treated sample.

Figures 17 and 18 give the plots of NAP vs. surface coverage of the NO adsorption on H950 and N950. It is interesting to observe that there is a correspondence between the energetics of the adsorption and the adsorption kinetics. However here we still can not give a satisfying interpretation.

\subsection{Adsorption of $\mathrm{H}_{2} \mathrm{O}$}

Experiments were conducted to explore the influence of both hydrogen and nitrogen treatments at $950^{\circ} \mathrm{C}$ on the ability of $\mathrm{Nc}$ carbon to adsorb water. Additional experiments were conducted to determine the effect of subsequent mild surface oxidation on the adsorption of water. The mild oxidation experiments were intended to verify the hypothesis that only on acid 
sites does true condensation occur. On surfaces without any type of such primary adsorption sites PAS only physical adsorption was detected.

Isotherms (Figure19a) demonstrate that pretreatment conditions dramatically impact the amount of water adsorbed. Several features require particular attention. First, the amount of water ultimately adsorbed is a function of treatment. There is a dramatic difference between the $\mathrm{H}_{2}$-treated sample which adsorbs virtually no water at any pressure and the other two samples which adsorb a considerable amount at high relative humidities. Second, the shapes of isotherms are also a function of treatment. On the $\mathrm{H}_{2}$-treated sample water adsorption increases almost linearly with pressure, whereas on the other two samples the uptake increases significantly when a threshold pressure is reached $\left(0.3 \mathrm{p} / \mathrm{p}_{0}\right.$ on $\mathrm{Nc}$ and $0.6 \mathrm{p} / \mathrm{p}_{0}$ on $\left.\mathrm{N} 950\right)$. Third, at low pressures the amount of water adsorbed on the $\mathrm{N}_{2}$-treated sample is significantly greater than that on the untreated sample. For values of $\mathrm{p} / \mathrm{p}_{0}$ greater than approximately 0.45 the amount of water on the untreated sample is greater than that on the $\mathrm{N}_{2}$-treated sample.

There are also dramatic changes in the heats of adsorption as a function of both the amount adsorbed and the relative pressure for different sample treatment, as shown in Figures $19 \mathrm{~b}$ and 19c. Most water on the untreated sample adsorbs with a heat slightly greater than 44 $\mathrm{kJ} / \mathrm{gmol}$ (the heat of water condensation). On the $\mathrm{N}_{2}$-treated sample the heat is quite high at first and then very gradually decreases until it too is similar to that of water condensation. The amount of water adsorbed with a "condensation heat" is clearly less on the $\mathrm{N}_{2}$-treated sample than on the untreated sample. At even higher coverages on both of these samples measured heats clearly are less than the heat of condensation. 
On the $\mathrm{H}_{2}$-treated sample the heat-coverage relations show a completely different pattern. Most significant is the observation that no adsorption takes place with the heat of condensation (Figures 19b and 19c). Initially a very small amount of adsorption occurs at heats higher than that of condensation. This is followed by heats substantially below that of condensation.

Further experiments were conducted to determine the effect of deliberately increasing the number of surface acid sites. As shown in Figure 20, when the N950 sample is exposed to flowing oxygen at $150^{\circ} \mathrm{C}$ for $3 \mathrm{~h}$, it adsorbed far more water than when it was not previously exposed to oxygen. Moreover; the value of $\mathrm{p} / \mathrm{p}_{0}$ at which there is a dramatic increase in the amount of adsorbed water is far lower on the $\mathrm{O}_{2}$-treated sample (Figure 20a). Figure 21 shows that the amount of water adsorbed on a "mildly oxidized" H950 surface (treated for 3h at $150{ }^{\circ} \mathrm{C}$ in oxygen) is higher than that on $\mathrm{H} 950$ surface.

The heat of adsorption characteristics are also different in a significant fashion. As shown in Figure 20b, far less water is "strongly" adsorbed with (heats higher than the heat of condensation) on the $\mathrm{O}_{2}$-exposed $\mathrm{N}_{2}$-treated sample; moreover, the highest heats are far lower. It is also noteworthy that most of the adsorption occurs with a heat value less than that expected for condensation.

\subsection{Desorption}

The TPD results are complementary to the results obtained by calorimetry. Figure 22 shows the desorption spectra for as-received Nc activated carbon. As is typical for high- 
surface-area chars [70-72] a broad, low-temperature $\mathrm{CO}_{2}$ peak and higher-temperature $\mathrm{CO}$ peaks are the dominant fingerprint features, reflecting the fact that each additional bond to a chemisorbed atom weakens the bonding of the carbon atom to the graphite-like lattice. The spectra obtained after controlled $\mathrm{O}_{2}$ adsorption experiments in the calorimeter (and subsequent exposure to room-temperature air) are summarized in Figures 23-26 and Table 7. In agreement with the calorimetric results, they indicate that much more oxygen is adsorbed on the $\mathrm{N}_{2}$-treated samples than on $\mathrm{H}_{2}$-treated samples. They also reflect the fact that $\mathrm{H} 950$ adsorbed much more oxygen at $150^{\circ} \mathrm{C}$ than $25^{\circ} \mathrm{C}$ and that the suppression of $\mathrm{O}_{2}$ adsorption by acid washing is more pronounced at $150^{\circ} \mathrm{C}$ for both $\mathrm{H} 950$ and $\mathrm{N} 950$ (Table 7). There is, however, at best a semiquantitative agreement between the total oxygen uptakes determined by the two techniques. (The agreement with the data shown in table 4 is even less quantitative because of the inherent limitations of oxygen determination by elemental analysis.) The correlation coefficient is of the order of 0.96 . This is not too surprising, given the possibility of $\mathrm{O}_{2}$ adsorption or desorption during sample transfer and of incomplete complex recovery by desorption at $950^{\circ} \mathrm{C}$. For example, it is seen in Table 7 that for samples from the adsorption experiments at $150^{\circ} \mathrm{C}$ the TPD-derived values are consistently higher, in agreement with the expectation that additional uptake(of weakly bound $\mathrm{O}_{2}$, see figures 25 and 26) would occur upon room-temperature air exposure.

The $\mathrm{CO}_{2}$ desorption peak shown in Figure 23 and Figure 24 appears in the same temperature range as the $\mathrm{CO}$ peaks. The appearance of this $\mathrm{CO}_{2}$ is attributed in part to the secondary reaction between $\mathrm{CO}$ and surface oxygen $\left(\mathrm{CO}=\mathrm{C}(\mathrm{O}) \rightarrow \mathrm{CO}_{2}\right)$ in the pores of these 
high-surface-area carbons [73 ]. This feature of the desorption spectra is in contrast to the $\mathrm{CO}_{2}$ peaks shown in Figure 22, Figure 25, and (to lesser extent) Figure 26, where the lowtemperature portions of the broad $\mathrm{CO}_{2}$ peak are evident. The significance of these results is discussed in the next section. Finally, there is a good correlation between the results shown in Figure $10 \mathrm{~b}$ and the trend observed in Figure 25: Low-temperature $\mathrm{CO}_{2}$ desorption is most prominent for the same sample (N950/150) for which the low-heat $\mathrm{O}_{2}$ adsorption at high surface coverage is most evident. 
Table2. Summary of textural properties of as-received and surface treated carbons.

\begin{tabular}{lllll}
\hline Sample code & $\begin{array}{l}\text { BET surface } \\
\text { area }\end{array}$ & $\begin{array}{l}\text { DR micropore } \\
\text { volume } \\
\left(\mathrm{cm}^{3} / \mathrm{g}\right)\end{array}$ & $\begin{array}{l}\text { Mesopore } \\
\text { volume }\end{array}$ & $\begin{array}{l}\text { Helium density } \\
\left(\mathrm{g} / \mathrm{cm}^{3}\right)\end{array}$ \\
\hline $\mathrm{Nc} / \mathrm{g})$ & 1378 & 0.31 & 0.55 & 1.623 \\
$\mathrm{~N} 950$ & 1257 & 0.37 & 0.50 & 2.128 \\
$\mathrm{H} 500$ & 1224 & 0.30 & 0.55 & \\
$\mathrm{H} 650$ & 1224 & 0.30 & 0.55 & \\
$\mathrm{H} 800$ & 1028 & 0.30 & 0.40 & \\
$\mathrm{H} 950$ & 1241 & 0.34 & 0.49 & \\
$\mathrm{Nc}(\mathrm{aw})$ & 1319 & $\sim 0.02$ & 0.67 & \\
$\mathrm{~N} 950(\mathrm{aw})$ & 1171 & $\sim 0.02$ & 0.62 & \\
$\mathrm{H} 950$ (aw) & 1053 & $\sim 0.02$ & 0.59 & \\
BPL & & & & \\
BPL-N950 & 1142 & 0.4745 & 0.0498 & 2.182 \\
BPL-H950 & 1159 & 0.4940 & 0.0591 & 2.196 \\
\hline
\end{tabular}


Table 3. Structural parameters for selected carbons (in $\AA$ )

\begin{tabular}{lllll}
\hline & $\mathrm{D}_{002}$ & $\mathrm{~L}_{\mathrm{c}}$ & $\mathrm{L}_{\mathrm{a}}$ & $\mathrm{L}_{a} / \mathrm{L}_{\mathrm{c}}$ \\
\hline $\mathrm{Nc}$ & 3.78 & 9.02 & & \\
$\mathrm{~N} 950$ & 3.78 & 10.8 & 30.4 & 2.8 \\
$\mathrm{H} 950$ & 3.78 & 10.1 & 35.4 & 3.5 \\
$\mathrm{Nc} / 1800$ & 3.68 & 11.1 & 41.7 & 3.7 \\
$\mathrm{~N} 950 / 1800$ & 3.68 & 10.3 & 40.5 & 3.9 \\
$\mathrm{H} 950 / 1800$ & 3.68 & 11.3 & 48.6 & 4.3 \\
$\mathrm{Nc} / 2600$ & 3.44 & 18.1 & 52.0 & 2.9 \\
$\mathrm{~N} 950 / 2600$ & 3.44 & 18.1 & 62.4 & 3.4 \\
$\mathrm{H} 950 / 2600$ & 3.44 & 20.4 & 72.8 & 3.6 \\
\hline
\end{tabular}


Table 4. Chemical analyses of as-received and chemically modified carbons ${ }^{\mathrm{a}}$.

\begin{tabular}{|c|c|c|c|c|c|c|c|c|c|c|}
\hline Carbon & $\begin{array}{l}\text { wt } \% \mathrm{C} \\
\text { (daf) }\end{array}$ & $\begin{array}{l}\text { wt } \% \mathrm{H} \\
\text { (daf) }\end{array}$ & $\begin{array}{l}\mathrm{wt} \% \mathrm{~N} \\
\text { (daf) }\end{array}$ & $\begin{array}{l}\mathrm{wt} \% \mathrm{O} \\
\text { (daf) }\end{array}$ & $\begin{array}{l}{ }^{b} \mathrm{H} / \mathrm{C} \\
(\mathrm{M})\end{array}$ & $\begin{array}{l}\mathrm{O} / \mathrm{C} \\
(\mathrm{M})\end{array}$ & $\begin{array}{l}\text { ash } \\
(\mathrm{wt} \%)\end{array}$ & $\begin{array}{l}S \\
(w t \%)\end{array}$ & $\begin{array}{l}\mathrm{P} \\
(\mathrm{wt} \%)\end{array}$ & $\begin{array}{l}\text { wt } \% \\
\text { loss }\end{array}$ \\
\hline $\mathrm{Nc}$ & 82.3 & 2.3 & 0.3 & 15.1 & 0.335 & 0.138 & 0.70 & 0.02 & 0.12 & \\
\hline N500 & 90.0 & 2.3 & 0.4 & 7.3 & 0.301 & 0.061 & & & & 6.7 \\
\hline N950 & 94.2 & 0.6 & 0.6 & 4.6 & 0.076 & 0.037 & 0.67 & 0.01 & 0.09 & 8.3 \\
\hline H500 & 91.8 & 2.3 & 0.6 & 5.3 & 0.301 & 0.043 & & & & 11.2 \\
\hline H650 & 94.8 & 1.6 & 0.5 & 3.1 & 0.203 & 0.025 & & & & 12.6 \\
\hline H800 & 97.0 & 0.9 & 0.9 & 1.2 & 0.111 & 0.009 & & & & 17.5 \\
\hline H950 & 99.0 & 0.4 & 0.3 & 0.3 & 0.048 & 0.002 & & & 0.07 & 20.2 \\
\hline $\mathrm{H} 500 / \mathrm{PtC}$ & 95.5 & 2.2 & 0.6 & 1.7 & 0.276 & 0.013 & & & & 15.5 \\
\hline Cbk & 96.3 & 0.6 & 0.1 & 3.0 & 0.075 & 0.023 & & & & \\
\hline CbkH950 & 98.5 & 0.3 & 0.5 & 0.7 & 0.037 & 0.005 & & & & 3.0 \\
\hline $\mathrm{Nc}(\mathrm{aw})$ & 83.6 & 2.3 & 0.4 & 13.7 & 0.330 & 0.122 & 0.35 & $>0.01$ & & \\
\hline N950(aw) & 94.8 & 0.5 & 0.6 & 4.1 & 0.063 & 0.032 & 0.34 & $>0.01$ & & \\
\hline H950(aw) & 98.4 & 0.4 & 0.3 & 0.9 & 0.049 & 0.007 & 0.35 & $>0.01$ & & \\
\hline $\mathrm{Nc} / 1800$ & 99.6 & $>0.01$ & 0.2 & 0.2 & $\sim 0$ & 0.002 & $>0.01$ & $>0.01$ & & \\
\hline H950/1800 & 99.7 & $>0.01$ & 0.2 & 0.1 & $\sim 0$ & 0.001 & $>0.01$ & $>0.01$ & & \\
\hline $\mathrm{Nc} / 2600$ & 100.0 & $>0.01$ & $>0.01$ & $>0.01$ & $\sim 0$ & $\sim 0$ & $>0.01$ & $>0.01$ & & \\
\hline N950/2600 & 100.0 & $>0.01$ & $>0.01$ & $>0.01$ & $\sim 0$ & $\sim 0$ & $>0.01$ & $>0.01$ & & \\
\hline
\end{tabular}

a wt $\%=$ weight percent; daf $=$ dry, ash-free; ${ }^{\mathrm{b}}$ Obtained by difference . 
Table 5. Chemical analyses of as-received and chemically modified carbons (in which oxygen was determined directly).

\begin{tabular}{lllllll}
\hline Sample & wt\% C & wt\% H & wt\% N & wt\% S & wt\% O & $\begin{array}{c}\text { wt\% } \\
\text { Ash }\end{array}$ \\
\hline Nc & 82.11 & 2.72 & 0.18 & 0.03 & 14.97 & 0.54 \\
N950 & 93.00 & 0.67 & 0.21 & 0.02 & 5.12 & - \\
H950 & 97.46 & 0.48 & 0.17 & 0.01 & 1.49 & - \\
BPL & 88.15 & 0.33 & 0.60 & 0.85 & 2.66 & 5.71 \\
BPL-N950 & 90.97 & 0.33 & 0.60 & 0.87 & 2.39 & - \\
BPL-H950 & 90.18 & 0.30 & 0.54 & 0.06 & 0.34 & - \\
\hline
\end{tabular}


Table 6. Electrochemical properties of as-received and surface-treated carbons.

\begin{tabular}{|llll|}
\hline Sample code & PZC & Sample code & PZC \\
\hline Nc & 2.5 & H500/PtC & 9.0 \\
PtC & 9.8 & H500/PtC & 8.5 \\
Ptc-Ox & 3.6 & H500/PtC & 8.5 \\
N500 & & H500/PtC & 8.8 \\
N950 & 3.8 & & \\
H150 & 5.2 & Nc(aw) & 3.0 \\
H350 & & N950(aw) & 6.1 \\
H425 & 2.5 & H950(aw) & 8.6 \\
H500 & 2.7 & & 8.9 \\
H650 & 3.3 & Nc/1800 & 8.8 \\
H800 & 5.6 & N950/1800 & 8.5 \\
H950 & 6.3 & H950/1800 & 7.6 \\
H150/PtC & 7.5 & Nc/2600 & 7.5 \\
H350/PtC & 9.0 & N950/2600 & 7.2 \\
H425/PtC & 2.6 & H950/2600 & 7.1 \\
\hline & 3.6 & BPL-N950 & 8.9 \\
\hline
\end{tabular}




\begin{tabular}{|l|l|}
\hline BPL-H950 & 9.5 \\
\hline
\end{tabular}

${ }^{\mathrm{a}}$ With PtC reused twice. ${ }^{\mathrm{b}}$ With PtC reused three times. ${ }^{\mathrm{C}} \mathrm{PtC}: \mathrm{Nc}=1: 2$ by mass.

Table 7. Amounts of $\mathrm{CO}, \mathrm{CO}_{2}$ and $\mathrm{O}_{2}$ calculated from TPD experiments and of $\mathrm{O}_{2}$ adsorbed in the calorimetry experiments.

\begin{tabular}{|c|c|c|c|c|c|}
\hline \multirow[t]{3}{*}{ Carbon } & \multicolumn{3}{|c|}{ TPD $(\mu \mathrm{mol} / \mathrm{g})$} & \multirow{2}{*}{\multicolumn{2}{|c|}{$\frac{\text { Calorimetry }}{\mathrm{O}_{2}(\mu \mathrm{mol} / \mathrm{g})}$}} \\
\hline & \multirow[b]{2}{*}{$\mathrm{CO}$} & \multirow[b]{2}{*}{$\mathrm{CO}_{2}$} & \multirow[b]{2}{*}{$\mathrm{O}_{2}$ equiv. } & & \\
\hline & & & & (a) & (b) \\
\hline $\mathrm{Nc}$ & 2444 & 859 & 2081 & & \\
\hline N950/150 & 1211 & 307 & 913 & 800 & 600 \\
\hline N950(aw)/150 & 777 & 202 & 591 & 450 & 300 \\
\hline N950/25 & 757 & 127 & 506 & 550 & 425 \\
\hline N950(aw)25 & 533 & 194 & 461 & 390 & 260 \\
\hline H950/150 & 324 & 180 & 342 & 250 & 175 \\
\hline $\mathrm{H} 950(\mathrm{aw}) / 150$ & 438 & 120 & 339 & 225 & 165 \\
\hline H950/25 & 48 & 31 & 55 & 120 & 25 \\
\hline H950(aw)/25 & 36 & 21 & 39 & 110 & 24 \\
\hline
\end{tabular}

(a) Total amount of oxygen adsorbed in the calorimeter.

(b) Oxygen more strongly adsorbed. Calculated by extrapolation of the isotherm's plateau (see 
Figures $9 \mathrm{~b}$ and 10b).

Note: $\mathrm{N} 950 / 150$ is $\mathrm{N} 950$ obtained after $\mathrm{O}_{2}$ adsorption calorimetry experiment at $150^{\circ} \mathrm{C}$. All the other samples are designated by the same way. 


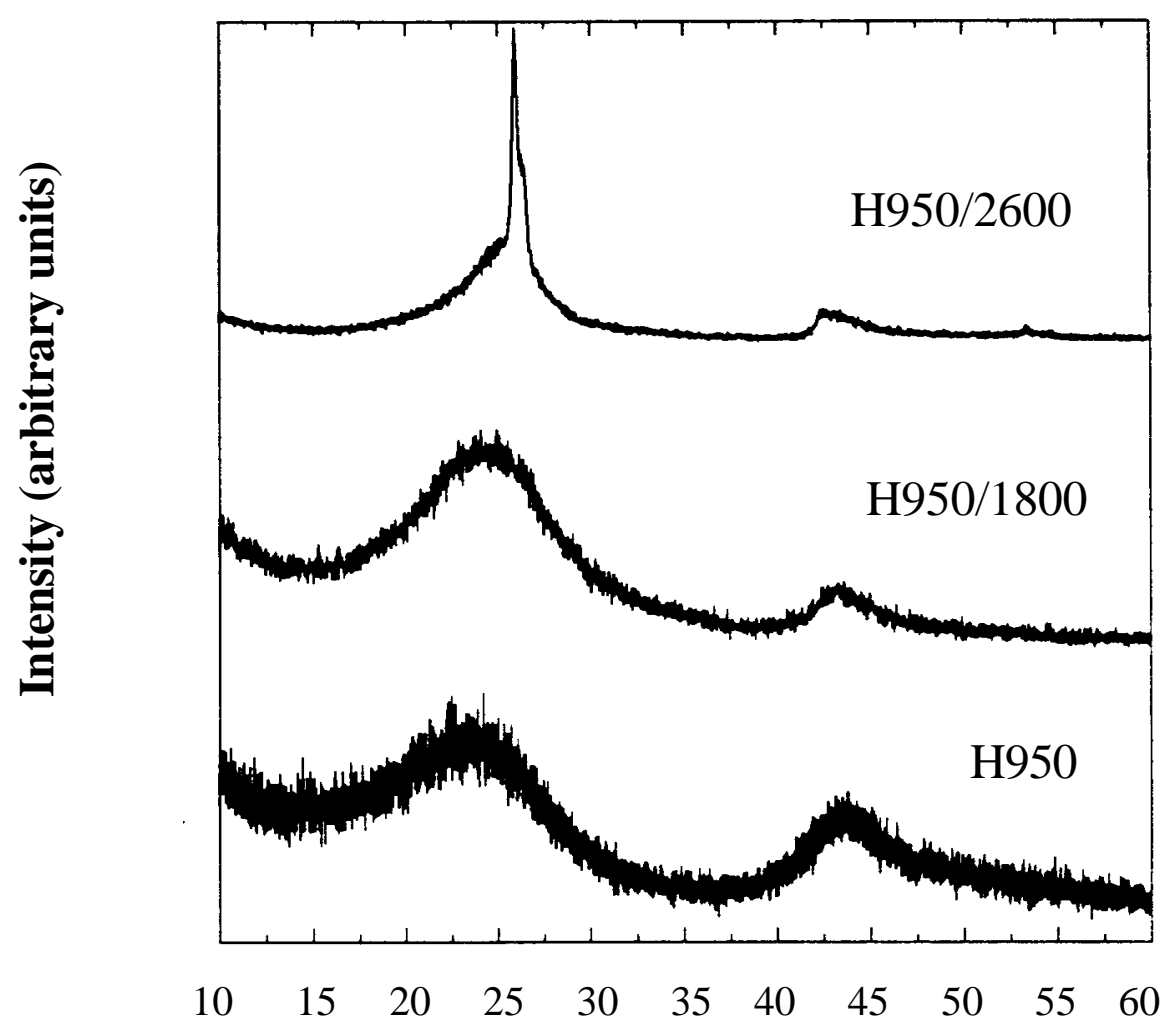

Diffraction Angle ( ${ }^{\circ 2}$ )

Figure 3. Representative x-ray diffractograms for activated carbon $\mathrm{H} 950$ and carbons obtained after heat treatments at $1800(\mathrm{H} 950 / 1800)$ and $2600^{\circ} \mathrm{C}(\mathrm{H} 950 / 2600)$. 


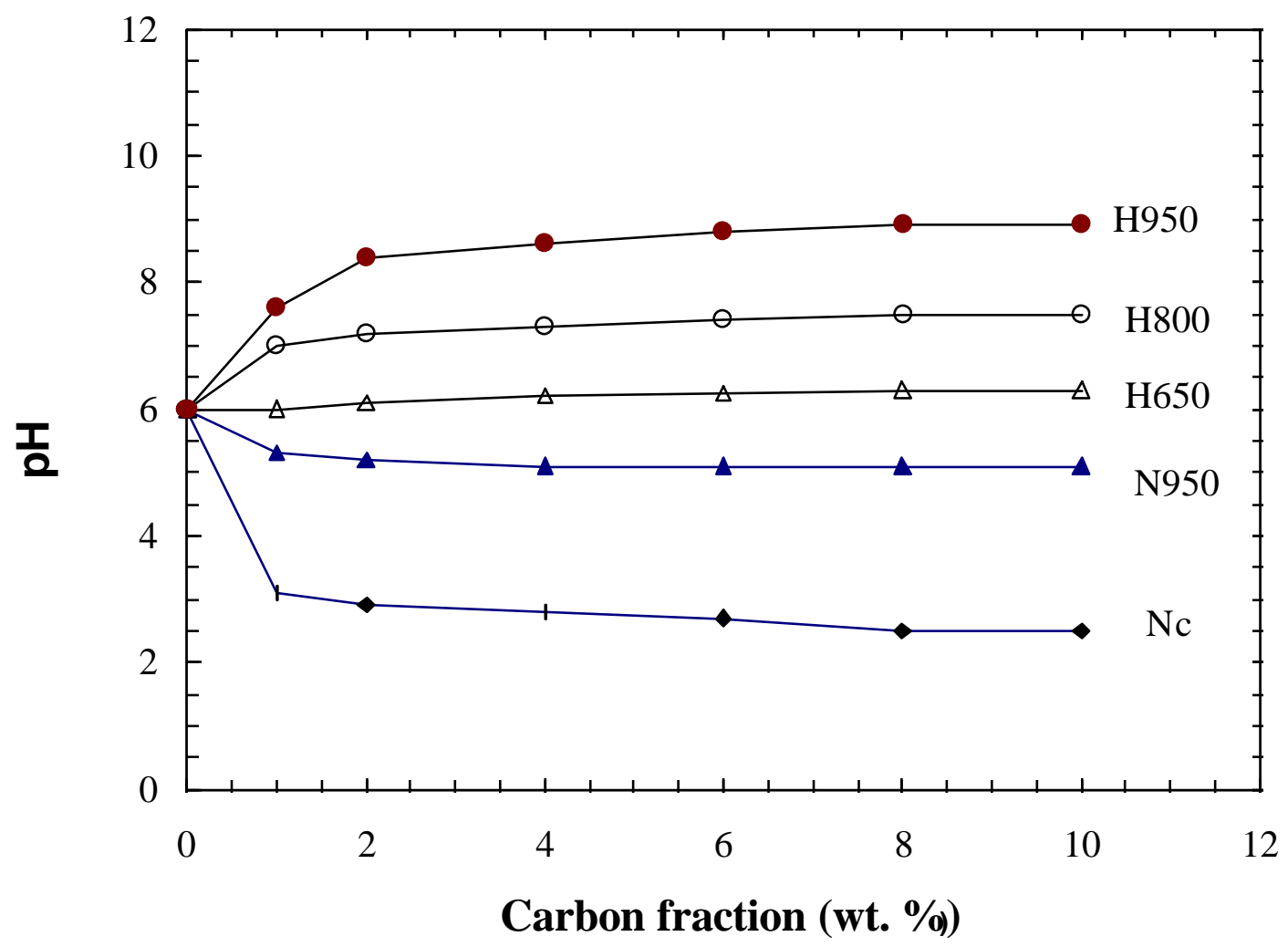

Figure 4. Mass titration curves for as-received and surface-treated carbons. 


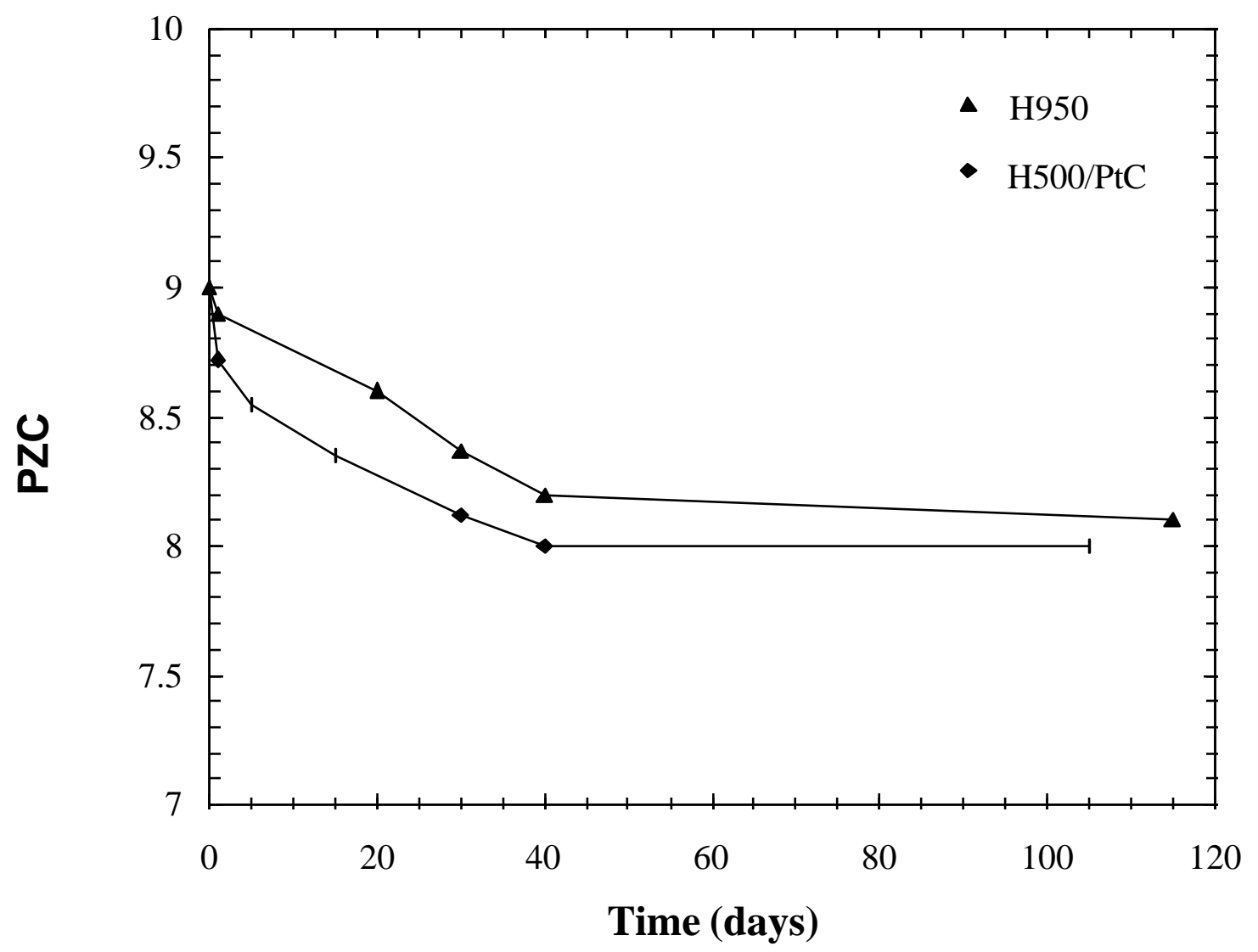

Figure 5. Changes in the point of zero charge of $\mathrm{H} 950$ and $\mathrm{H} 500 / \mathrm{PtC}$ upon exposure to ambient air. 


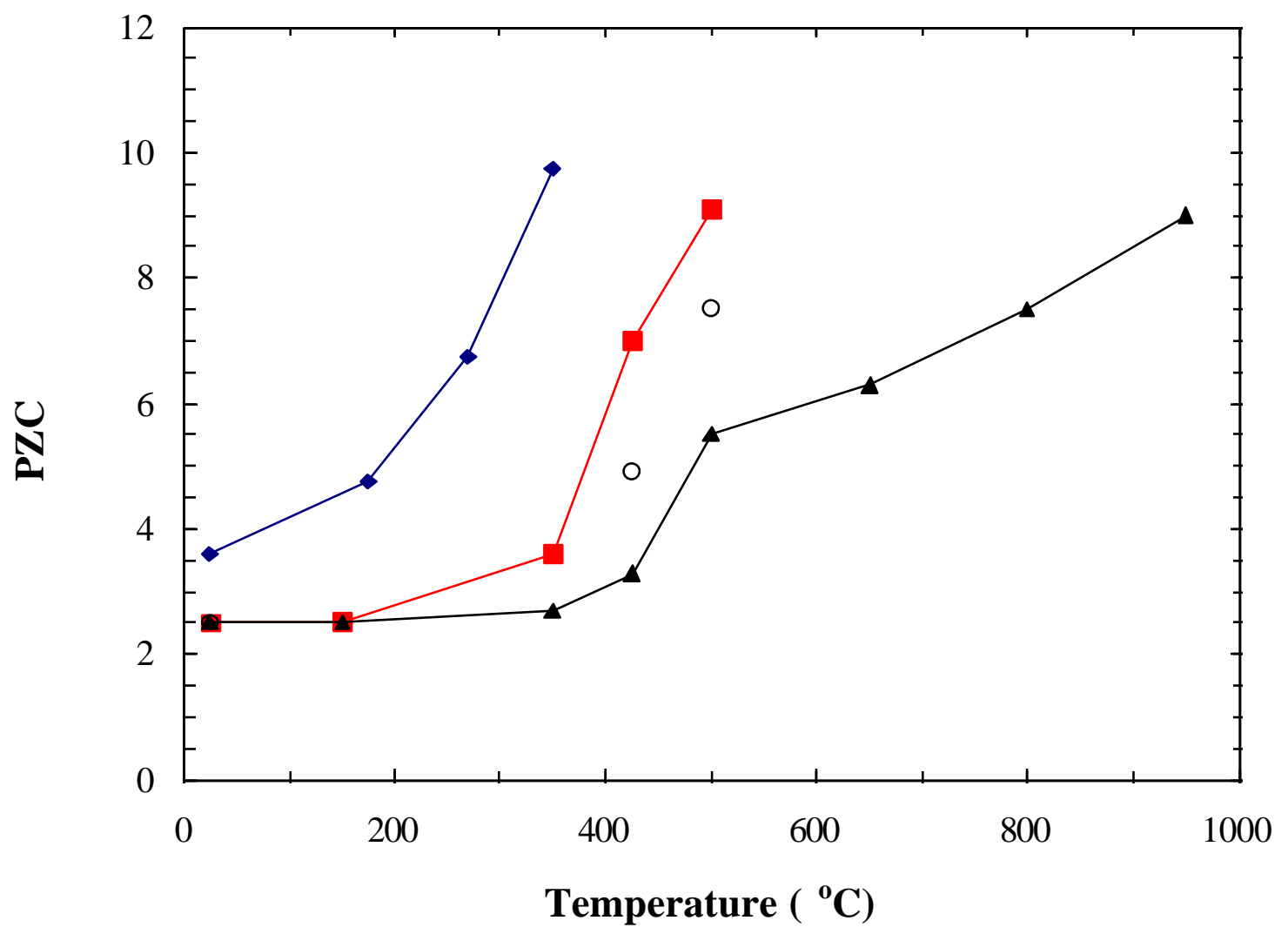

Figure 6. Variations in the point of zero charge $(\mathrm{PZC})$ with treatment temperature $\left(\mathrm{in}_{2}\right)$ for asreceived Norit $\mathrm{C}$ carbon $(\boldsymbol{\Delta})$ and for surface-modified carbon samples in the presence of a $\mathrm{Pt}$ catalyst: $\mathbf{\square}$, Norit $\mathrm{C}$ mixed with commercial activated carbon containing $1 \% \mathrm{Pt}$ catalyst (in a ratio of $1 ; 2) ; \mathrm{O}$, Norit $\mathrm{C}$ treated in a different boat downstream; $\bullet$, commercial activated carbon containing $1 \% \mathrm{Pt}$, previously exposed to concentrated nitric acid at $60^{\circ} \mathrm{C}$ for $64 \mathrm{~h}$. 


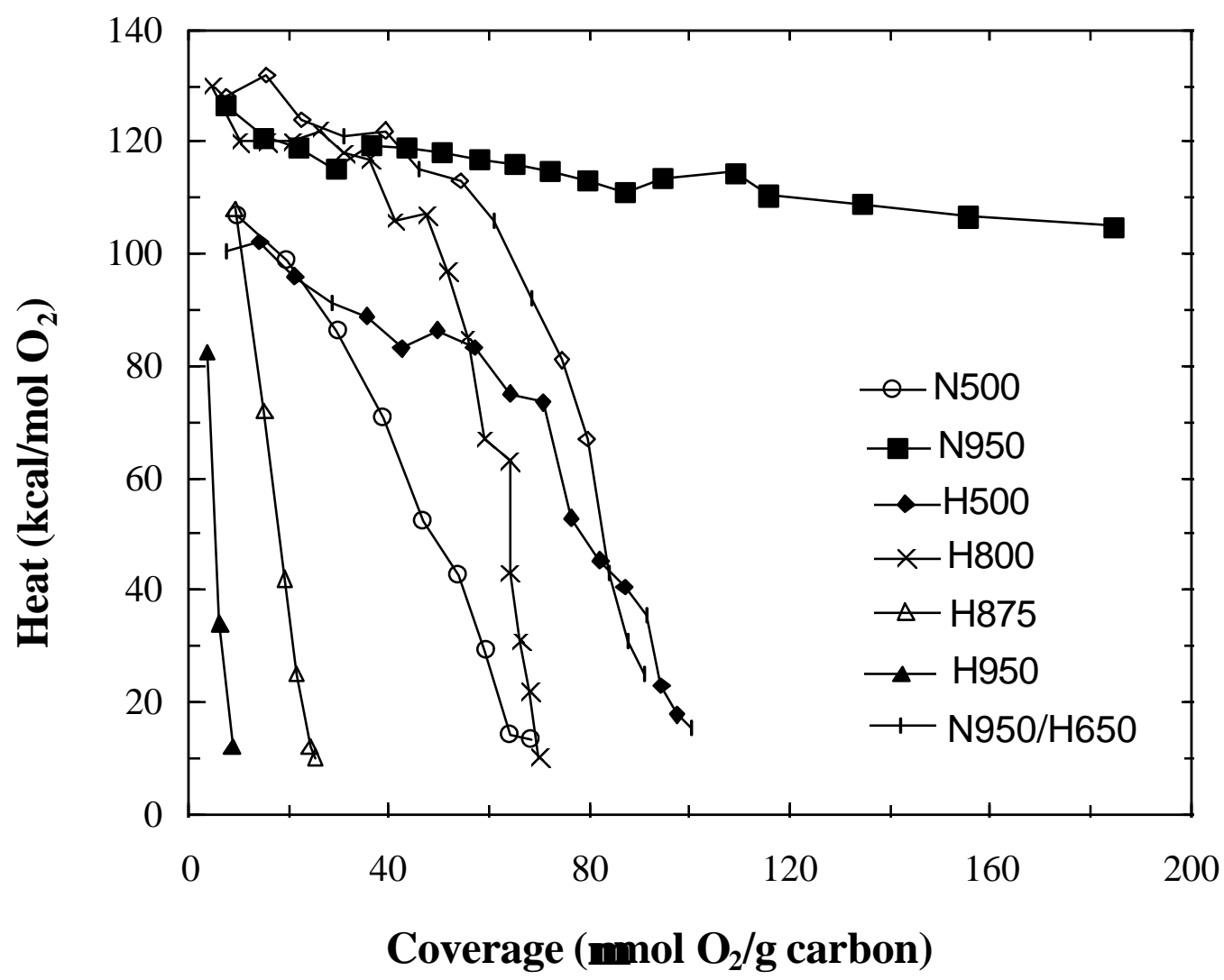

Figure 7. Differential heats of oxygen adsorption as a function of surface coverage for surface-treated $\mathrm{Nc}$ activated carbons at $25^{\circ} \mathrm{C}$. 


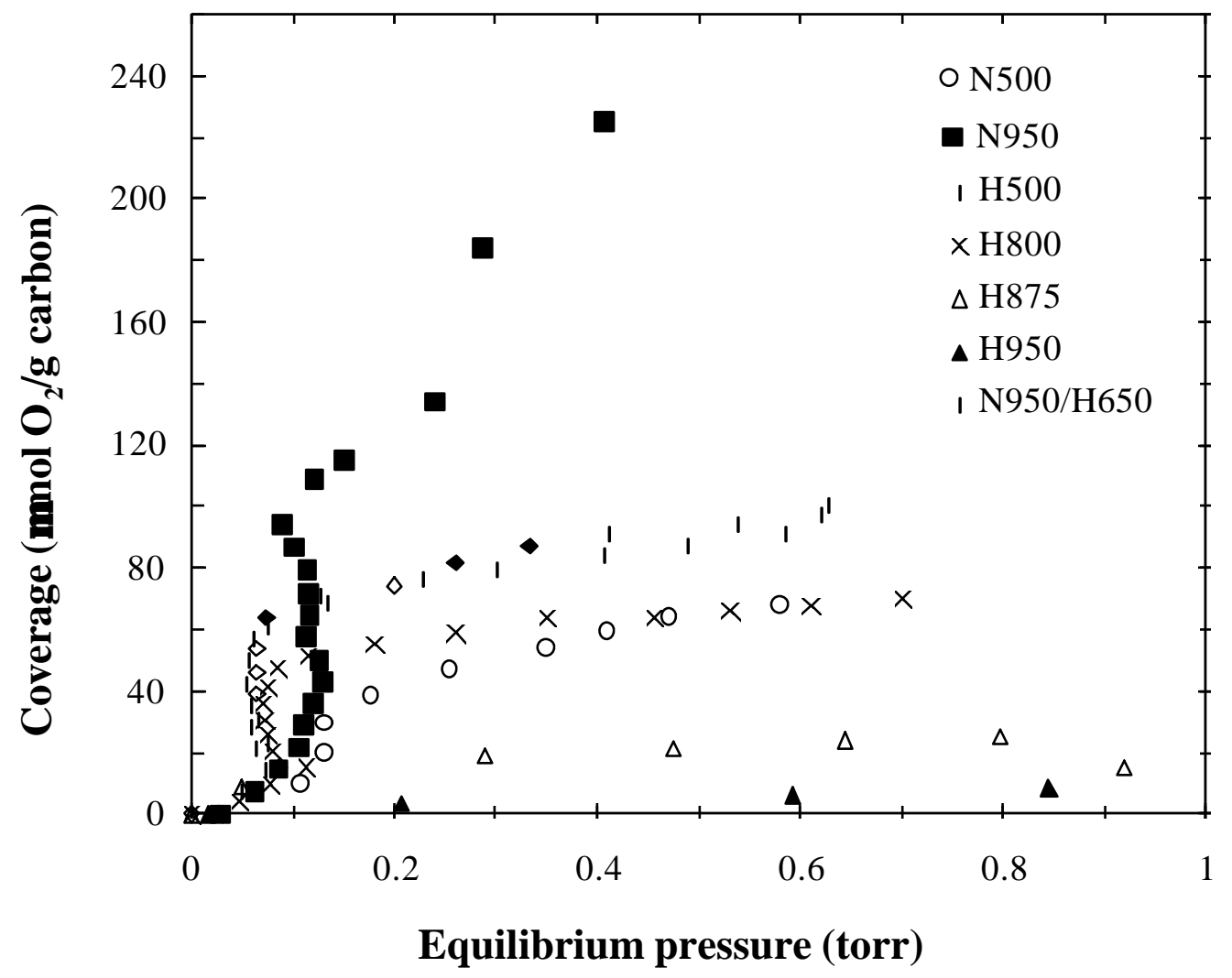

Figure 8. Oxygen adsorption isotherms at $25^{\circ} \mathrm{C}$ for surface-treated $\mathrm{Nc}$ activated carbons. 


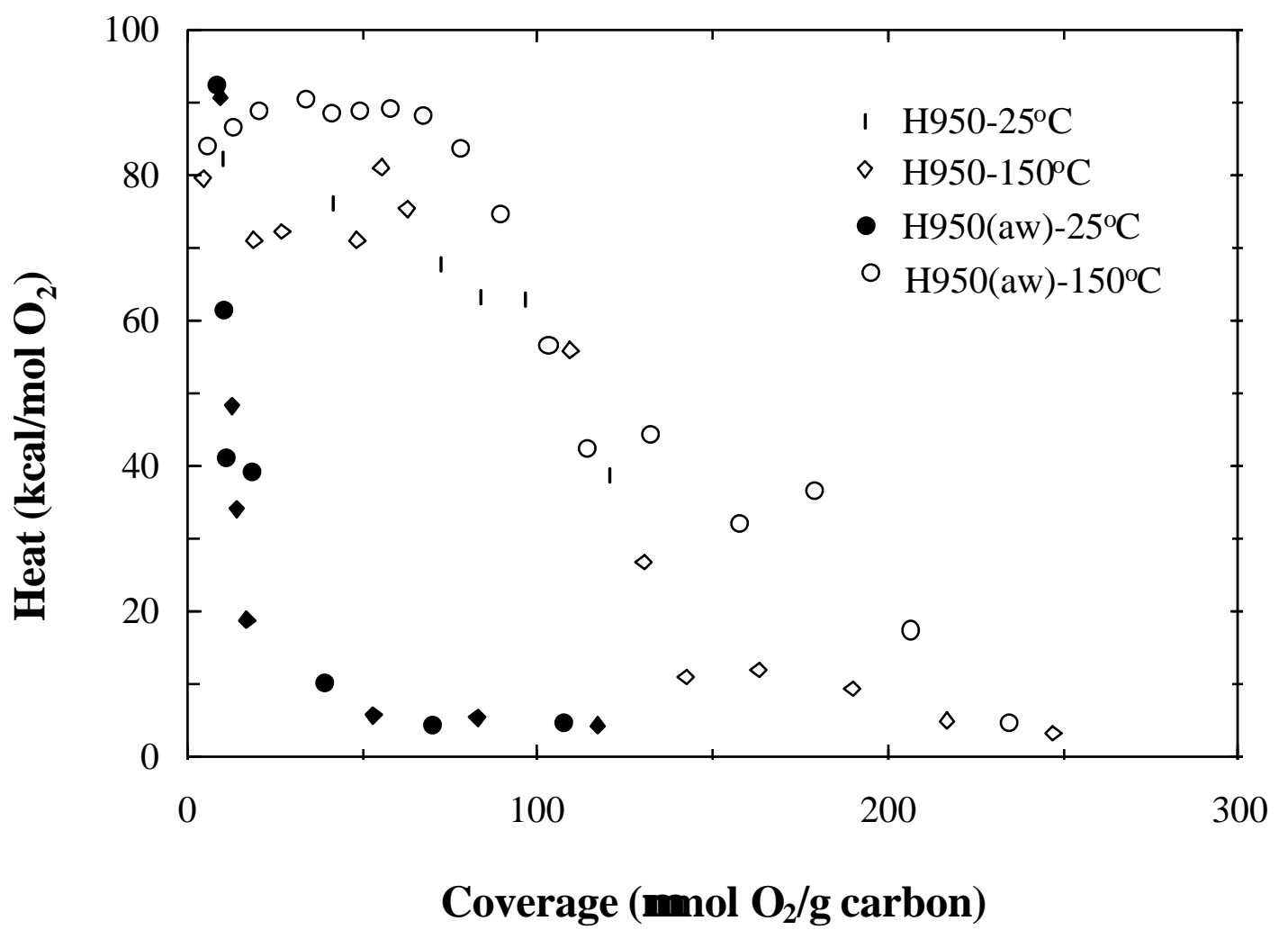

Figure 9a. Differential heats of $\mathrm{O}_{2}$ adsorption at 25 and $150^{\circ} \mathrm{C}$ as a function of surface coverage for as-received and acid washed $\mathrm{H}_{2}$-treated activated carbons. 


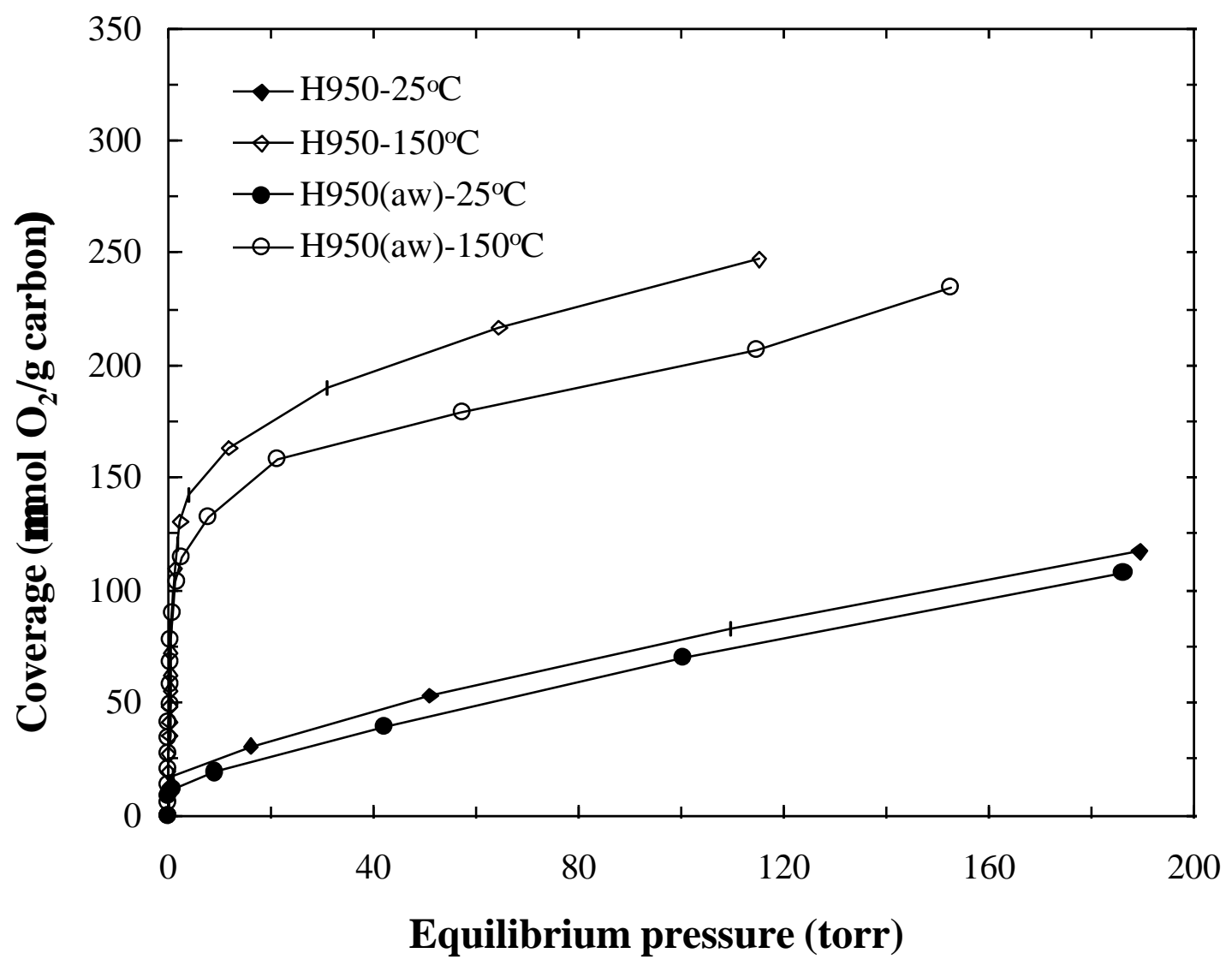

Figure $9 \mathrm{~b} . \mathrm{O}_{2}$ adsorption isotherms at 25 and $150^{\circ} \mathrm{C}$ for as-received and acid washed $\mathrm{H}_{2}$ treated activated carbons. 


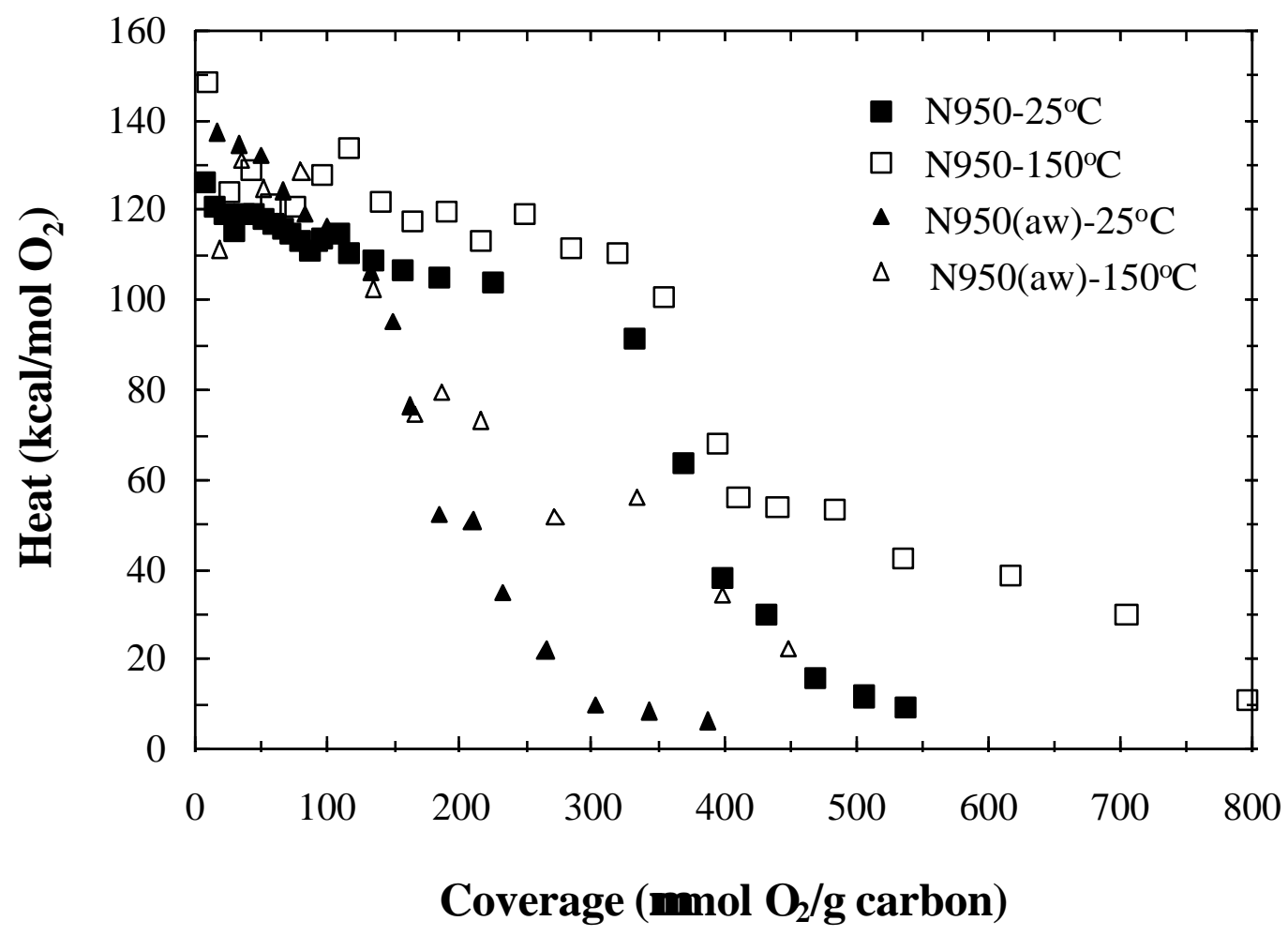

Figure 10a. Differential heats of $\mathrm{O}_{2}$ adsorption at 25 and $150^{\circ} \mathrm{C}$ as a function of surface coverage for as-received and acid washed $\mathrm{N}_{2}$-treated activated carbons. 


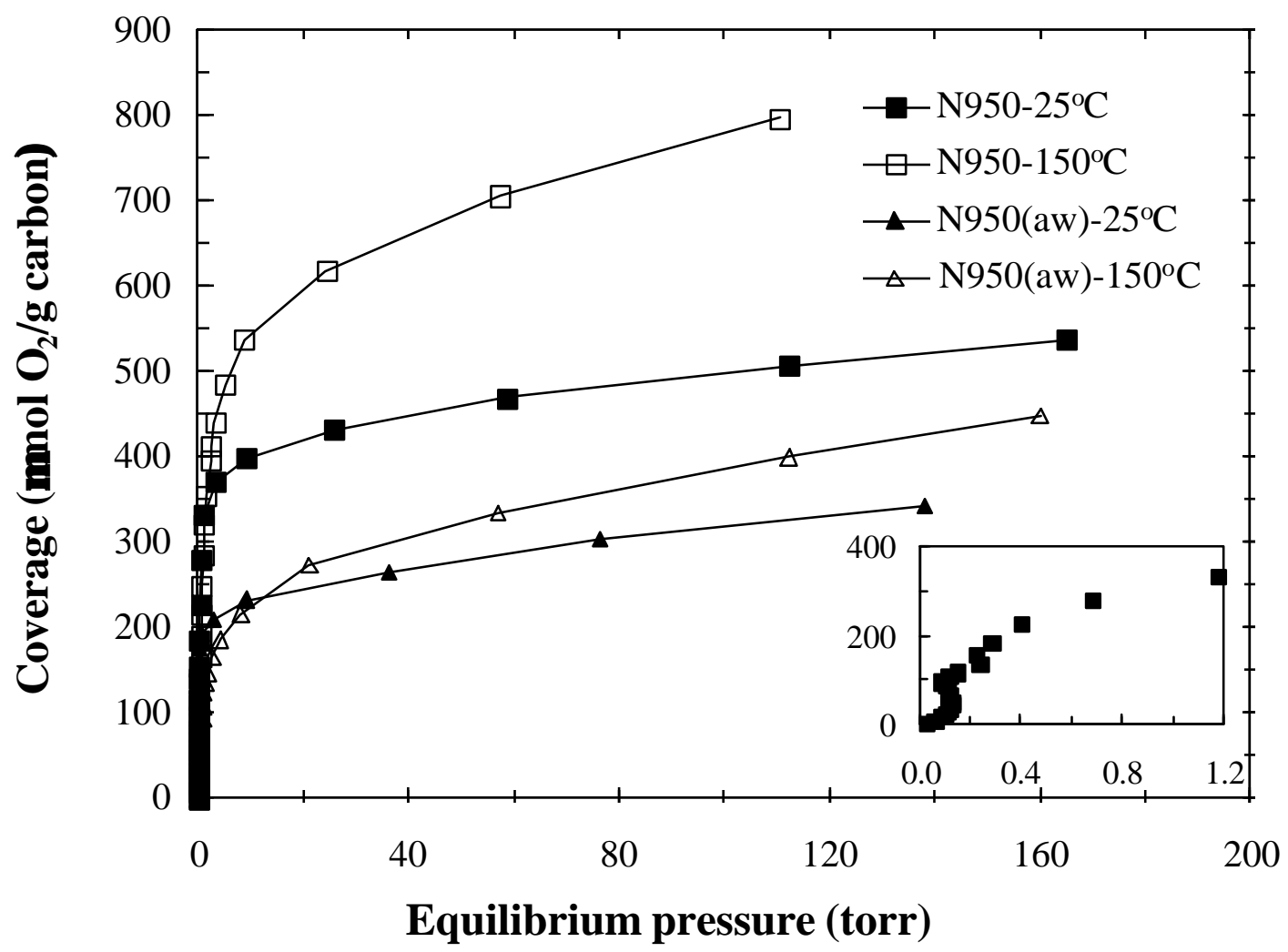

Figure $10 \mathrm{~b} . \mathrm{O}_{2}$ adsorption isotherms at 25 and $150^{\circ} \mathrm{C}$ for as-received and acid washed $\mathrm{N}_{2^{-}}$ treated activated carbons. 


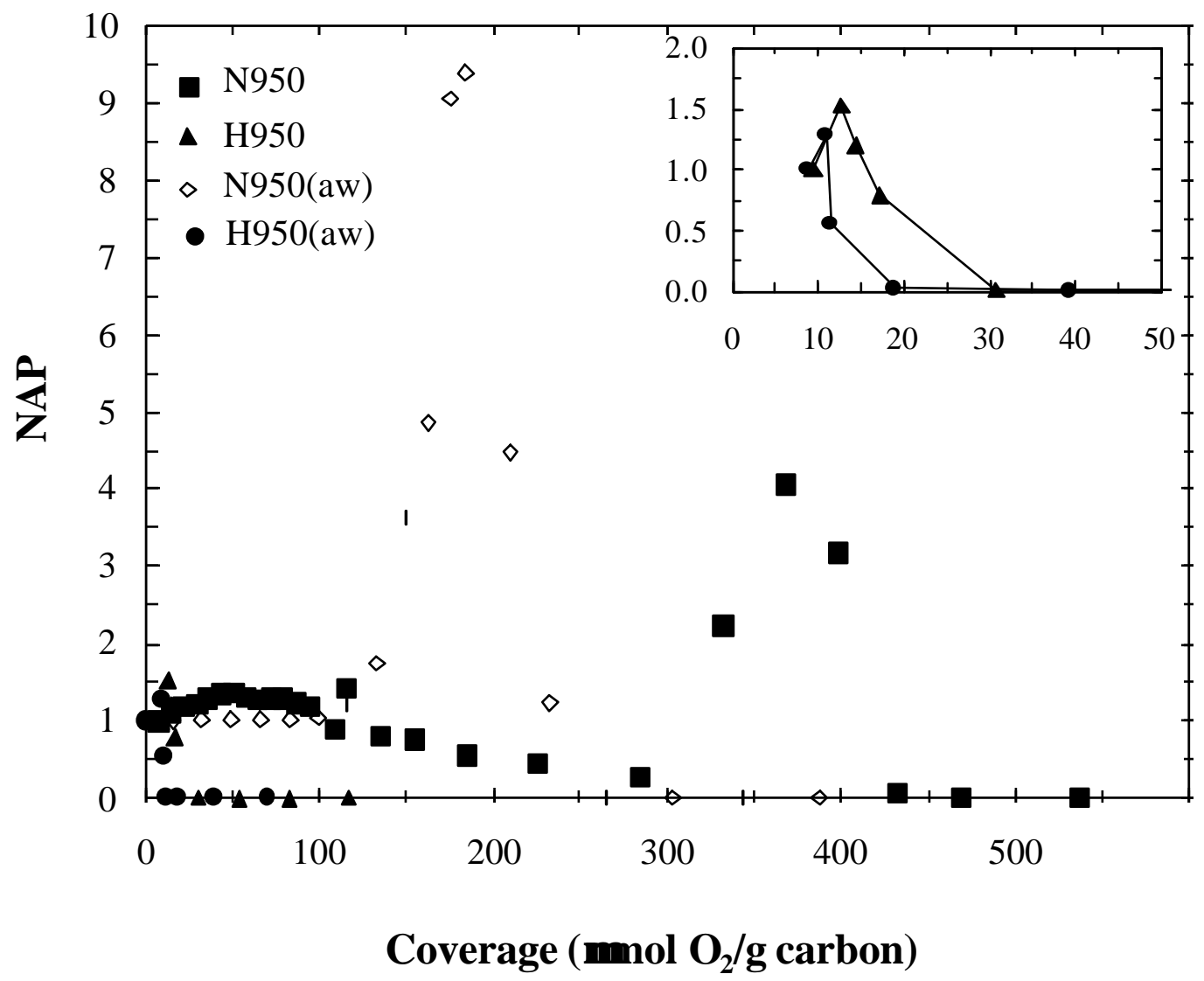

Figure 11a. Plots of the normalized adsorption parameter vs. surface coverage for $\mathrm{O}_{2}$ adsorption at $25^{\circ} \mathrm{C}$ for surface treated activated carbon Nc. 


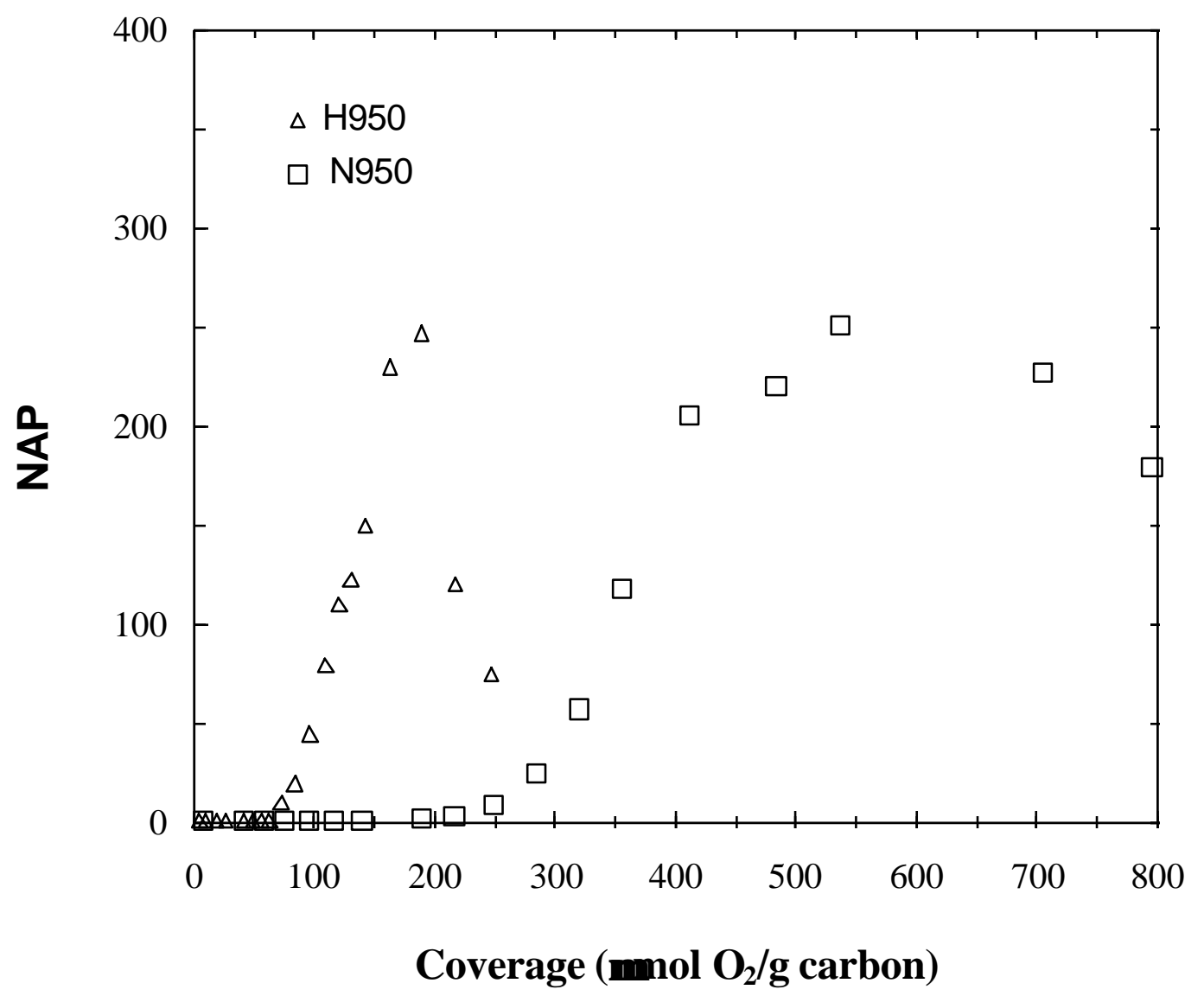

Figure 11b. Plots of the normalized adsorption parameter vs. surface coverage for $\mathrm{O}_{2}$ adsorption at $150^{\circ} \mathrm{C}$ for surface treated activated carbon $\mathrm{Nc}$. 


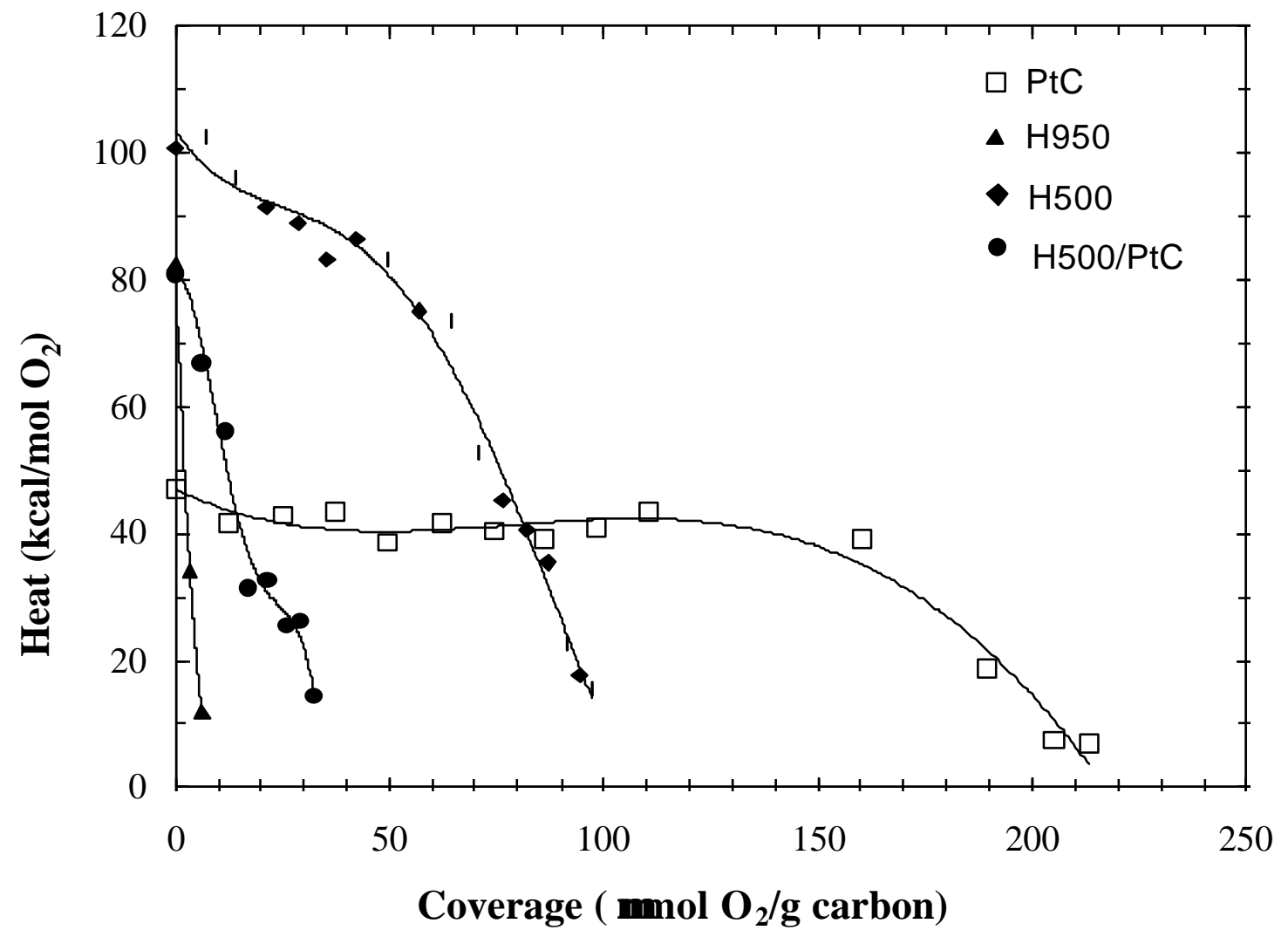

Figure 12a. Heats of $\mathrm{O}_{2}$ adsorption as a function of surface coverage at $25^{\circ} \mathrm{C}$ on as-received and surface-treated carbons. 


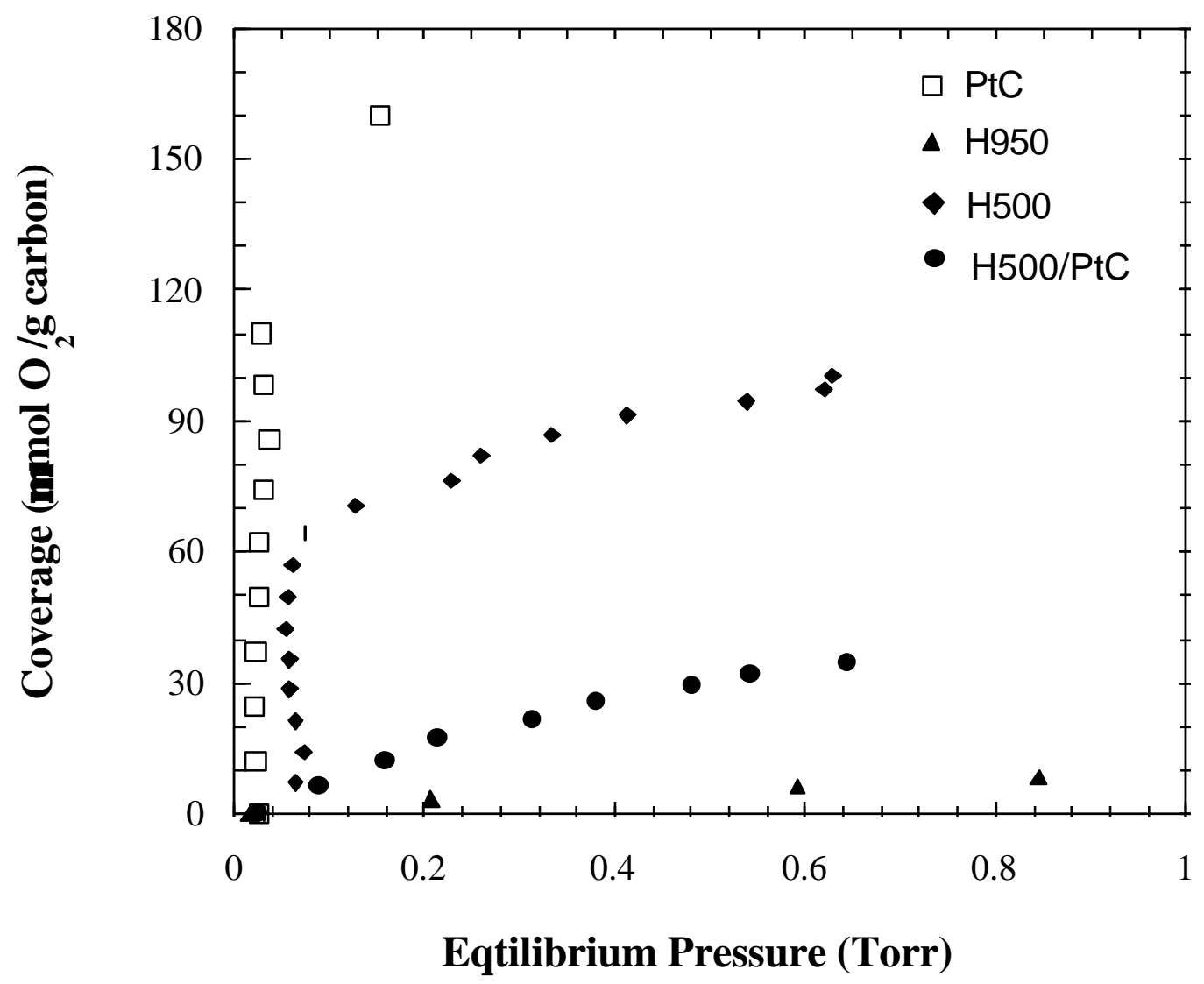

Figure $12 \mathrm{~b} . \mathrm{O}_{2}$ adsorption isotherms at $25^{\circ} \mathrm{C}$ on as-received and surface-treated carbons. 


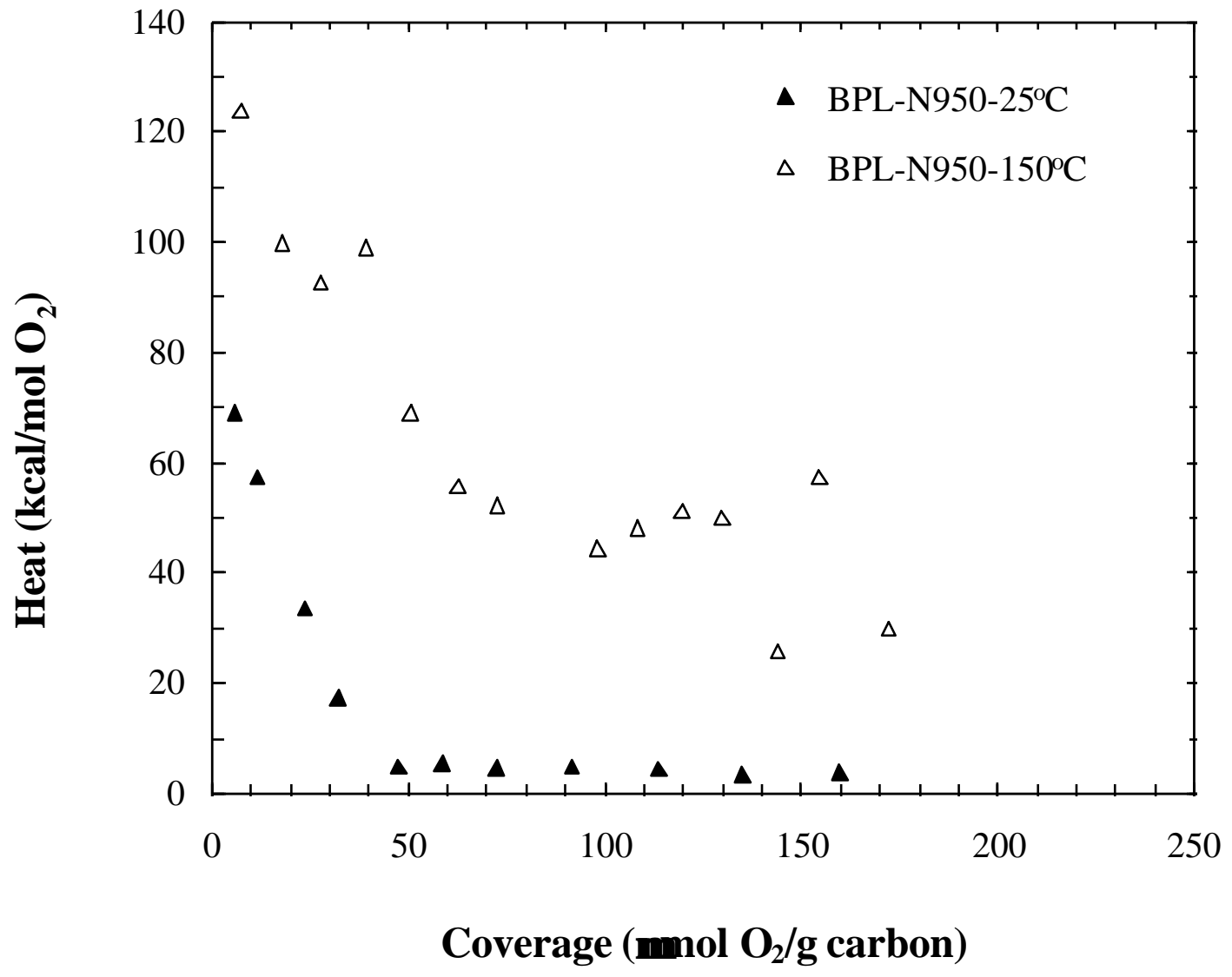

Figure $13 \mathrm{a}$. Heats of $\mathrm{O}_{2}$ adsorption on $\mathrm{N}_{2}$-treated BPL carbon at $25^{\circ} \mathrm{C}$ and $150^{\circ} \mathrm{C}$. 


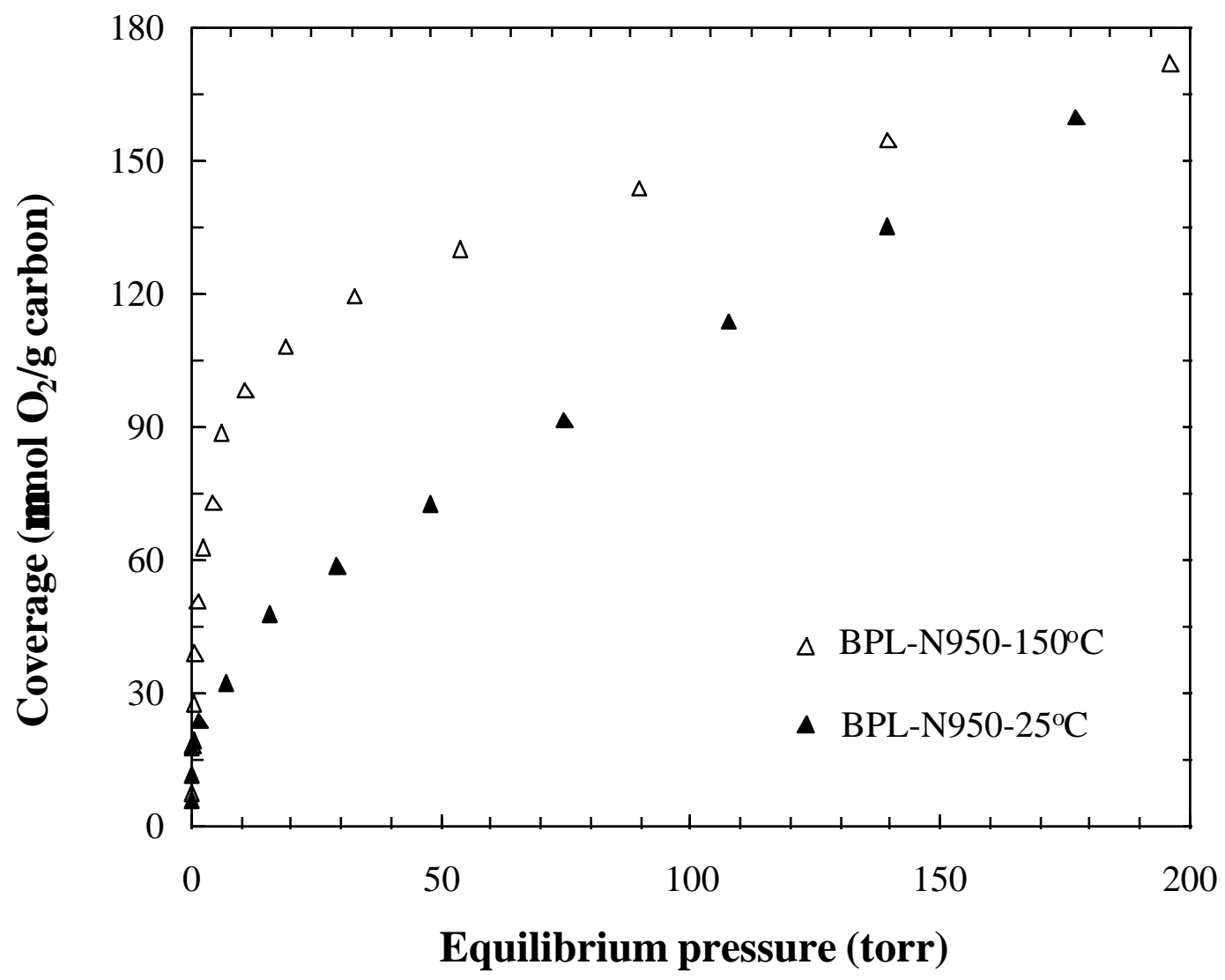

Figure $13 \mathrm{~b} . \mathrm{O}_{2}$ adsorption isotherms on $\mathrm{N}_{2}$-treated BPL carbon at $25^{\circ} \mathrm{C}$ and $150^{\circ} \mathrm{C}$. 


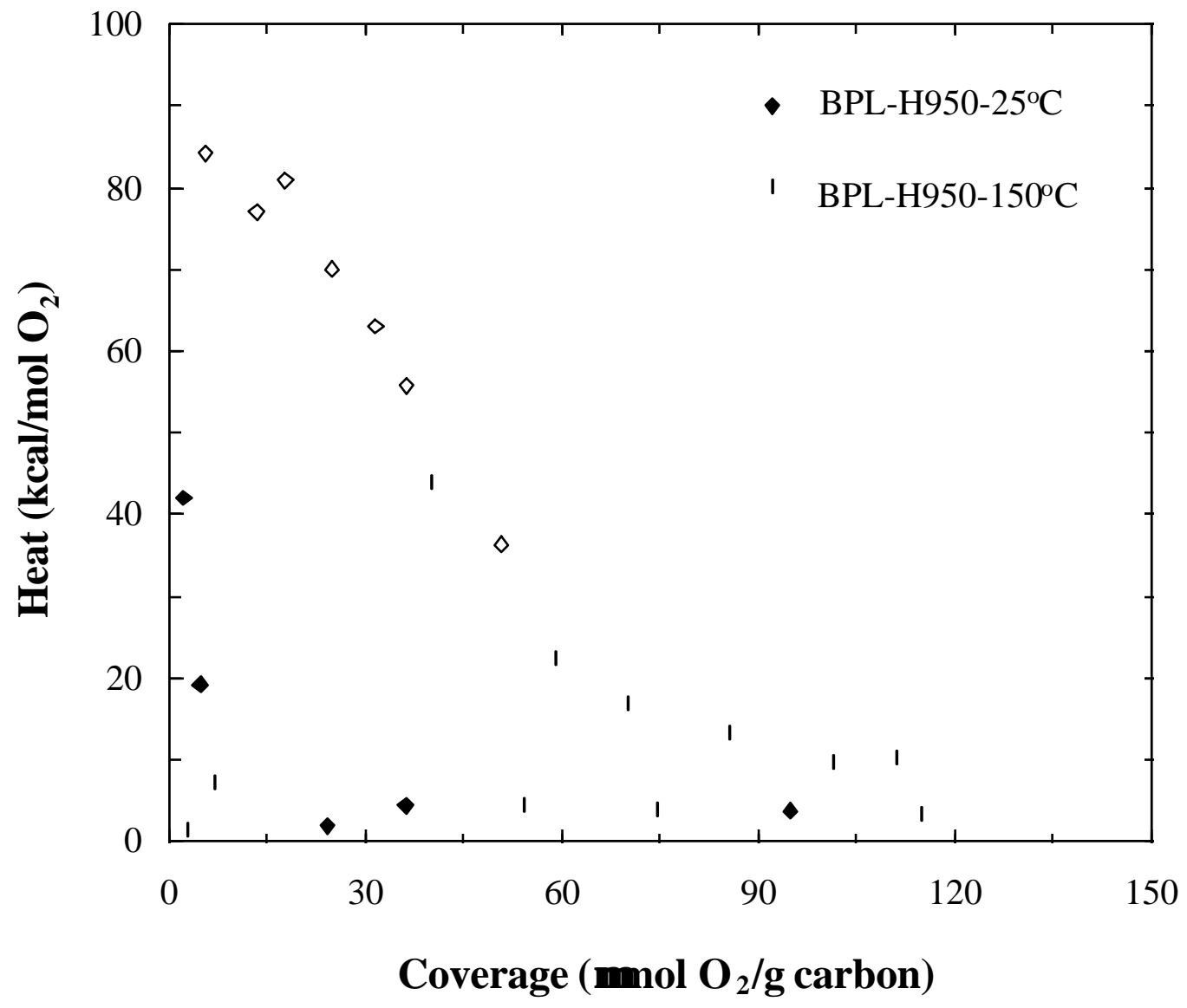

Figure 14a. Heats of $\mathrm{O}_{2}$ adsorption on $\mathrm{H}_{2}$-treated BPL carbon at $25^{\circ} \mathrm{C}$ and $150^{\circ} \mathrm{C}$. 


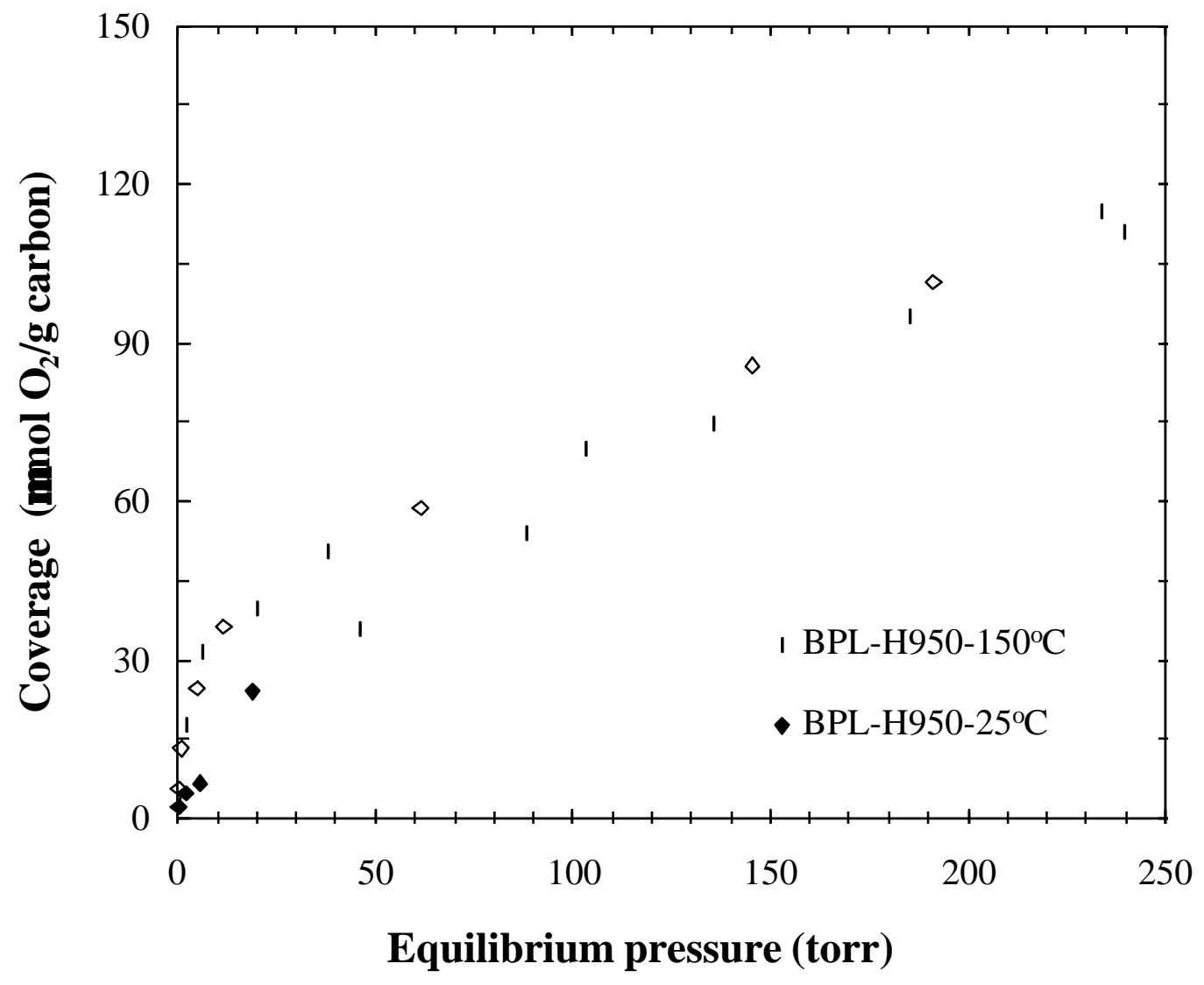

Figure $14 \mathrm{~b} . \mathrm{O}_{2}$ adsorption isotherms on $\mathrm{H}_{2}$-treated $\mathrm{BPL}$ carbon at $25^{\circ} \mathrm{C}$ and $150^{\circ} \mathrm{C}$. 


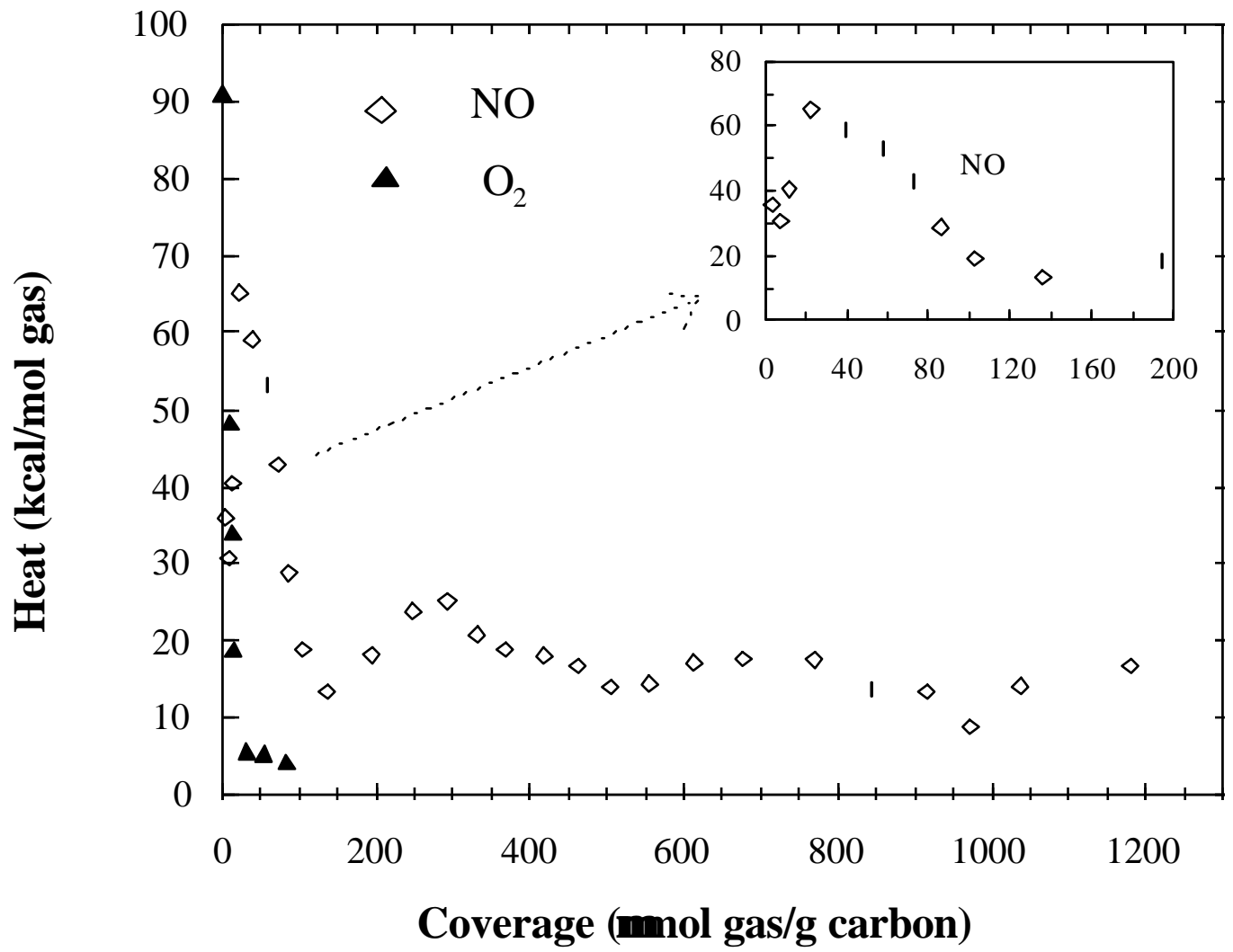

Figure 15a. Heats of adsorption of $\mathrm{NO}$ and $\mathrm{O}_{2}$ as a function of surface coverage at $25^{\circ} \mathrm{C}$ for $\mathrm{H}_{2}$-treated activated carbon $\mathrm{H} 950$. 


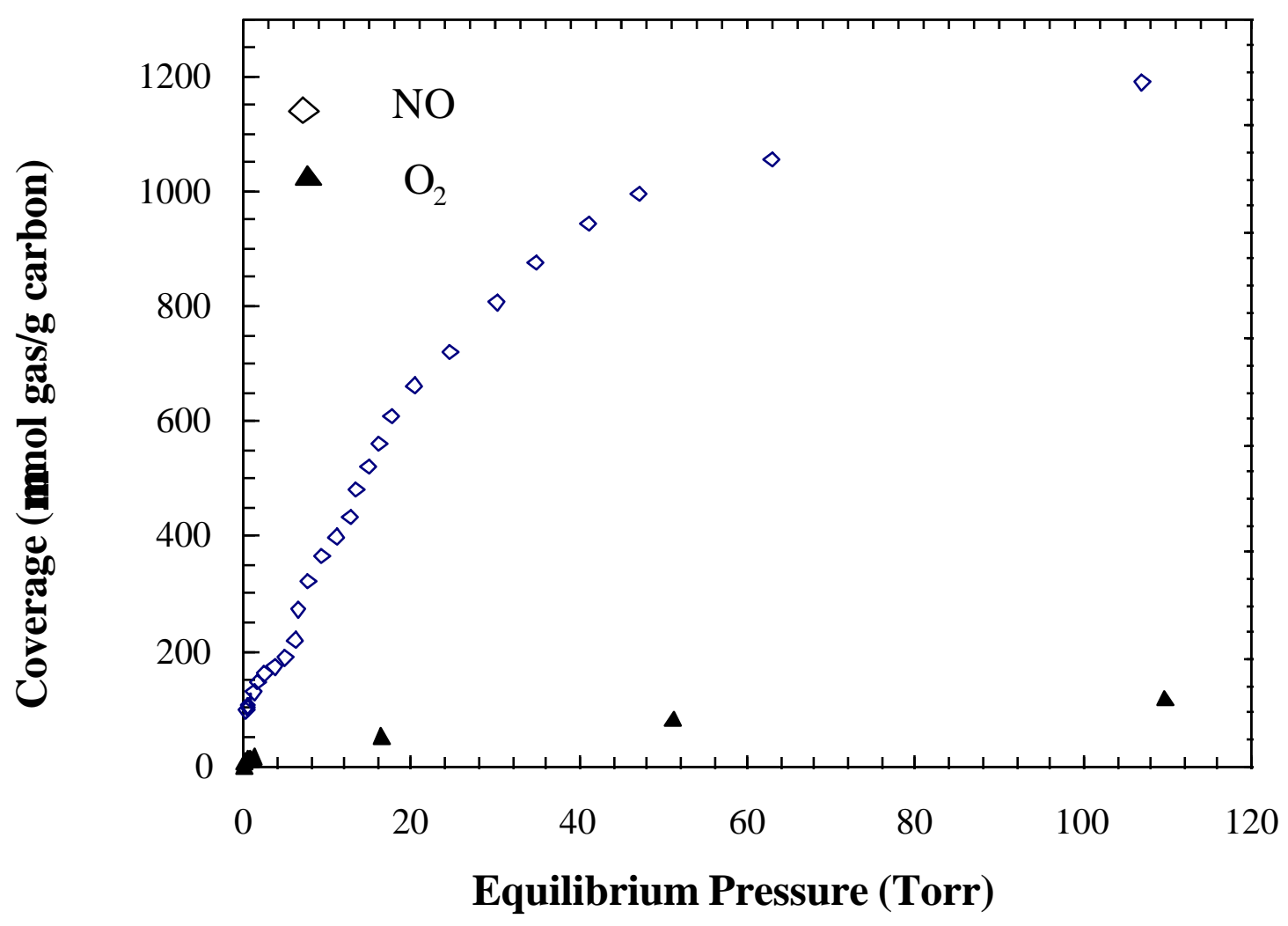

Figure $15 b . \mathrm{O}_{2}$ and $\mathrm{NO}$ adsorption isotherms at $25^{\circ} \mathrm{C}$ for $\mathrm{H}_{2}$-treated activated carbon $\mathrm{H} 950$. 


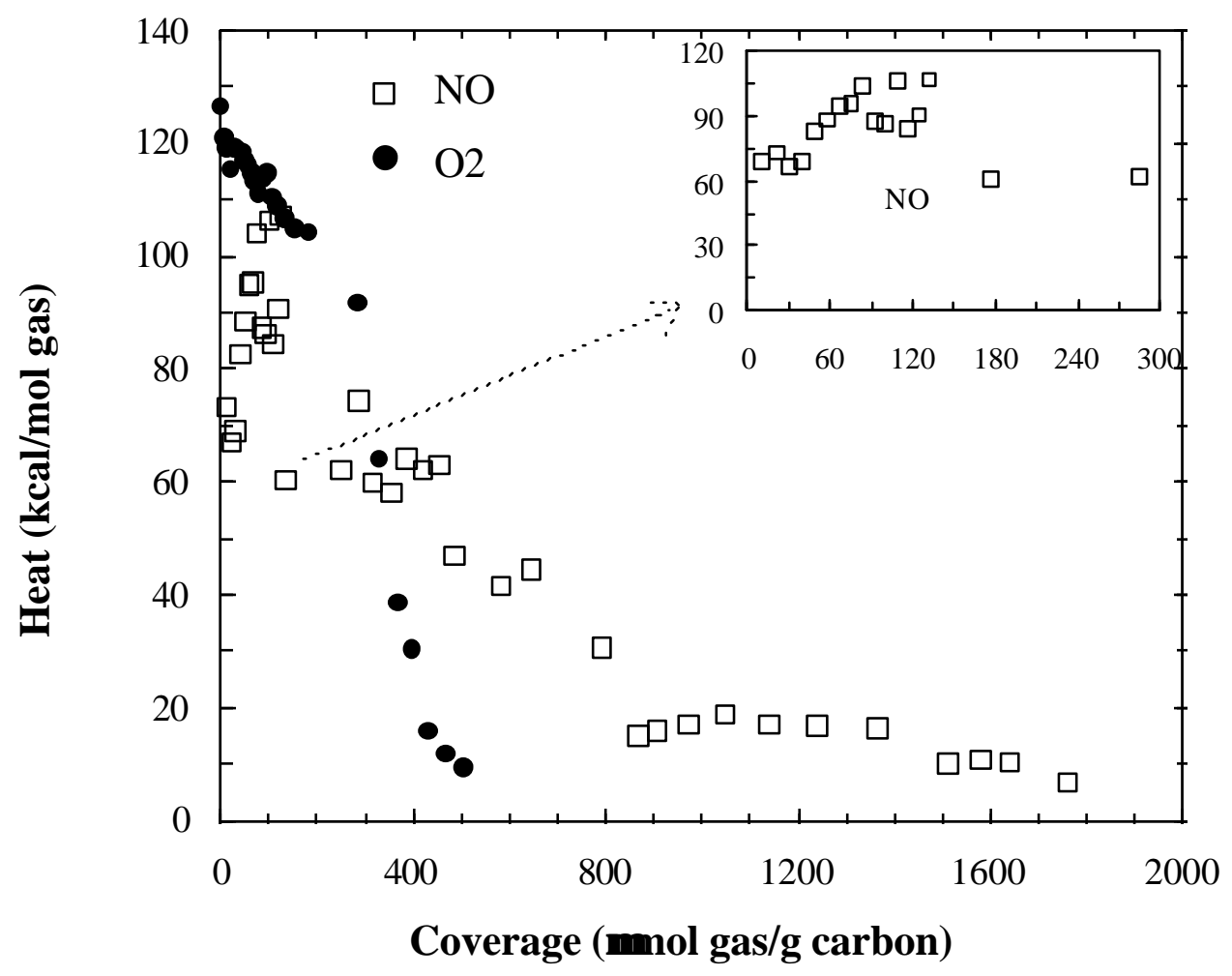

Figure 16a. Heats of adsorption of $\mathrm{NO}$ and $\mathrm{O}_{2}$ as a function of surface coverage at $25^{\circ} \mathrm{C}$ for $\mathrm{N}_{2}$-treated activated carbon N950. 


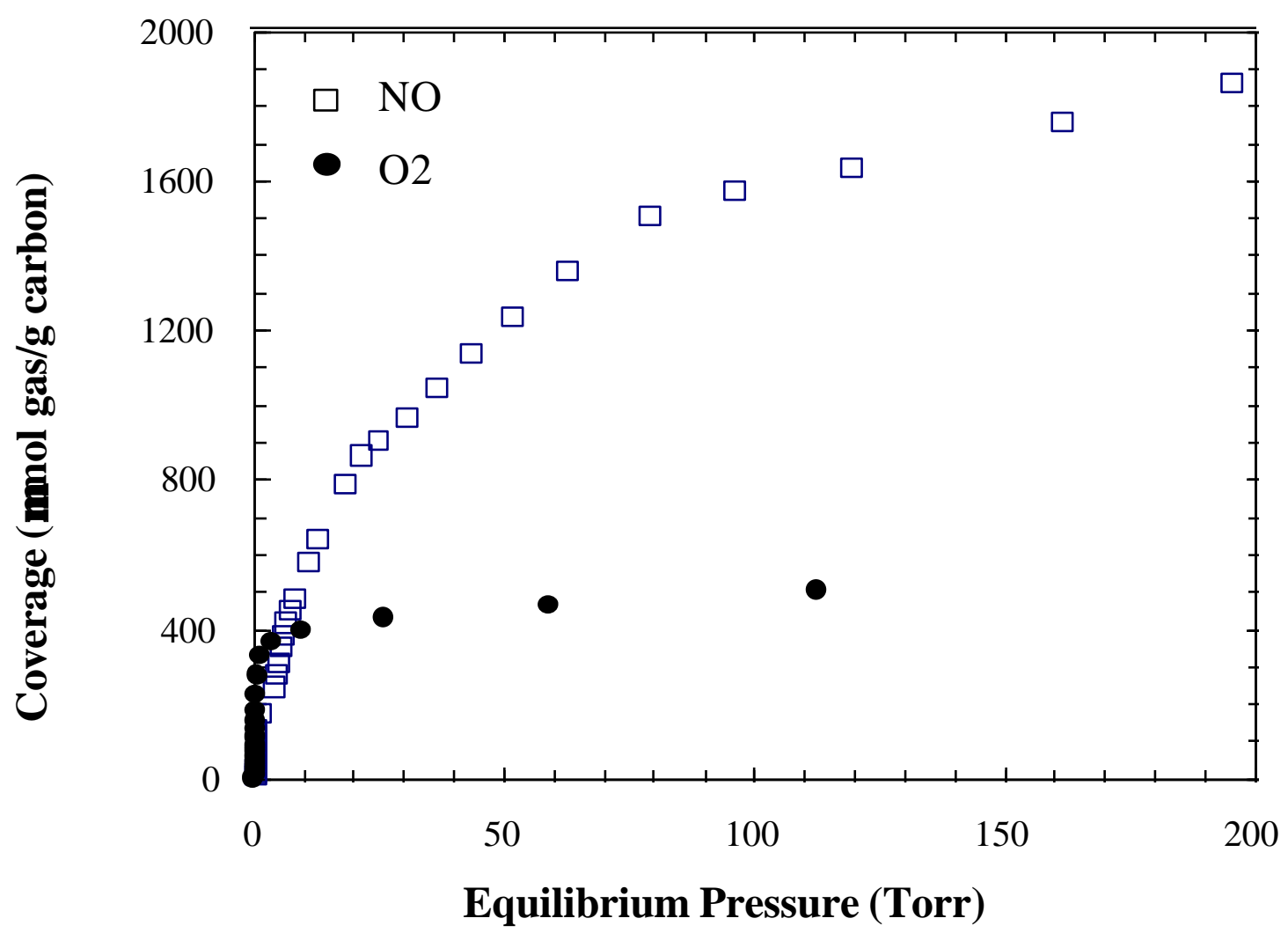

Figure 16b. $\mathrm{O}_{2}$ and $\mathrm{NO}$ adsorption isotherms at $25^{\circ} \mathrm{C}$ for $\mathrm{N}_{2}$-treated activated carbon $\mathrm{N} 950$. 


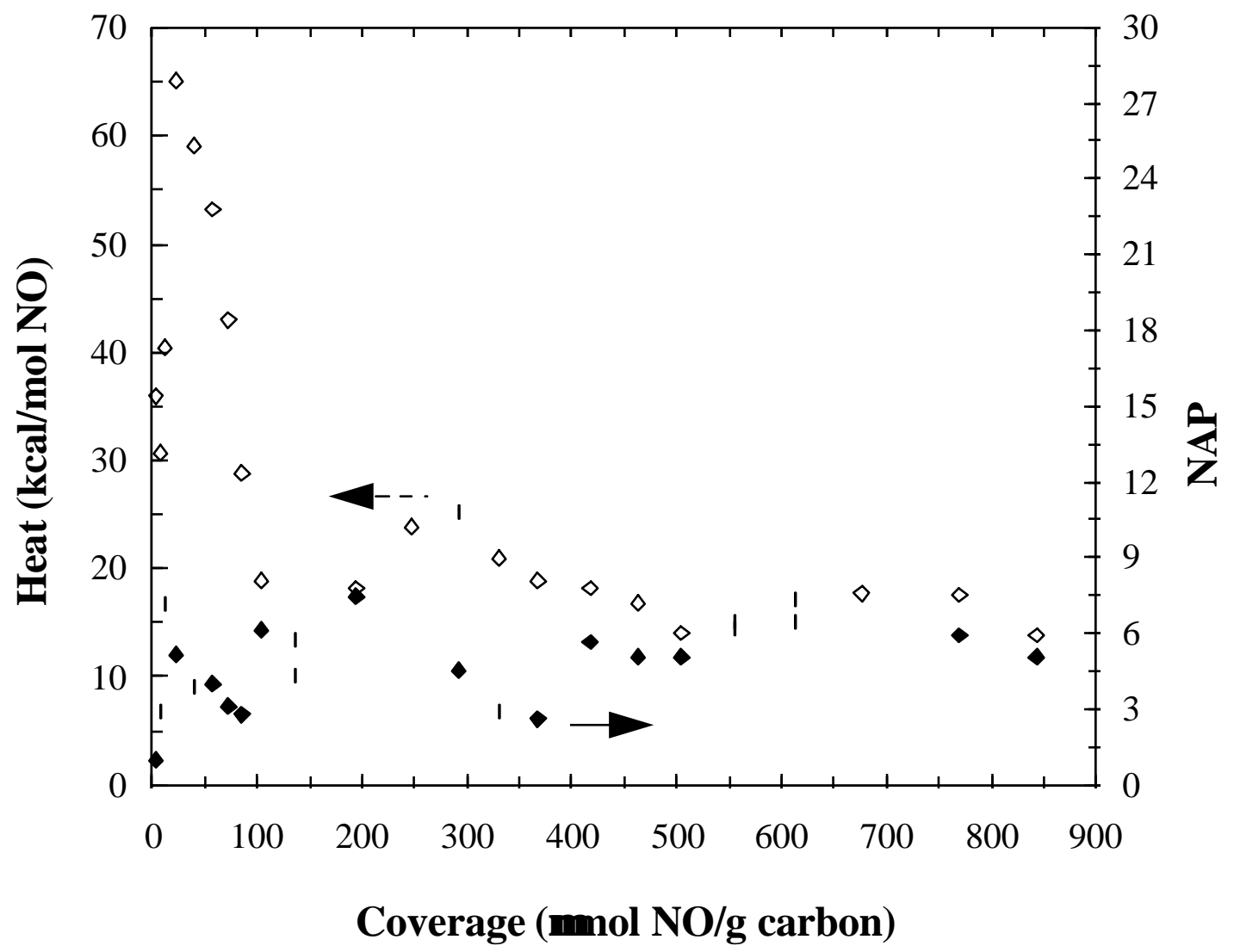

Figure 17. Plot of heat and the normalized adsorption parameter vs. surface coverage for NO adsorption on $\mathrm{H} 950$ at $25^{\circ} \mathrm{C}$. 


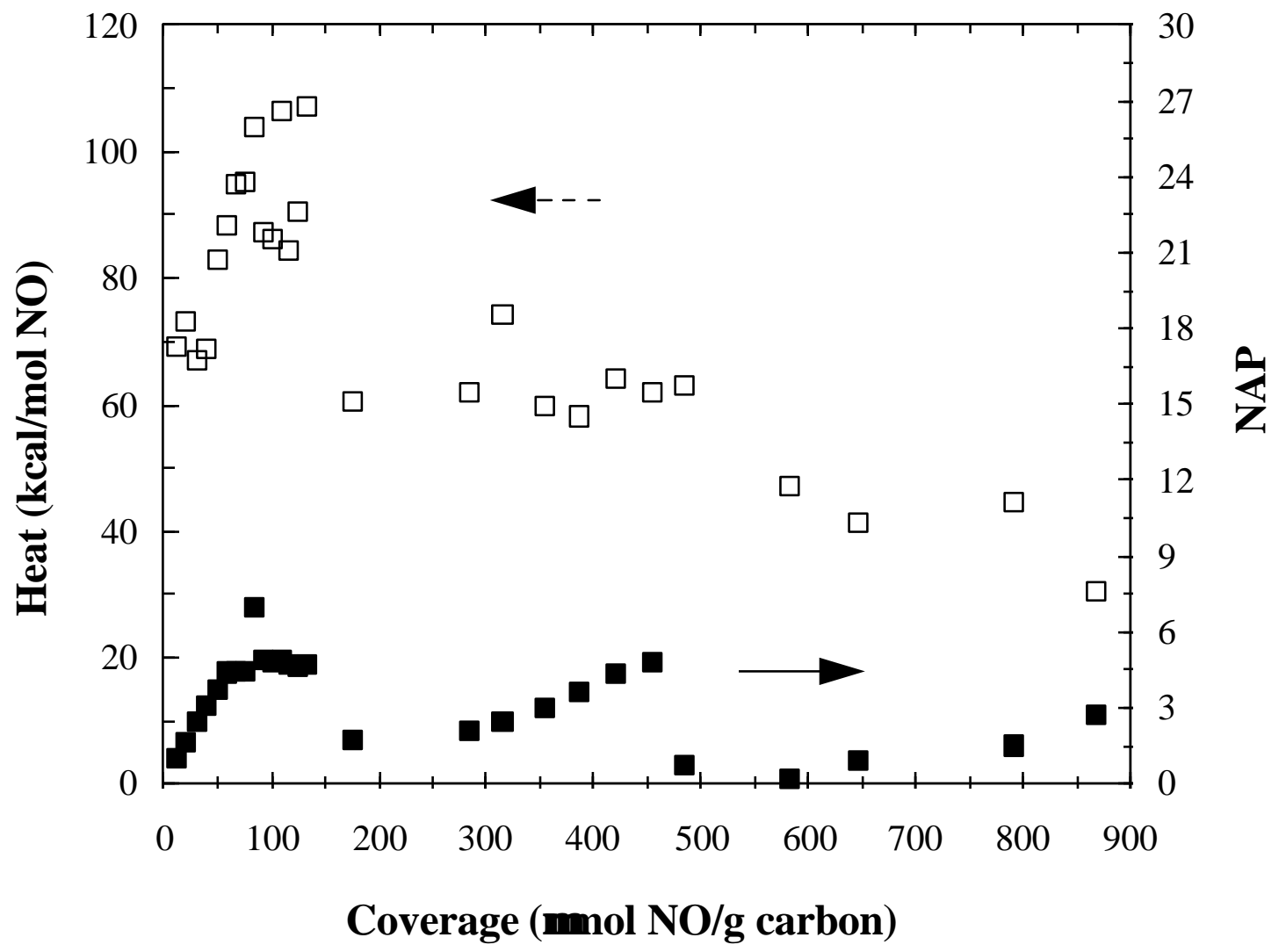

Figure 18. Plot of heat and the normalized adsorption parameter vs. surface coverage for NO adsorption on $\mathrm{N} 950$ at $25^{\circ} \mathrm{C}$. 


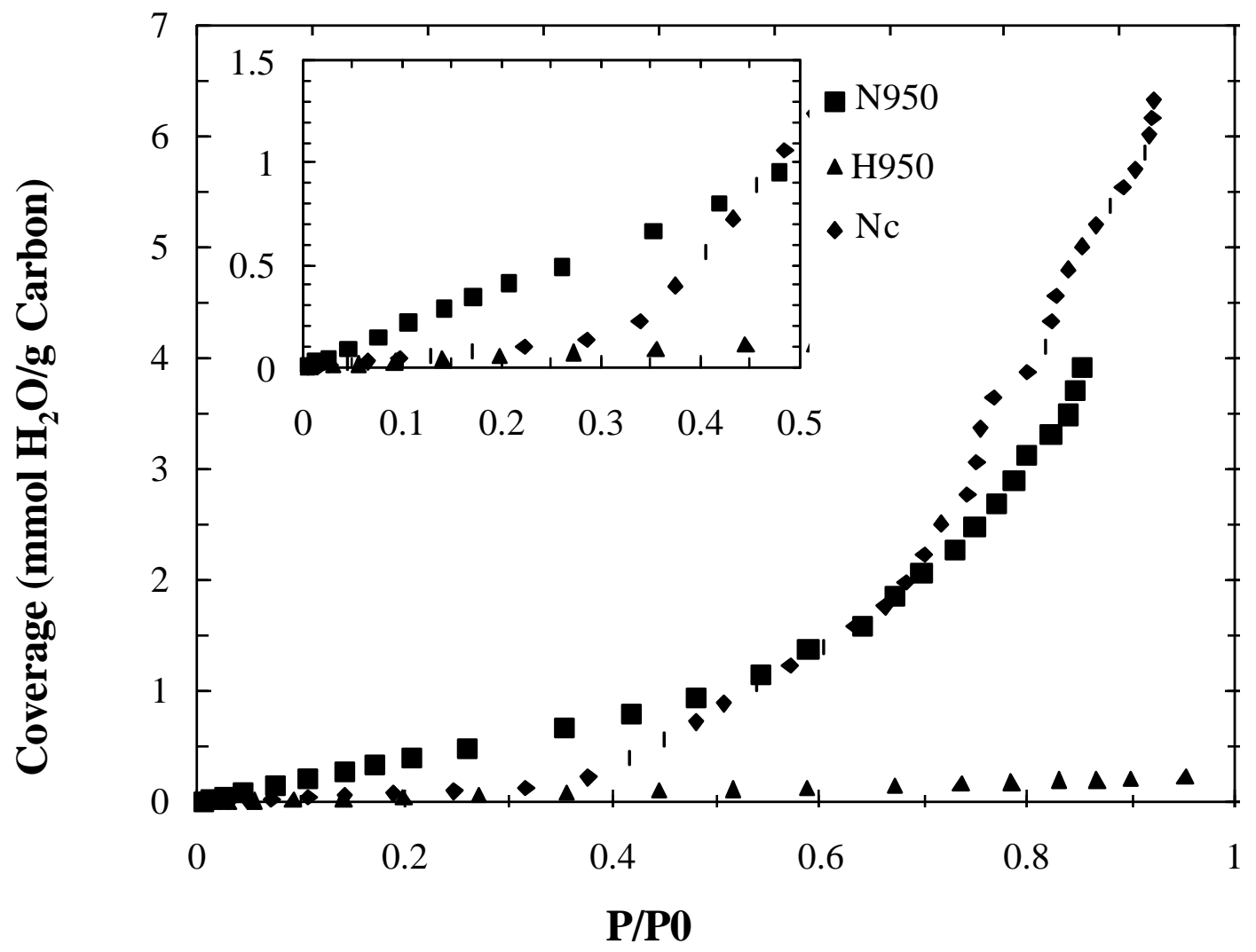

Figure 19a. Water vapor adsorption isotherms at $70^{\circ} \mathrm{C}$ for activated carbon $\mathrm{Nc}$ and carbons treated in $\mathrm{N}_{2}$ (N950) and in $\mathrm{H}_{2}$ (H950). 


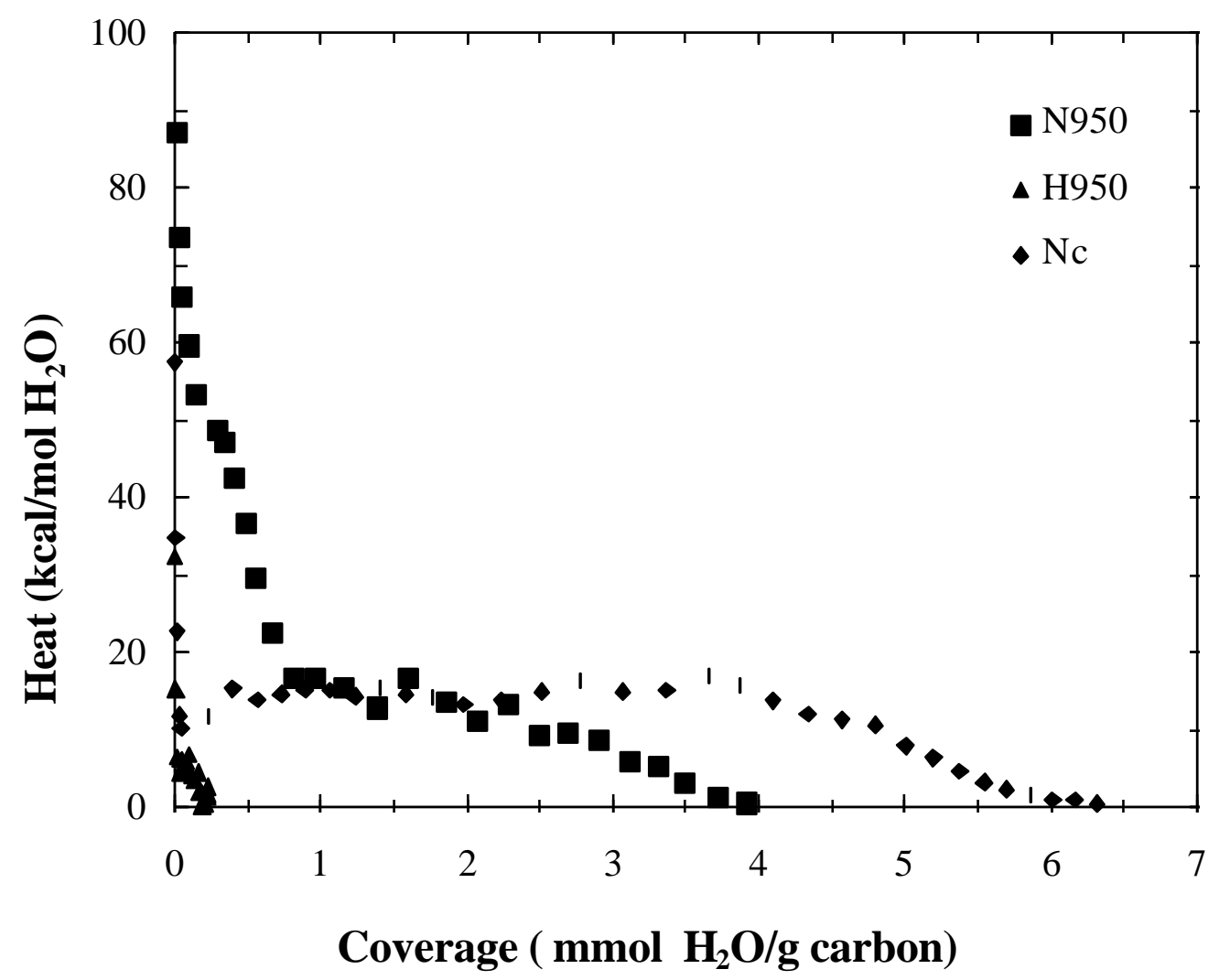

Figure $19 \mathrm{~b}$. Heats of water vapor adsorption as a function of surface coverage at $70^{\circ} \mathrm{C}$ on activated carbon $\mathrm{Nc}$ and carbons treated in $\mathrm{N}_{2}$ (N950) and in $\mathrm{H}_{2}(\mathrm{H} 950)$. 


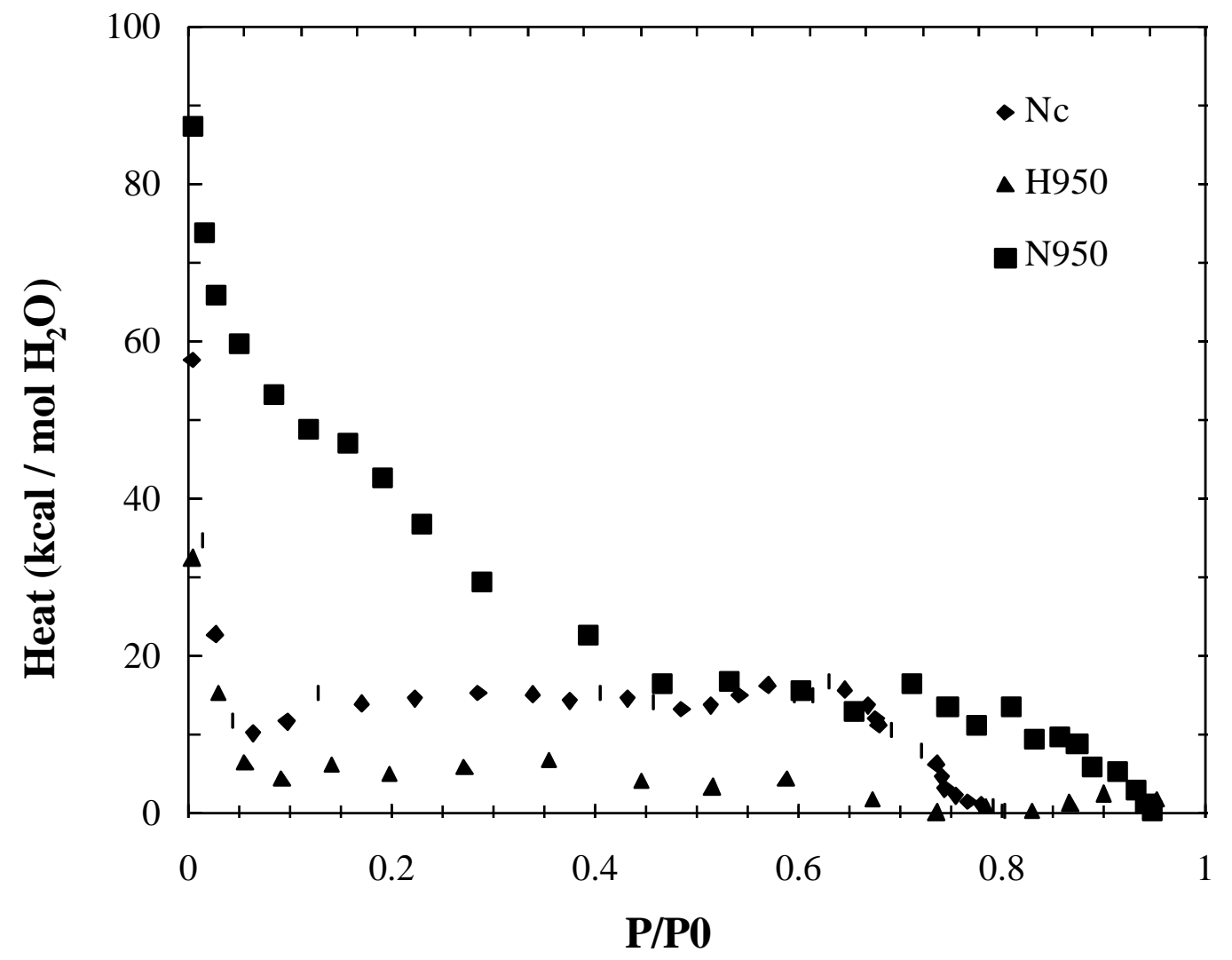

Figure $19 \mathrm{c}$. Heats of water vapor adsorption as a function of relative pressure at $70^{\circ} \mathrm{C}$ on activated carbon $\mathrm{Nc}$ and carbons treated in $\mathrm{N}_{2}(\mathrm{~N} 950)$ and in $\mathrm{H}_{2}(\mathrm{H} 950)$. 


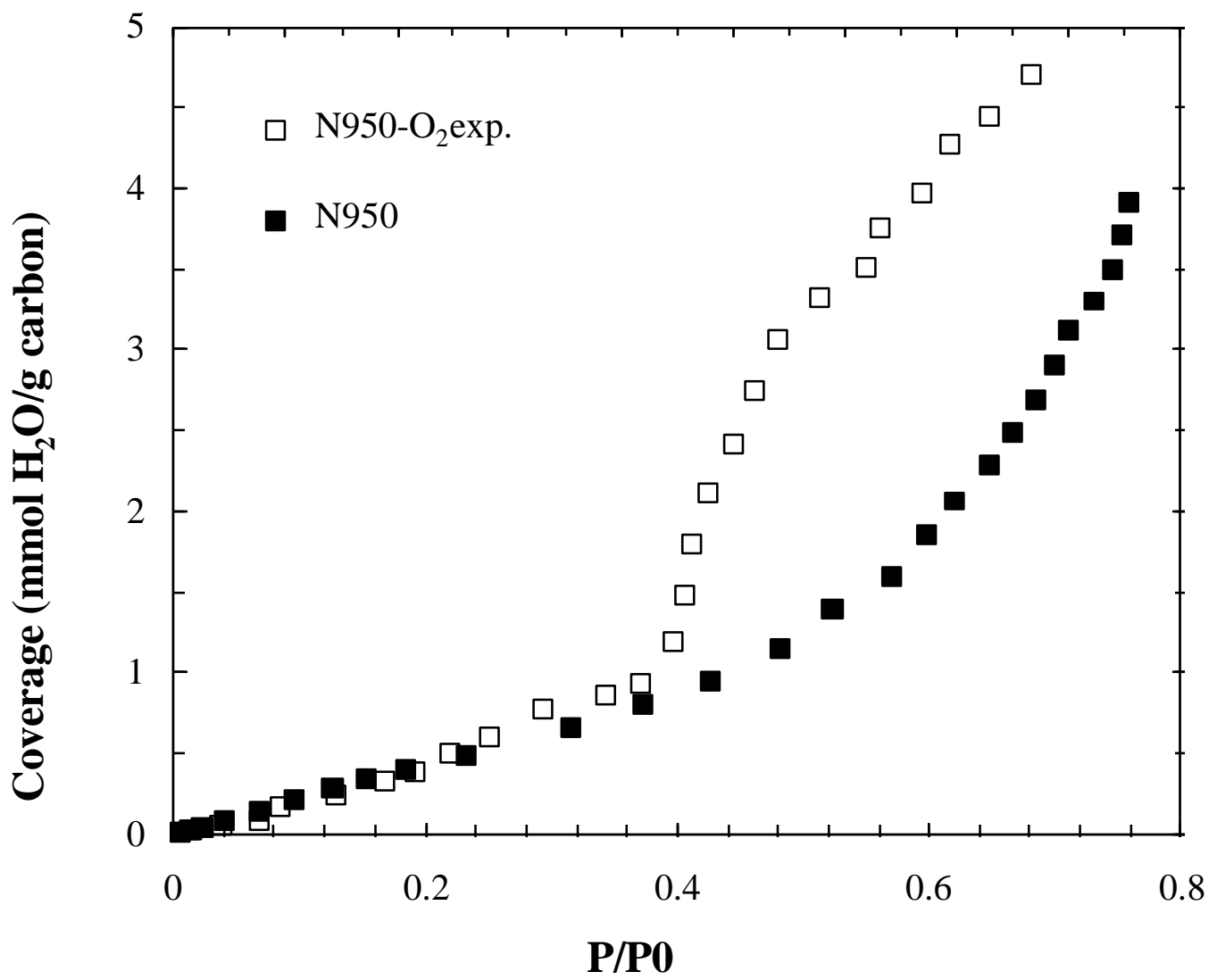

Figure 20a. Water vapor adsorption isotherms at $70^{\circ} \mathrm{C}$ on $\mathrm{N} 950$ and $\mathrm{O}_{2}$ exposed $\mathrm{N} 950$. 


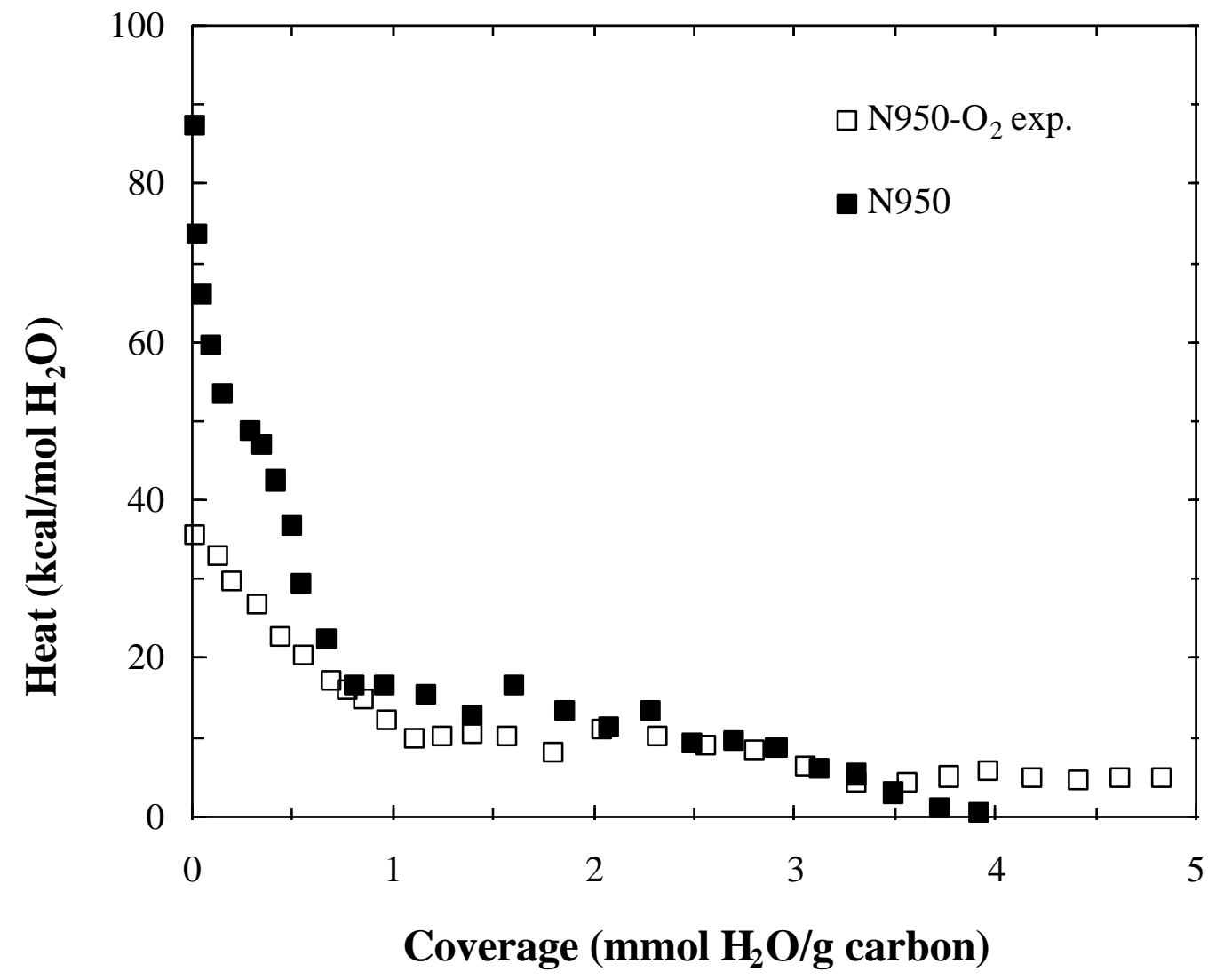

Figure 20b. Heats of water vapor adsorption as a function of surface coverage at $70^{\circ} \mathrm{C}$ on N950 and $\mathrm{O}_{2}$ exposed N950. 


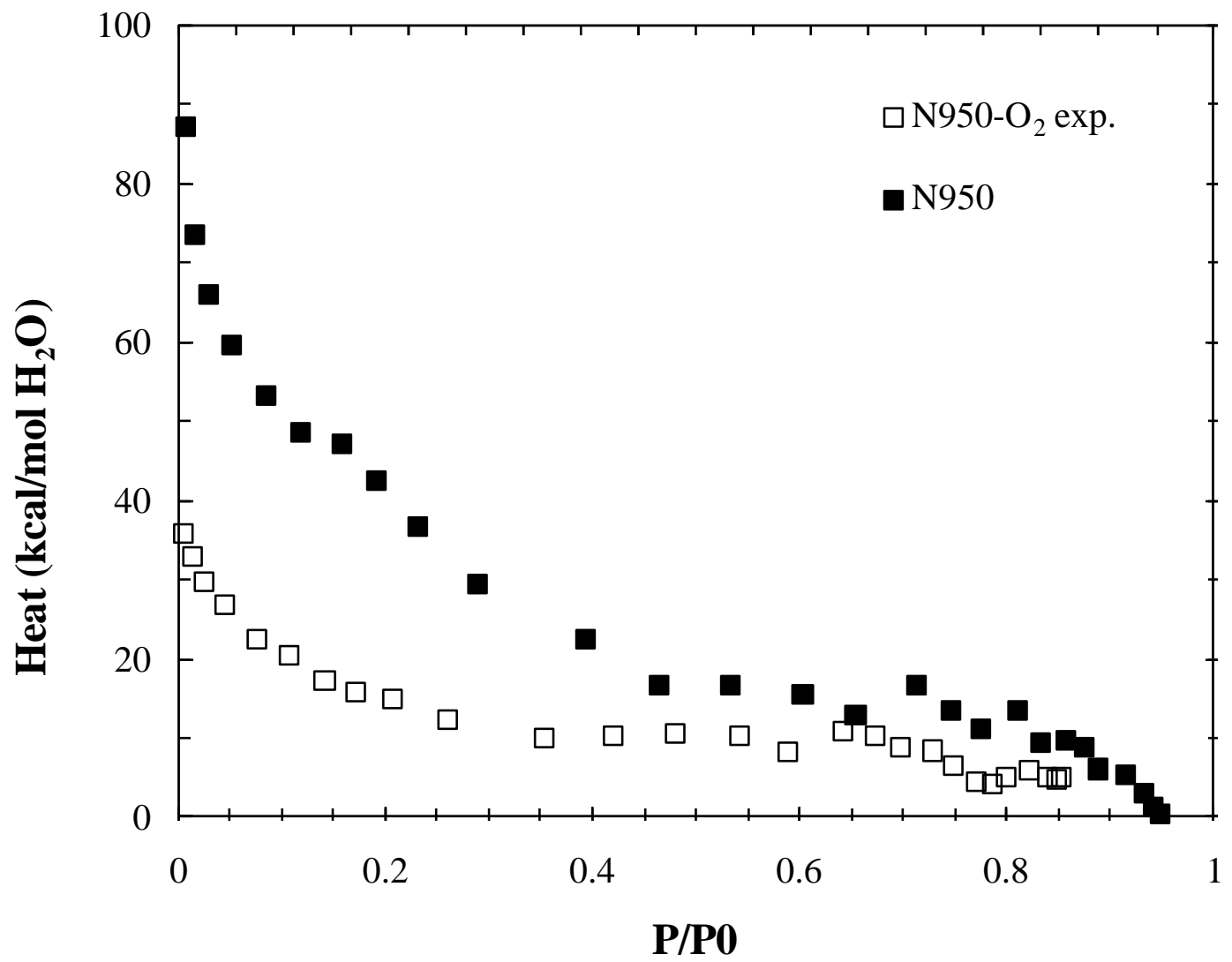

Figure 20c. Heats of water vapor adsorption as a function of relative pressure at $70^{\circ} \mathrm{C}$ on N950 and $\mathrm{O}_{2}$ exposed N950. 


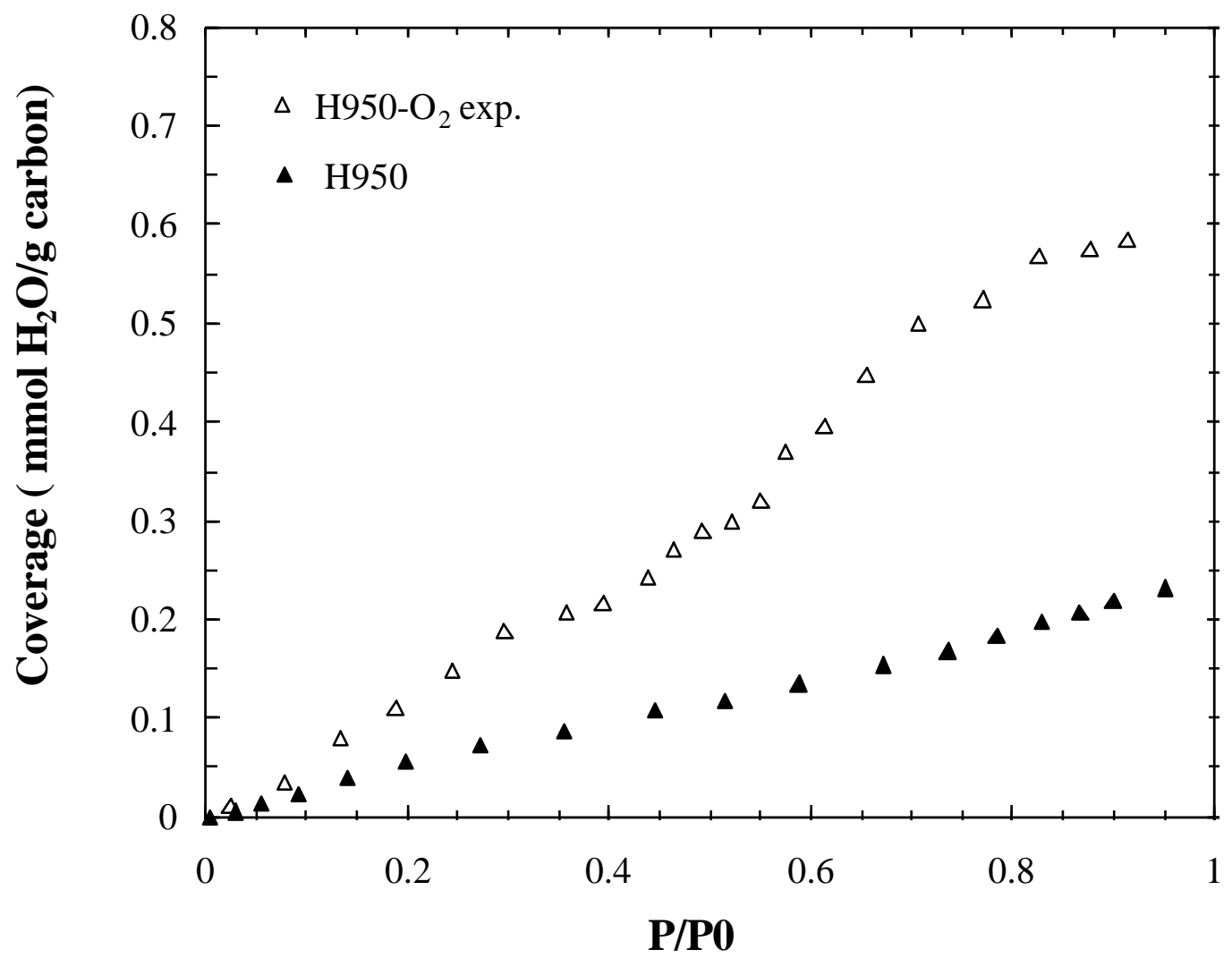

Figure 21a. Water vapor adsorption isotherms at $70^{\circ} \mathrm{C}$ on $\mathrm{H} 950$ and $\mathrm{O}_{2}$ exposed $\mathrm{H} 950$. 


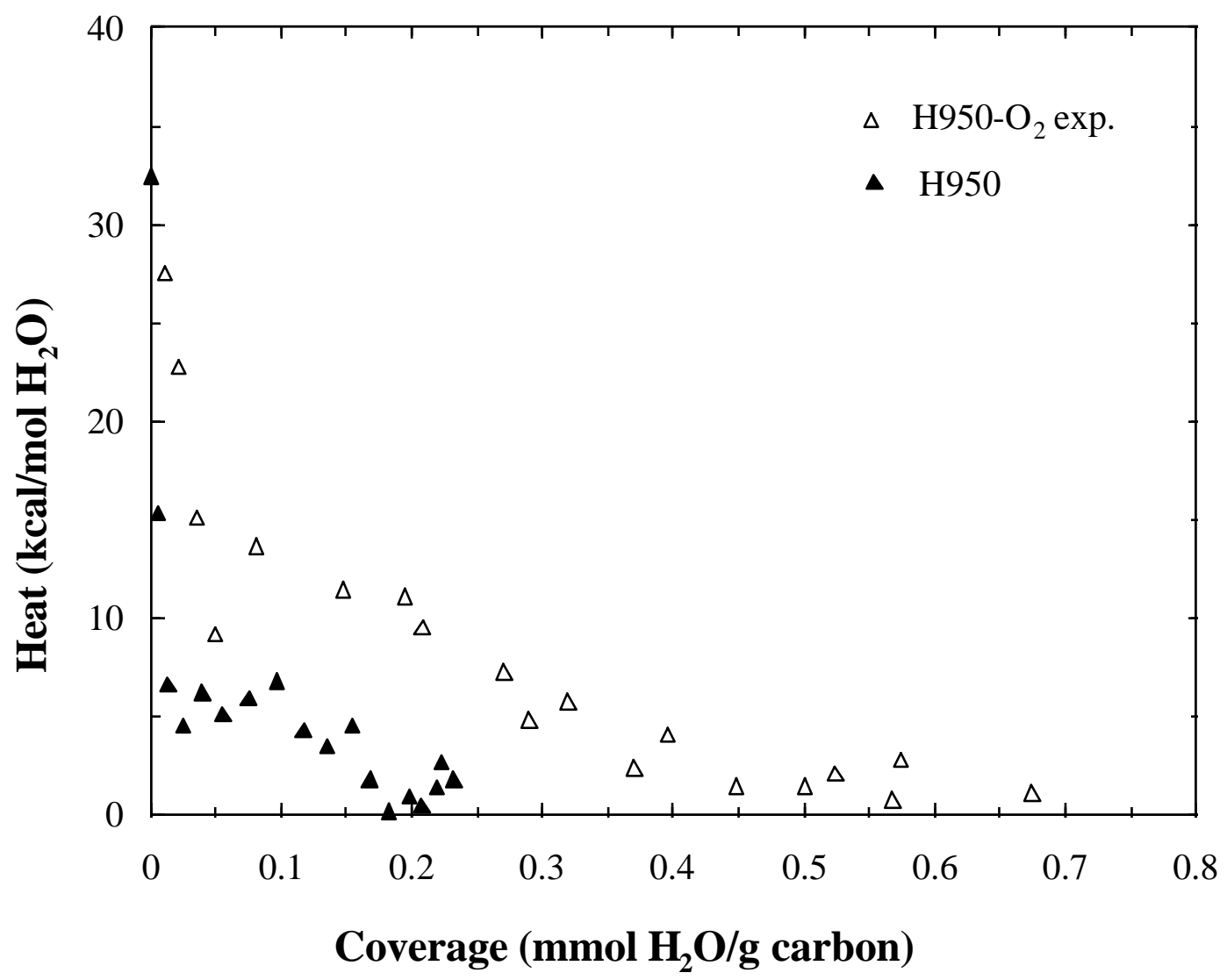

Figure $21 \mathrm{~b}$. Heats of water vapor adsorption as a function of surface coverage at $70^{\circ} \mathrm{C}$ on $\mathrm{H} 950$ and $\mathrm{O}_{2}$ exposed $\mathrm{H} 950$. 


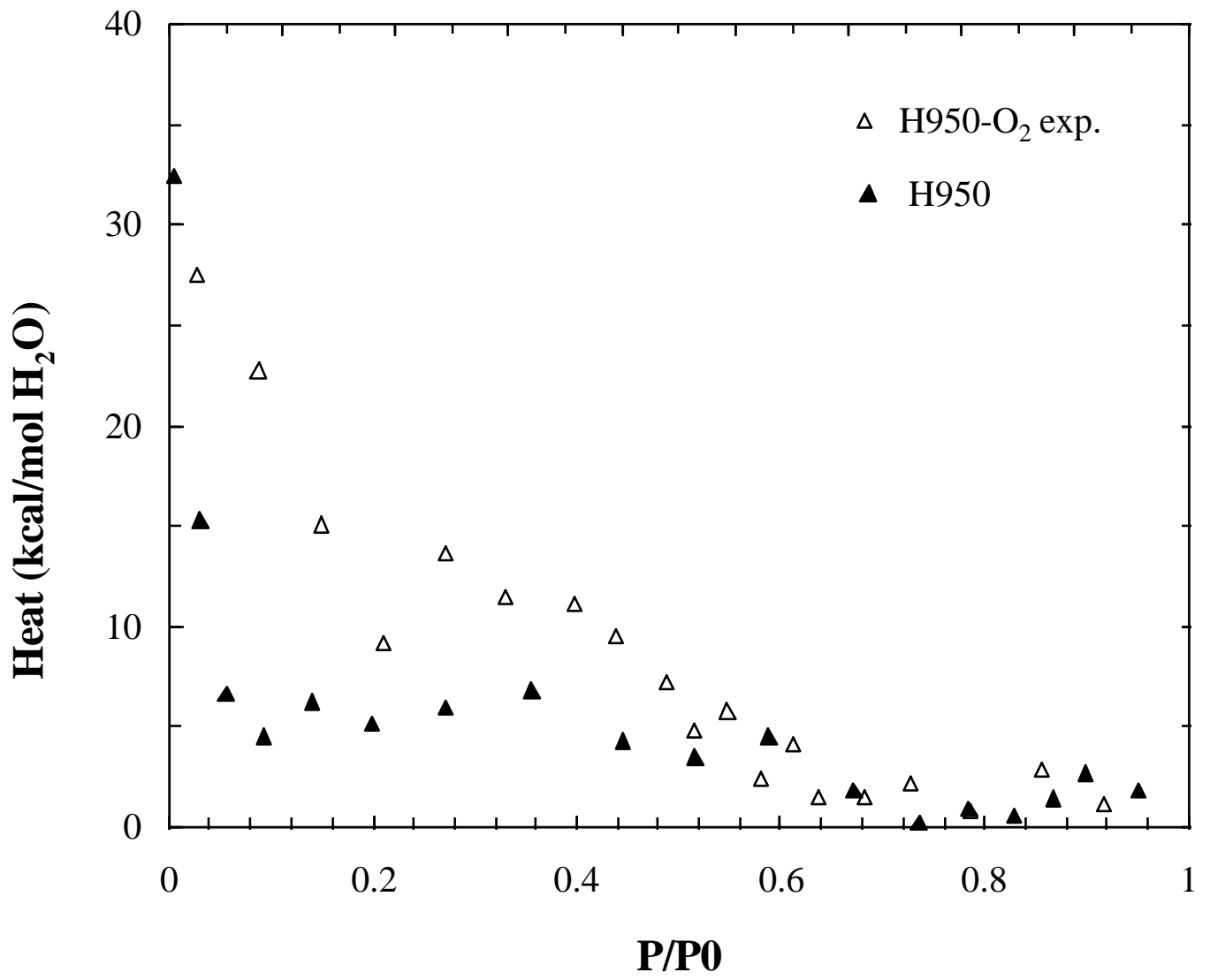

Figure 21c. Heats of water vapor adsorption as a function of relative pressure at $70^{\circ} \mathrm{C}$ on $\mathrm{H} 950$ and $\mathrm{O}_{2}$ exposed $\mathrm{H} 950$. 


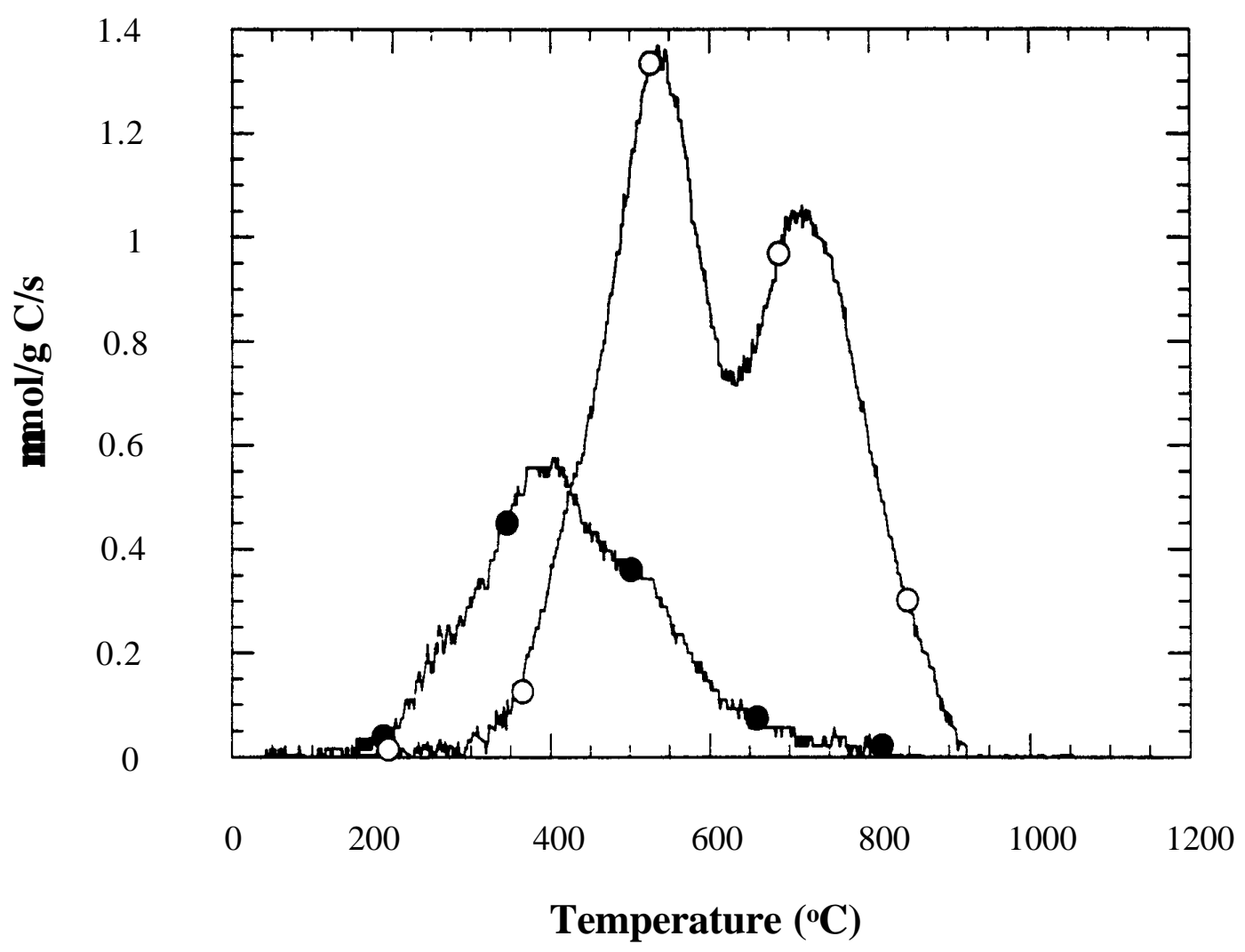

Figure 22. Temperature Programmed Desorption spectra for the as-recieved activated carbon $\mathrm{Nc:} \mathrm{O}, \mathrm{CO} ; \mathrm{O}, \mathrm{CO}_{2}$. 


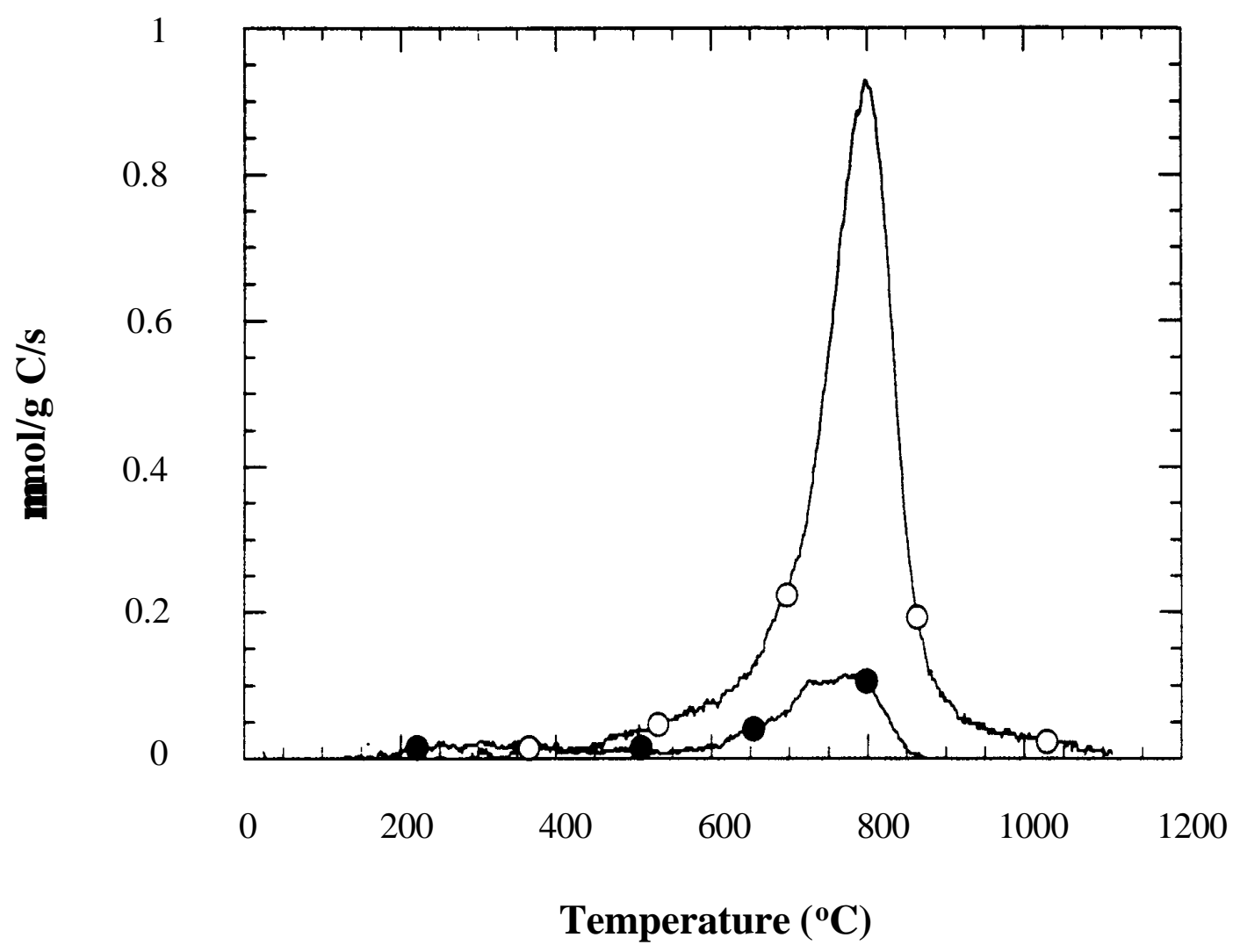

Figure 23. Temperature Programmed Desorption spectra for the $\mathrm{N} 950$ obtained after $\mathrm{O}_{2}$ adsorption calorimetry experiment at $25^{\circ} \mathrm{C} . \mathrm{O}, \mathrm{CO} ; \mathbf{O}, \mathrm{CO}_{2}$. 


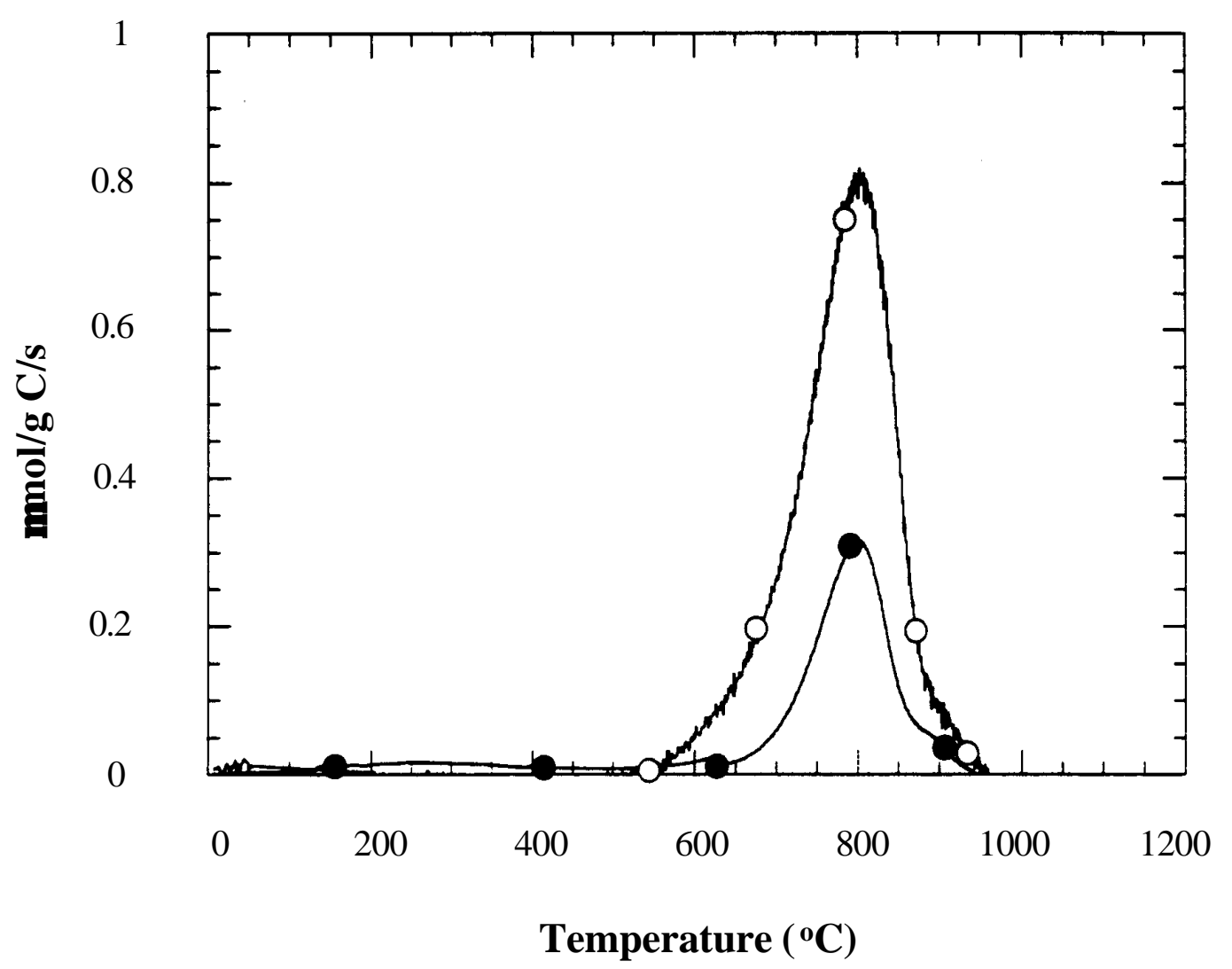

Figure 24. Temperature Programmed Desorption spectra for the N950(aw) obtained after $\mathrm{O}_{2}$ adsorption calorimetry experiment at $25^{\circ} \mathrm{C}$. $\mathrm{O}, \mathrm{CO} ; \mathrm{O}, \mathrm{CO}_{2}$. 


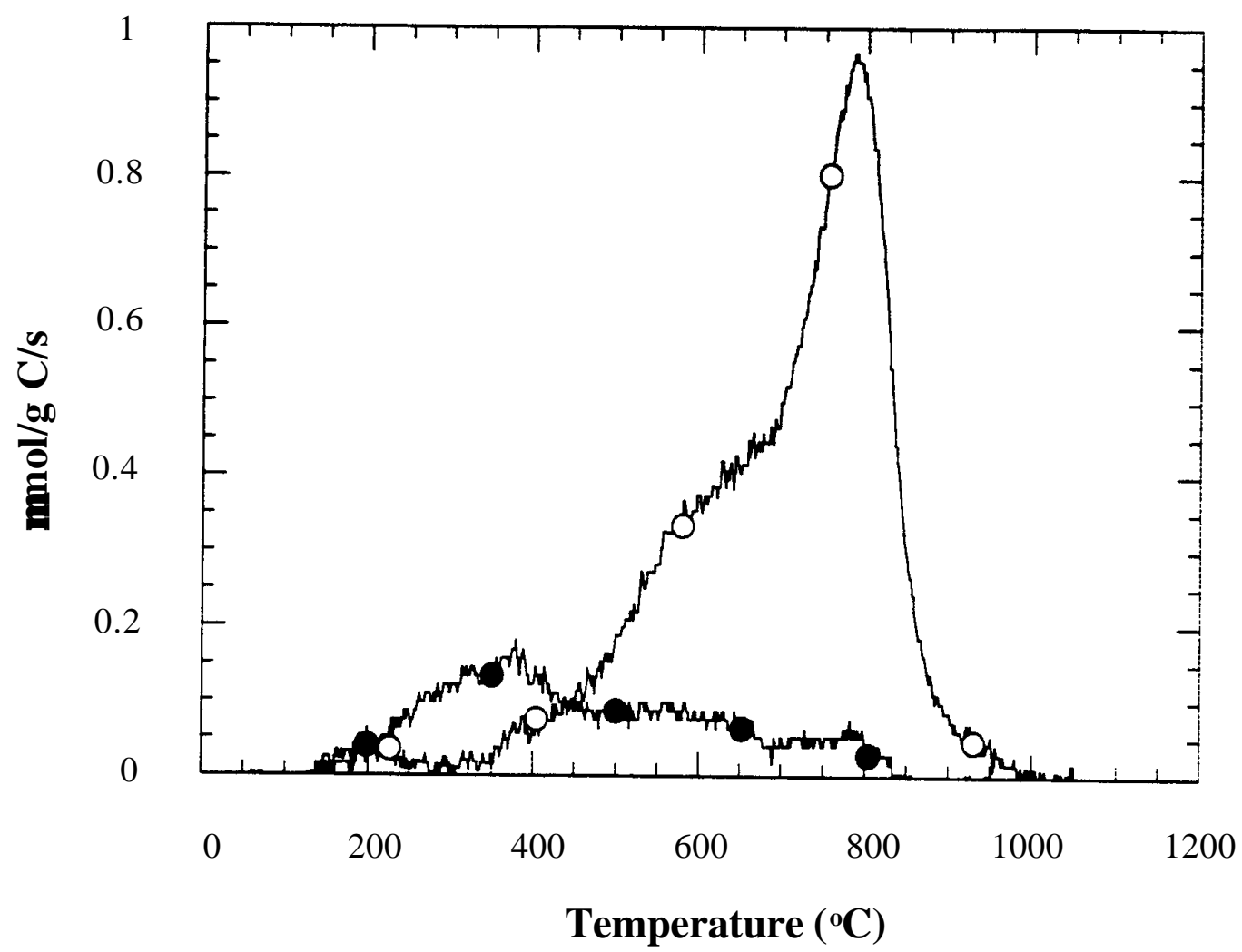

Figure 25. Temperature Programmed Desorption spectra for the $\mathrm{N} 950$ obtained after $\mathrm{O}_{2}$ adsorption calorimetry experiment at $150^{\circ} \mathrm{C} . \mathrm{O}, \mathrm{CO} ; \mathrm{O}, \mathrm{CO}_{2}$. 


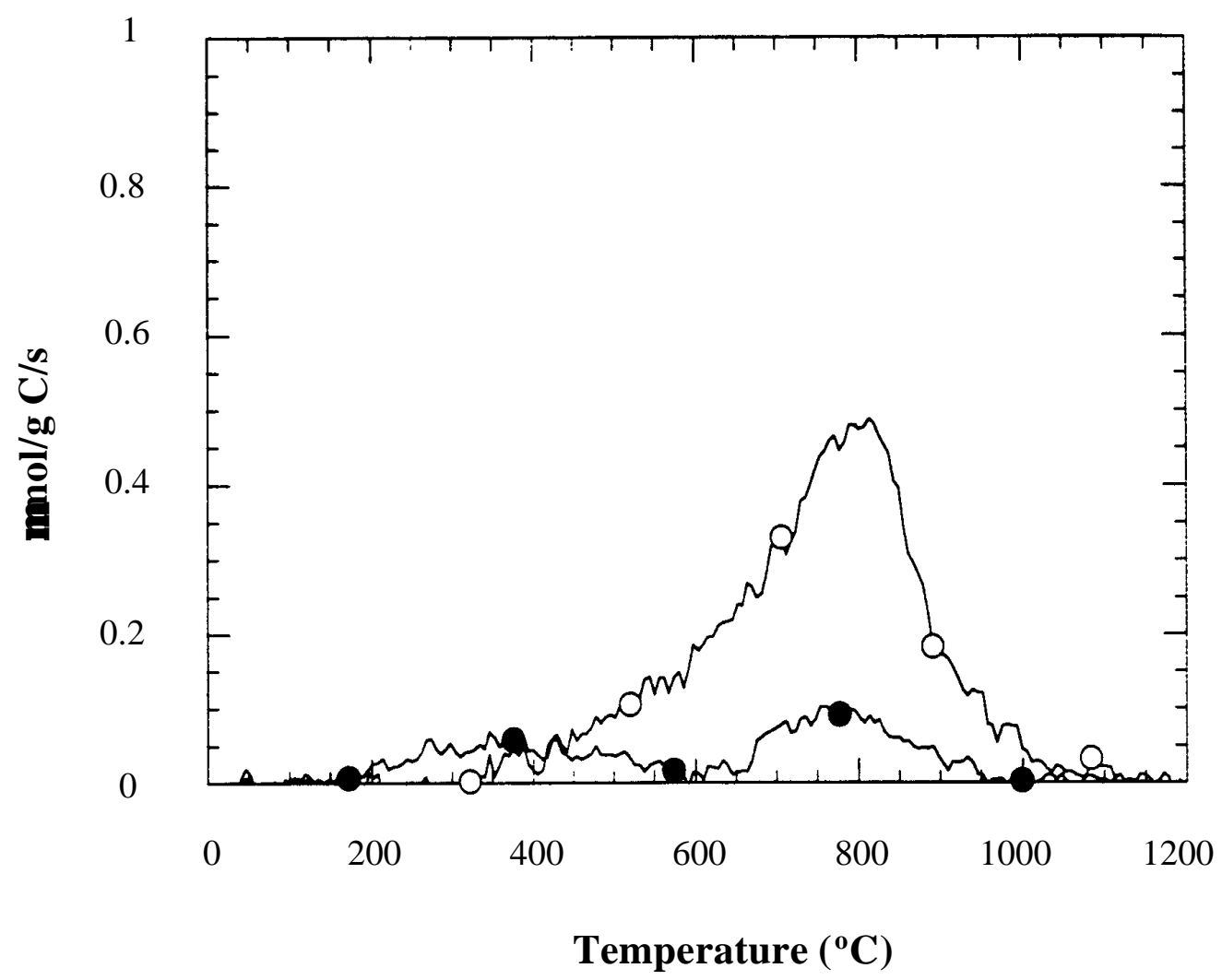

Figure 26. Temperature Programmed Desorption spectra for the N950(aw) obtained after $\mathrm{O}_{2}$ adsorption calorimetry experiment at $150^{\circ} \mathrm{C}$. $\mathrm{O}, \mathrm{CO} ; \mathrm{O}, \mathrm{CO}_{2}$. 


\section{Chapter 4}

\section{DISCUSSION}

\subsection{Effects of Chemical Treatments}

In this discussion, it is shown that very simple ideas regarding the structure and formation mechanism of surface active sites can explain the myriad observations presented in the preceding chapter. In essence, the model is simple: inert gas treatment removes $\mathrm{CO}$ and $\mathrm{CO}_{2}$ in such a fashion that "dangling carbons" and other highly unsaturated sites are formed. These sites are highly active for strong oxygen, NO and water adsorption. In contrast, hydrogen treatment removes not only oxygen groups, but unsaturated carbons as well. The remaining unsaturated edge atoms are of low activity and hydrophobic. Thus, water and oxygen adsorption are suppressed under ambient conditions.

Consider the chemical surface effects produced in carbon N950. It is well known that essentially all oxygen-containing functional groups are removed during this treatment[74, 75], but the resultant surface is very active and both elemental analysis (Table 4) and microcalorimetry (Figures 7 and 8) show significant oxygen adsorption upon re-exposure to $\mathrm{O}_{2}$ (air) at room temperature. Indeed, Table 6 and Figure 4 confirm the acidic nature of the stabilized form of this carbon, in agreement with the findings of Lau et al.[75] on aging effects in carbon blacks.

Consider now the chemical surface effects produced in carbon treated with $\mathrm{H}_{2}$. As the severity of treatment increases, the weight loss increases as well. This could be due to the 
removal of carbon atoms by hydrogasification or to the removal of carbon, oxygen, and hydrogen atoms by decomposition of functional groups (e.g., desorption of $\mathrm{COOH}, \mathrm{C}=\mathrm{O}$, or C-O-C groups). The comparison of $\mathrm{H} / \mathrm{C}$ ratios (Table 4) is intriguing: treatments in both $\mathrm{N}_{2}$ and $\mathrm{H}_{2}$ cause important reductions in $\mathrm{H}$ content, but as the severity of $\mathrm{H}_{2}$ treatment increases, the $\mathrm{H} / \mathrm{C}$ ratio in the carbon decreases. On the other hand, as this severity increases, the basicity of the carbon increases (Table 6); its affinity for oxygen decreases correspondingly (Figures 7 and 8 ). Clearly, there is no correlation between the degree of hydrogen incorporation into the carbon and carbon's basicity (or carbon's affinity for oxygen). This finding is consistent with the notion [14] that the main contribution to carbon surface basicity is not from functional groups at the edges of carbon crystallites (where most of the functional groups reside) but from oxygenfree Lewis base sites within the graphene layers (which do not require stabilization by hydrogen).

The chemical surface effects produced from BPL are similar to that from Nc: At room temperature, high temperature $\mathrm{N}_{2}$-treated sample readsorbs $\mathrm{O}_{2}$ easily, while high temperature $\mathrm{H}_{2}$-treated sample is more resistant to $\mathrm{O}_{2}$ attack. Both of $\mathrm{N}_{2}$-or $\mathrm{H}_{2}$-treated BPL do adsorb oxygen (activated chemisorption) at elevated temperature.

\subsection{Surface Stabilization Model}

The results presented in Figures 5-8 and Tables 4-6 allow us to postulate the mechanisms of surface stabilization that are summarized in Figure 27 and discussed in detail next. 
Structure A shows the key features of interest at the edges of a carbon crystallite. Additional acidic oxygen surface groups (carboxyl, phenolic, etc.) $[27,30]$ are not shown because their fate is thought to be identical to that shown here for the lactone and pyrone groups. Thermal treatment removes oxygen in the form of $\mathrm{CO}_{2}$ (predominantly at lower temperatures) and $\mathrm{CO}$ (predominantly at higher temperatures), leaving unsaturated carbon atoms (“dangling carbons") at the edges, structure B. The subsequent fate of this highly unstable structure of carbon active sites was proposed as structures C, D, E, and F, which can explain our experimental findings. Structure B, which results from thermal treatment in the inert $\mathrm{N}_{2}$ gas, include two types of active sites: (i) "dangling carbons" which is single bonded to the basal plane (type I). (ii) edge sites forming an in-plane $\sigma$ pair, with $\mathrm{s}^{2} \mathrm{p}^{2}$ hybridization (type II, in Coulson's terminology [76]). Obviously, sites of type I makes this surface very reactive and, upon subsequent exposure to room-temperature air, $\mathrm{O}_{2}$ will readily chemisorb on it.

Structure C and D in Figure 27 illustrate the two mechanisms by which surface stabilization is achieved in the presence of $\mathrm{H}_{2}$. In the more straightforward one, leading to structure D, hydrogen treatment removes the least saturated carbon atoms ("dangling carbons") from the edges (probably as methane) and also forms stable $\mathrm{C}-\mathrm{H}$ bonds with the carbon active sites. The fact that hydrogen will interact with carbon at elevated temperatures to produce methane is well documented [77]. The suggestion that hydrogasification takes place in the present case, especially at higher temperatures, is consistent with the large weight losses observed following hydrogen treatments (Table 4); the only new idea in the present model is the 
hypothesis that weakly bonded carbons are more readily (selectively) hydrogasified and that the reactive type I sites are thus eliminated under these conditions.

The mechanism leading to structure $\mathrm{C}$ is more complex. The need for its contribution to the stabilization of structure $\mathrm{B}$ - primarily in $\mathrm{H}_{2}$ and to some extent in $\mathrm{N}_{2}$ - is a consequence of two experimental facts: (a) the $\mathrm{H} / \mathrm{C}$ ratio of the sample treated in $\mathrm{H}_{2}$ is not larger than that of the sample treated in $\mathrm{N}_{2}$ at the same temperature (Table 4); (b) no significant increase in microporosity was detected upon $\mathrm{H}_{2}$ treatment despite the large weight loss, especially at higher temperature (Table 2). Condensation of the graphene layers, e.g., in the presence of the transient $\mathrm{CH}_{2}$ radicals, is the process that we propose to be responsible for these findings. On one hand, the much greater abundance of such radicals in the presence of $\mathrm{H}_{2}$ is another explanation for the consequent low concentration of the very active type I sites in structure C. On the other hand, there is evidence in the literature [78] for gasification-induced carbon densification (illustrated in structure $\mathrm{C}$ ). It is also worth noting that structure $\mathrm{C}$ in particular could easily lead to the formation of pyrone-type surface groups $[15,79]$ upon carbon re-exposure to $\mathrm{O}_{2}$ at room temperature.

The structure $\mathrm{E}$, and $\mathrm{F}$ are proposed to be equilibrium with $\mathrm{C}$ and $\mathrm{D}$, particularly in the case that the hydrogen treatment temperature is relative low.

The unusually high differential heats of oxygen adsorption $(125 \mathrm{kcal} / \mathrm{mol})$ observed in this study (Figure 7 ) can also be explained by this model. These heats are probably too high to be explained by the formation of oxygen complexes at "low energy" edge sites, such as type II (Figure 27). In contrast, chemisorption of $\mathrm{O}_{2}$ at sites of type I could release considerably more 
heat than the average heats observed on carbons, especially under nondifferential conditions. As shown in the Figure 27, "dangling carbon" (type I) atoms have already broken two basal-plane bonds and are in a higher energy state than the normal edge atoms with only one broken basalplane bond. Therefore, they can more strongly bond with oxygen (higher heats) than the edge atoms with two nearest-neighbor basal planes, thus accounting for the higher heats of adsorption observed.

One question remains regarding the heats of oxygen adsorption. There are several possible reasons why such high values (>100 kcal/mol) apparently have not been reported before. While this question is the subject of our continued research, one obvious explanation is that their detection requires the use of both a clean surface and a truly differential microcalorimeter. The contention that both conditions were met in our study is further supported by the results shown in Figure 8 and Figure 28. The anomalous behavior shown in Figure 8 (decreasing "equilibrium" pressure with increasing surface coverage at very low equilibrium pressure) is an artifact which is a consequence of the existence of highly reactive sites on the surface of incompletely stabilized carbons (e.g., N950, N500, H800, and N950/H650, but not $\mathrm{H} 875$ and $\mathrm{H} 950$ ). That is, the first microdoses of $\mathrm{O}_{2}$ introduced in the calorimeter at room temperature, produce some $\mathrm{CO}$ by gasification of the highly reactive sites of type I which are thus responsible for the very high heats of adsorption observed. This is illustrated in Figure 28, obtained in a separate experiment. Sample N950 was prepared in a quartz reactor connected to a quadrupole mass spectrometer; after cooling to room temperature, it was contacted with $50 \mathrm{~cm}^{3} /$ min He containing $5 \% \mathrm{O}_{2}$. The production of $\mathrm{CO}$, i.e., 2 mol of gas produced for every 
mole of gas consumed $\left(2 \mathrm{C}^{*}+\mathrm{O}_{2}=2 \mathrm{CO}\right)$, is indeed consistent with the anomalous lowcoverage isotherm behavior shown in Figure 8.

According to this model, the nature of some of the active sites is drastically different after treatments in $\mathrm{H}_{2}$ vs $\mathrm{N}_{2}$. After treatment in $\mathrm{H}_{2}$, divalent in-plane sigma pairs at the edges of graphene layers (type II sites, in Coulson's terminology) are thought to be the dominant active sites [76]. After treatment in $\mathrm{N}_{2}$, on the other hand, the highly reactive, highly energetic "dangling carbon" sites appear to be dominant. Adsorption of $\mathrm{O}_{2}$ on these structures is illustrated schematically in Figure 29. The high-energy sites in $\mathrm{N}_{2}$-treated samples (Figure 29a) can be titrated either at 25 or $150{ }^{\circ} \mathrm{C}$, but the lower-energy sites (e.g., those that are predominant in $\mathrm{H}_{2}$-treated samples) are only accessible at higher adsorption temperatures (Figure 29b). This is true for both as-received and acid-washed Nc and also BPL carbons. Clearly, the characteristics of activated adsorption, in terms of quantity and heat, are very similar on both $\mathrm{H}_{2}$ - and $\mathrm{N}_{2}$-treated samples (Figures 9, 10, 13, 14). This indicates that both surfaces have the same type of lower-energy sites. The difference between them is simply the lack of high-energy sites on the $\mathrm{H}_{2}$-treated surface.

One exception in the behavior of as-received vs acid-washed Nc is revealing, however, it may have important practical implications: the acid-washed N950 sample is the least sensitive to an increase in the adsorption temperature (Figure 10). This finding is thought to be evidence for the selective poisoning of the high-energy sites by acid washing. Upon treatment with $\mathrm{HCl}$, strong $\mathrm{C}-\mathrm{Cl}$ bonds are formed on a portion of the carbon surface and they are left intact by $\mathrm{N}_{2}$ treatment at $950^{\circ} \mathrm{C}[28]$. In contrast, $\mathrm{H}_{2}$ treatment of acid-washed carbon at $950^{\circ} \mathrm{C}$ restores 
the oxygen chemisorption capacity of this portion of the carbon surface, albeit by creating sites of lower activity.

Further insight and correlating evidence about the nature of carbon active sites of $\mathrm{H}_{\mathbf{z}}$ vs $\mathrm{N}_{2}$-treated carbons is provided by analyzing the TPD results. In a detailed study of $\mathrm{O}_{2}$ activated microporous chars derive from a phenol-formaldehyde resin, Zhuang et al.[80-82] observes two characteristic patterns of $\mathrm{CO}, \mathrm{CO}_{2}$ evolution. In one case the leading edge of the dominant $\mathrm{CO}_{2}$ peak, centered at $\sim 630^{\circ} \mathrm{C}$, occurs at temperature below the onset of significant $\mathrm{CO}$ evolution. In the other case, the dominant $\mathrm{CO}_{2}$ peak is centered at a somewhat higher temperature but the key point is that it is completely under the $\mathrm{CO}$ evolution peak, similar to the TPD patterns observed by Calo and Hall [73]. Interestingly, they do not discuss these differences, even though Calo and Hall attribute $\mathrm{CO}_{2}$ evolution in the latter case simply to secondary reactions between $\mathrm{CO}$ and surface oxygen. Instead, Zhuang et al.[80] interpreted their $\mathrm{CO}_{2}$ peaks as evidence for the presence of acid anhydride and lactone groups on the carbon surface. A less prominent low-temperature $\mathrm{CO}_{2}$ peak, centered at $\sim 260^{\circ} \mathrm{C}$, was attributed to the conversion of lactone and acid anhydride groups to carboxyl groups in the presence of moisture.

On the basis of these considerations, our results are thought to indicate, at least in part, the presence of $\mathrm{CO}$ - (e.g., carbonyls) and $\mathrm{CO}_{2}$-yielding $\mathrm{C}-\mathrm{O}$ surface groups (e.g., lactones). This is supported by the fact that both TPD and microcalorimetry data show the existence of low-energy sites on both the as-received Nc carbon (Figure 22) and the N950 carbons after 
$\mathrm{O}_{2}$ adsorption at $150^{\circ} \mathrm{C}$ (Figures 25 and 26). In agreement with much of the detailed literature on this topic, the $\mathrm{CO}_{2}$-yielding sites are seen to be less active than the $\mathrm{CO}$-yielding sites.

Finally, it is important to note that the proposed model is also consistent with the measured properties of all $\mathrm{H}_{2}$-treated samples. As the temperature of $\mathrm{H}_{2}$ treatment increases, the quantity of adsorbed oxygen decreases (Figures 7 and 8); the initial heat of adsorption also decreases (Figure 7). This is in agreement with well-known linear free energy correlations: as the temperature of hydrogen treatment is lowered, more and more of the active sites of progressively higher energy (e.g., types I ) "survive". Indeed, the weight loss-which is taken to correlate with the extent of hydrogasification-increases as the treatment temperature increases. The model is also consistent with the chemical analyses (Table 4) which do not show an increase in $\mathrm{H} / \mathrm{C}$ ratio following hydrogen treatment at increasing temperatures. A temptingly simple alternative model, according to which hydrogen atoms "passivate" all the surface sites by forming $\mathrm{C}-\mathrm{H}$ bonds, can thus be discarded. At intermediate temperatures (which will depend on carbon reactivity), a trade-off appears to exists. On one hand, the relatively high $\mathrm{H} / \mathrm{C}$ ratios (e.g., 0.203 for sample H650) suggest that many reactive sites have indeed been passivated (by C-H bond formation). On the other hand, the weight loss, PZC, and microcalorimetry data show that many reactive sites remain on the surface (e.g., from the decomposition of relatively unstable carboxyl groups) which are not hydrogasified and thus susceptible to $\mathrm{O}_{2}$ readsorption.

\subsection{NO Selective Adsorption}


The fact that some active sites remain oxygen-free at room temperature could have important practical applications. For example, other compounds with a lower activation energy than $\mathrm{O}_{2}$ could be selectively adsorbed, in the presence of $\mathrm{O}_{2}$, by these sites. Indeed, our results show the amount of NO strongly adsorbed (heat of adsorption $>20 \mathrm{kcal}$ ) at $25^{\circ} \mathrm{C}$ by a $\mathrm{H}_{2}-$ treated sample is almost 20 times greater than the amount of $\mathrm{O}_{2}$ strongly adsorbed. the total amount of $\mathrm{NO}$ adsorbed is more than 10 times more than the adsorbed $\mathrm{O}_{2}$ (Figure 15a). Actually, in the work of Zarifyanz et al.[83], room temperature irreversible adsorption of NO was also shown to occur on a freshly cleaved graphite surface to a much larger extent than adsorption of $\mathrm{O}_{2}$. Furthermore, it was also shown that the sample with preadsorbed NO did not adsorb any $\mathrm{O}_{2}$. These findings are consistent with the notion that NO not only occupies the active sites attacked by $\mathrm{O}_{2}$ at room temperature but also adsorbs on (at least some of) the sites that are not occupied by $\mathrm{O}_{2}$ at room temperature.

\subsection{Carbon Basicity}

The presence of oxygen on the carbon surface is known to have a profound influence on the behavior of this material as an acid or a base [30]. This in turn is crucial for the effectiveness of carbons as catalyst supports [3] or liquid-phase adsorptions [18]. Recently, it has been confirmed [14] that the alkaline character of solid carbons is dependent not only on the absence of oxygen-containing surface groups but also, perhaps more importantly, on the Lewis base character of the graphene layers in the carbon crystallites. It was of interest, therefore, to analyze the relative roles of those two factors by varying the heat treatment 
temperature (HTT) in both $\mathrm{N}_{2}$ and $\mathrm{H}_{2}$ over a wide range. Table 6 confirms the fact that carbons treated in $\mathrm{H}_{2}$, at temperatures below $1000^{\circ} \mathrm{C}$, are much more basic than those treated in an inert atmosphere.

Tables 3 and 4 show that, as the HTT increases, the concentration of (primarily acidic) oxygen functional groups decreases dramatically while the average size of the graphene layers increases to some extent. While no significant structural differences were observed at the same HTT between $\mathrm{N}_{2^{-}}$and $\mathrm{H}_{2}$ - treated samples (Table 3), the extent of growth of graphene layers $\left(\mathrm{L}_{\mathrm{a}} / \mathrm{L}_{\mathrm{c}}\right)$ is consistently higher for the $\mathrm{H}_{2}$-treated samples. This finding correlates in general with the somewhat lower $\mathrm{O} / \mathrm{C}$ ratios and $\mathrm{PZC}$ values of the latter samples (Tables 4 and 6).

A surprising and very significant result is the lower PZC value for samples subjected to $2600^{\circ} \mathrm{C}$ than for those subjected to $1800^{\circ} \mathrm{C}$. A similar maximum in the carbon suspension $\mathrm{pH}$ as a function of HTT was reported recently by Ishihara et al.[84], who offered no explanation for it. We propose that the following phenomena are responsible for this maximum in carbon basicity at intermediate HTT: (a) At relatively low temperatures, the removal of acidic oxygen functional groups leads to the increasing dominance of the residual basic sites, both the more stable oxygen-containing groups (e.g., pyrone-like structures) and the oxygen -free edge sites (e.g., Type II, see Figure 27) as well as basal-plane carbon sites. (b) At relatively high temperatures (e.g., in excess of $1800^{\circ} \mathrm{C}$ ), where the effect of oxygen-containing basic groups becomes negligible, the observed basicity is a result of "competition" between Lewis-basetype edge sites and Lewis-base basal plane sites. The concentration of the former is known to 
decrease with increasing HTT (Table 3). Obviously, then, this appears to have the dominant effect on carbon basicity.

\subsection{Carbon Hydrophobicity}

This investigation demonstrates that calorimetry can provide clarification of the present understanding of the nature of water adsorption on carbon. Most important, it shows that a calorimeter can be employed to discover the dominant mechanism of water adsorption, as a function of carbon surface chemistry, saturation pressure, temperature, etc. Specifically, the present data suggest there are three modes of water adsorption on carbon, and each can account for a significant amount of adsorption. Moreover, the extent of these types of adsorption observed on any particular carbon surface is clearly a function of the surface chemistry. First, there is chemical adsorption (heats greater than $50 \mathrm{~kJ} / \mathrm{mol} \mathrm{H}_{2} \mathrm{O}$ ), which can occur between unsaturated carbon surface sites and water. Second, water "condenses" at primary adsorption sites (PAS) with heats around $45 \mathrm{~kJ} / \mathrm{mol} \mathrm{H}_{2} \mathrm{O}$. Both of acid oxygen containing groups and the chemsorbed water molecules can be the PAS. As generally agreed, in this step, the hydrogen bonding between the water and PAS, or between water and water play an important role [85]. The steep rise of the isotherm is a function of the number and character of PAS sites, as well as the pore structure. Third, there is physical adsorption with heats around $25 \mathrm{~kJ} / \mathrm{mol} \mathrm{H}_{2} \mathrm{O}$, in which only weak dispersion interaction occur between water and hydrophobic carbon basal planes. The present set of data from $\mathrm{Nc}$ carbons provides evidence 
to support the existence of all three types of adsorption. The particular "mix" and extent of each type is shown to be a function of surface pretreatment.

N950. It is particularly instructive to begin with a discussion of water adsorption on the nitrogen treated Norit carbon N950, as adsorption on this sample appears to occur via all three modes. Initial adsorption heats on this sample $\left(\mathrm{p} / \mathrm{p}_{0}<0.4\right.$, or coverage $<1 \mathrm{mmol} \mathrm{H}_{2} \mathrm{O} / \mathrm{g}$ carbon) are high, and clearly consistent with chemical adsorption. It was anticipated that chemical adsorption would occur on this sample, as previous work established that the treatment given leaves a high concentration of highly unsaturated carbon atoms ("dangling carbons") on the surface. Indeed, the amount of chemically adsorbed water observed in this case is similar to the amount of oxygen which strongly adsorbs on equivalent samples.

Next, there is a plateau in the measured heat of adsorption at about $45 \mathrm{~kJ} / \mathrm{mol} \mathrm{H}_{2} \mathrm{O}$. This value is virtually identical to that anticipated for heat from condensation around PAS. Thus, following the lead of earlier workers [86], we assign adsorption which occurs at this heat to condensation. In fact, there is a relatively limited amount of condensation that takes place $(0.4$ $<\mathrm{p} / \mathrm{p}_{0}<0.7$, or for coverage between 1 and $2 \mathrm{mmol} / \mathrm{g}$ carbon). As the initial high temperature treatment removes all oxygen functional groups, it is reasonable to suggest that it is actually adsorbed water molecules which in this case are acting as PAS for condensation. This is not a new concept. Chemically adsorbed water has been proposed to act as PAS by others as well [87]. Still, it is apparent that only a small fraction of the chemically adsorbed water molecules are acting as PAS. Indeed, the ratio of chemically adsorbed to condensed water on this sample 
is only about one. In fact, it is generally understood that some acid sites are "better" PAS than others $[88,89]$.

At high relative pressures ( $\mathrm{p} / \mathrm{p}_{0}>0.7$, or coverage $>2 \mathrm{mmol} / \mathrm{gm}$ carbon) the heat of adsorption clearly is less than that associated with condensation. Low heats of this character are generally associated with simple physical adsorption. In fact, previous groups computing the heats of water interaction with various surface groups indicate that the heats could be less than that of condensation $[87,90]$. (The relatively high heat of water condensation reflects the formation of hydrogen bonds.) Thus, we postulate that the low heat processes are a form of physical adsorption.

The clear distinction in the heats of adsorption between "condensation" and "physical adsorption" suggests a distinction in the character of the two processes. It is understood that condensation involves the formation of a three dimensional liquid water phase, nucleated by a primary adsorption site, in the pores with the heat of condensation reflecting primarily hydrogen bonding between water molecules. In contrast, physical adsorption is assumed to be a monolayer structure, thus adsorption energy is determined by weak carbon-water interactions, not water-water hydrogen bonds. The notion that condensation/multilayer adsorption can only take place around special sites (PAS) is generally accepted. In fact, in recent models it has been shown that certain arrangements of PAS can significantly reduce the critical size of a stable water droplet. In particular it was shown that the critical size for near neighbor oxygen functional groups is far less than that around single acid sites [91]. Moreover, in the absence of PAS, critical radii are large, and stable droplets are not expected to form below saturation 
pressure. The fact that a significant amount of monolayer water adsorption can take place at low heats does not appear to be generally understood.

One question which naturally arises is the capacity of the Norit $\mathrm{C}$ for a monolayer of physically adsorbed water. A calculation based on the measured BET area of the material and the assumption that each molecule requires $25 \AA$ of surface area [92] indicates that the total monlayer capacity of Norit $\mathrm{C}$ is more than $10 \mathrm{mmol} \mathrm{H}_{2} \mathrm{O} / \mathrm{g}$ carbon. This is clearly more than the amount observed.

In the absence of direct heat measurments, that is with only isotherm data, all of the adsorption taking place above $\mathrm{p} / \mathrm{p}_{0}=0.4$ might mistakenly be associated with condensation. This may have been done in previous investigations. It is also true that in the existing literature the difference between condensation and physical adsorption is generally not clearly expressed.

Untreated Nc. There are two significant distinctions to be made between N950 and untreated Norit C. First, very little chemisorption occurs on the latter, and second significantly more condensation takes place. There are also similarities. Most important is the fact that physical adsorption dominates in both cases for $\mathrm{p} / \mathrm{p}_{0}>0.7$.

The calorimetry data also suggests a basis for the "crossover" of the the isotherms of the Norit treated in nitrogen and the untreated material. At low $\mathrm{p} / \mathrm{p}_{0}$ more water is found on the N950 sample because chemical adsorption takes place on it, whereas on the untreated sample, there is almost no active site capable of water chemisorption. On this surface, water can only adsorb on PAS (unremoved oxygen) through hydrogen bonds. From about $\mathrm{p} / \mathrm{p}_{0}>0.4$ to $\mathrm{p} / \mathrm{p}_{0}$ 
$<0.6$ condensation occurs on both materials. As there are more PAS sites on the untreated sample, more condensation occurs on this surface than on the N950 sample. Thus, the total amount of water on the untreated sample surpasses that on N950 sample over this range of partial pressures. At higher $\mathrm{p} / \mathrm{p}_{0}$ values physical adsorption dominates on both samples.

It is assumed here, as elsewhere [93, 1], that the amount of water which will condense is a function of the density of PAS. Complete pore filling is not observed until a minimum PAS density exists. Here we advance a new explanation for this frequent observation. Specifically, it is suggested that complete pore filling will take place in any pore, or pore network, containing a true PAS. Yet, it is clear that for carbons not all pores are connected. Thus, assuming a random distribution of PAS in pores, not all pores and pore networks will contain PAS until a certain apparent "density" of PAS exist. Earlier models implied that PAS needed to have a certain proximity for complete pore filling to occur. This implies that droplets around any PAS have a maximum size. We do not believe this is physically reasonable.

H950. The $\mathrm{H}_{2}$-treated sample $\mathrm{N} 950$ was found extremely hydrophobic. Initially there is a very small amount of chemical adsorption, and this is followed by very, very small amount of physical adsorption. This result was anticipated as several prior studies [94] have shown that high temperature $\mathrm{H}_{2}$-treated graphites and activated carbons are hydrophobic. and also consistent with our earlier studies of the surface chemistry following hydrogen treatment. Indeed, in earlier studies it was found that the $\mathrm{H}_{2}$-treated surface was quite basic and had no active sites capable of adsorbing oxygen at low temperatures. Moreover, it was argued that on $\mathrm{H}_{2}$-treated 
surfaces there are two types of basicity: localized less active sites and the basal planes themselves. Thus, not only is no chemisorption of the variety measured on the N950 anticipated, but also it is reasonable to expect that the basal plane basicity will even reduce the extent of condensation in the pores.

Oxygen exposed N950 and H950. The first indication of differences in behavior as a function of $\mathrm{O}_{2}$ exposure induced modifications in surface chemistry can be seen in the heat of adsorption at low coverages. Water adsorption on the freshly prepared (no $\mathrm{O}_{2}$ exposure) $\mathrm{N}_{2}$ treated carbon N950 led to a great deal of strong chemical adsorption of water, whereas, far less water strongly adsorbed on the $\mathrm{O}_{2}$-exposed $\mathrm{N} 950$. This is anticipated as the freshly treated surface has no oxygen groups, while it has a significant amount of unsaturated ("dangling carbons") edge sites. The initial water reactions are thus anticipated to be chemical adsorptions at these active sites. In contrast, $\mathrm{O}_{2}$ exposure should result in most of the unsaturated edges becoming saturated with oxygen. Thus, as measured, once in the calorimeter less water will interact in a chemical fashion, and only at weaker unsaturated sites which didn't become oxygen saturated during $\mathrm{O}_{2}$ exposure at room temperature.

There is also a lower threshold for rapid condensation on the $\mathrm{O}_{2}$ exposed sample. The threshold is related to the density of primary adsorption sites. This is expected to be initially higher on the $\mathrm{O}_{2}$-exposed sample, because the surface of this sample contains oxygen groups. In contrast, water introduced to the fresh sample is divided between two duties; chemically adsorbing thus forming primary adsorption sites, and condensing on them. The net effect, is that 
at any pressure there are probably fewer PAS on the fresh sample. Another major difference, one with potential practical consequences, is that ultimately far more water adsorbs on the $\mathrm{O}_{2}$ exposed sample. Possibly the acid groups formed from adsorbed oxygen make stronger primary adsorption sites.

The impact of surface chemistry is also evident in the contrast between adsorption on $\mathrm{H}_{2^{-}}$and $\mathrm{N}_{2^{-}}$prepared Norit C. Freshly prepared $\mathrm{H}_{2}$-treated material adsorbs virtually no water. After "mild oxidation" at $150^{\circ} \mathrm{C}$, a sample adsorbs significant more water; although, there is still no "threshold" for rapid condensation. Again, these observations are consistent with the model and expected surface chemistry of this carbon. $\mathrm{H}_{2}$-treated Norit $\mathrm{C}$ is known to have virtually no oxygen groups. Also, the unsaturated edge sites are known to be "inert" at low temperatures, but are capable of adsorbing oxygen at elevated temperature as shown by prior calorimetric studies. On high temperature $\mathrm{N}_{2}$-treated Norit $\mathrm{C}$, highly unsaturated ("dangling carbons") edge sites, which adsorb oxygen rapidly at low temperature, are formed. These studies show that the edge sites on Norit $\mathrm{C}$ following $\mathrm{H}_{2}$ treatments are far less unsaturated, and hence oxygen adsorption on these surfaces requires activation. Thus, high temperature oxygen treatment is required to create acid-oxygen groups on $\mathrm{H}_{2}$-treated Norit $\mathrm{C}$. Such sites are needed to act as PAS for water adsorption at $300 \mathrm{~K}$. However these sites on H950 are much less than that on N950.

\subsection{Low-Temperature Generation of Basic Carbon Surfaces by Hydrogen Spillover}


Perhaps the most significant result of the present work is the empirical finding that stable basic carbons can be produced at far lower temperatures in the presence of platinum than in its absence. The PZC studies demonstrated that the basicity of the Nc carbon treated in a mixture with platinum-containing carbon $(\mathrm{PtC})$ is always higher than that of the $\mathrm{Nc}$ carbon treated at same temperature in the absence of noble metal. In fact, the PZC values of the Nc carbon treated in the mixtures were found to be equivalent to that of the Nc carbon treated at temperatures at least $400^{\circ} \mathrm{C}$ higher in the absence of platinum. Also, microcalorimetric and longterm PZC studies showed that Nc carbon gains stability against readsorption of oxygen at far lower temperatures when some platinum is present in the mixture.

Other findings are consistent with the suggestion that platinum (or another noble metal) is a key ingredient required to lower the temperature at which stable basic carbons are formed. First, PtC carbon, a high-surface-area carbon material containing platinum particles dispersed on its surface, becomes basic and stable after hydrogen treatments at remarkably low temperatures. Second, even the Nc carbon that is not in intimate contact with platinumcontaining carbon becomes basic at lower temperatures than Nc Carbon Treated neat.

Earlier work suggests an explanation for the action of the platinum [95-97]. It is postulated that platinum particles dissociate hydrogen molecules, creating hydrogen atoms that "spill over" to the carbon surface, both via surface and gas phase diffusion [98], hydrogasifying the most reactive surface carbon atoms (Figure 30). That is, the hydrogen atoms remove carbon atoms (probably as methane) that are left in a highly unsaturated state [76] due to the thermal removal of neighboring carbon atoms, as $\mathrm{CO}_{2}$ or $\mathrm{CO}$. The following two-step process is thus 
hypothesized to take place during the hydrogen treatment of $\mathrm{Nc}$ carbon mixed with $\mathrm{PtC}$ at $500^{\circ} \mathrm{C}$. First, the $\mathrm{Nc}$ carbon loses most of its oxygen as $\mathrm{CO}_{2}$ (and some $\mathrm{CO}$ ) owing to thermal decomposition of the surface oxygen groups (a process possibly accelerated in the presence of hydrogen atoms). Subsequently, hydrogen atoms generated by the platinum "hydrogasify" the highly unsaturated carbon atoms that are left behind by this thermal process.

The above model suggests that the difference between Nc treated neat in hydrogen at $500^{\circ} \mathrm{C}$ and $\mathrm{Nc}$ treated in the presence of platinum at the same temperature is solely the number of residual highly reactive carbon atoms on the surface. The same Nc treated in $\mathrm{H}$ in the presence of platinum will have very few such sites, while Nc treated without platinum present will have a significant number of highly unsaturated carbon atoms. These sites in the sample treated neat quickly adsorb oxygen upon air exposure at room temperature, returning the surface to an acidic condition. In contrast, on Nc treated with platinum present all unsaturated carbon atoms that remain are capable of adsorbing oxygen only at elevated temperatures. Indeed, it has long been known that on some carbon active sites oxygen will not adsorb at temperatures of less than $300^{\circ} \mathrm{C}[74]$.

There are other possible hypotheses that might explain the role of $\mathrm{H}$ atoms in stabilizing the surface. Indeed, it has been shown previously that high temperature $\mathrm{H}_{2}$ treatment (e.g., H950) accomplishes three tasks: (i) it removes surface oxygen; (ii) it stabilizes some of the reactive carbon sites by forming stable $\mathrm{C}-\mathrm{H}$ bonds; (iii) it hydrogasifies the most reactive carbon atoms. Data in Table 4 and Figure 12 and 5 indicate that the third process is the most significant when hydrotreating in the presence of platinum, as postulated. First, sample H500/PtC exhibits 
initial heats of $\mathrm{O}_{2}$ adsorption that are comparable to those of sample $\mathrm{H} 950$ and lower than those of sample H500 (Figure 12a), suggesting that oxygen adsorbs on sites similar to those found on the former. There is no evidence of adsorption on highly reactive sites. Second, the extent of room temperature $\mathrm{O}_{2}$ adsorption of sample $\mathrm{H} 500 / \mathrm{PtC}$ is much lower than that of samples H500 and N500 (Figures 12b and 8). Third, the weight loss during treatment of sample $\mathrm{H} 500 / \mathrm{PtC}$ is higher than that of samples N500 and H500 and consistent with gasification. All these observations are consistent with the postulate that at $500^{\circ} \mathrm{C} \mathrm{H}$ atoms generated by spillover are effective at removing highly reactive carbon atoms. It is concluded that experimental evidence supports the postulate that low-temperature stabilization in the presence of platinum occurs primarily by the hydrogasification of the most reactive carbon atoms (“dangling carbons").

It remains unclear, however, whether a secondary action of hydrogen atoms is to increase the rate of decomposition of oxygen-containing surface groups. The results are not conclusive. As noted above, sample $\mathrm{H} 500 / \mathrm{PtC}$ has a basicity and stability very similar to that of H950, yet its oxygen content is significant. This result does not support an acceleration of oxygen removal by hydrogen atoms. In contrast, the oxygen content of $\mathrm{H} 500 / \mathrm{PtC}$ is significantly lower (by a factor of 3) than that of H500. This latter observation could be interpreted as evidence that hydrogen atoms enhance surface oxygen removal. Nevertheless, it is possible that the difference in oxygen content between $\mathrm{H} 500$ and $\mathrm{H} 500 / \mathrm{PtC}$ can be traced to the fact that only the former sample had a significant number of highly reactive carbon atoms following treatment and that subsequent air exposure resulted in higher oxygen uptake prior to elemental 
analysis. This interpretation is certainly supported by the calorimetric results, which show that H500 adsorbs significant amounts of oxygen whereas H500/PtC does not. 
(A)

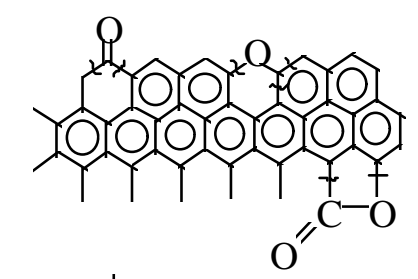

(E)

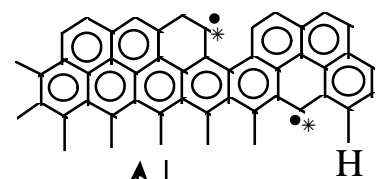

$\downarrow \Delta, \mathrm{N}_{2}$

(B)

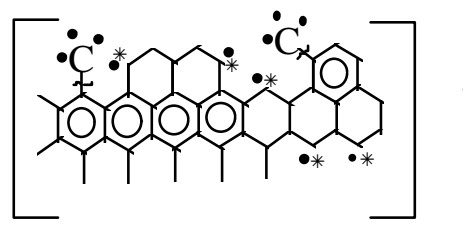

$+2 \mathrm{CO}$

$+\mathrm{CO}_{2}$<smiles>c1ccccc1</smiles>

. $H_{2}$
(C)

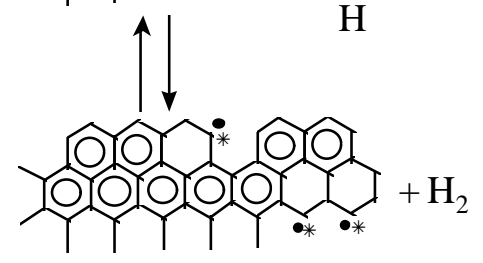

(D)

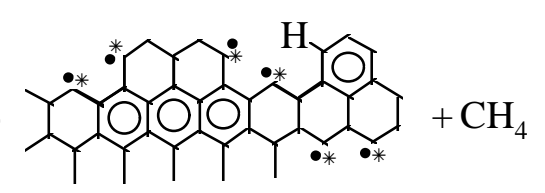

(F)

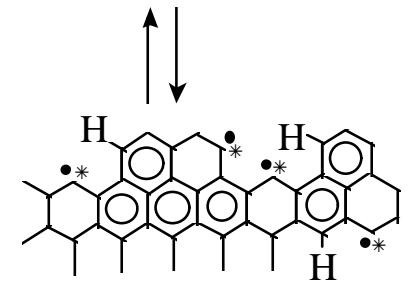

Figure 27. Proposed model for the stabilization of carbon surfaces upon heat treatment $(\Delta)$ in $\mathrm{N}_{2}$ (inert gas) and $\mathrm{H}_{2}$. For simplicity and illustrative purposes, only two types of oxygen surface groups (pyrone and lactone) and two types of carbon active sites are shown. These two types are in the order of increasing stability: (i) type I, "dangling carbon" sites (with only one nearest neighbor basal plane carbon); (ii) type II, divalent in-plane $\sigma$ pairs, Ar- $0 *$ (where $*$ represents a localized $\pi$ electron). Structures B is formed in $\mathrm{N}_{2}$, while structures $\mathrm{C}, \mathrm{D}, \mathrm{E}$ and $\mathrm{F}$ are formed in $\mathrm{H}_{2}$. 


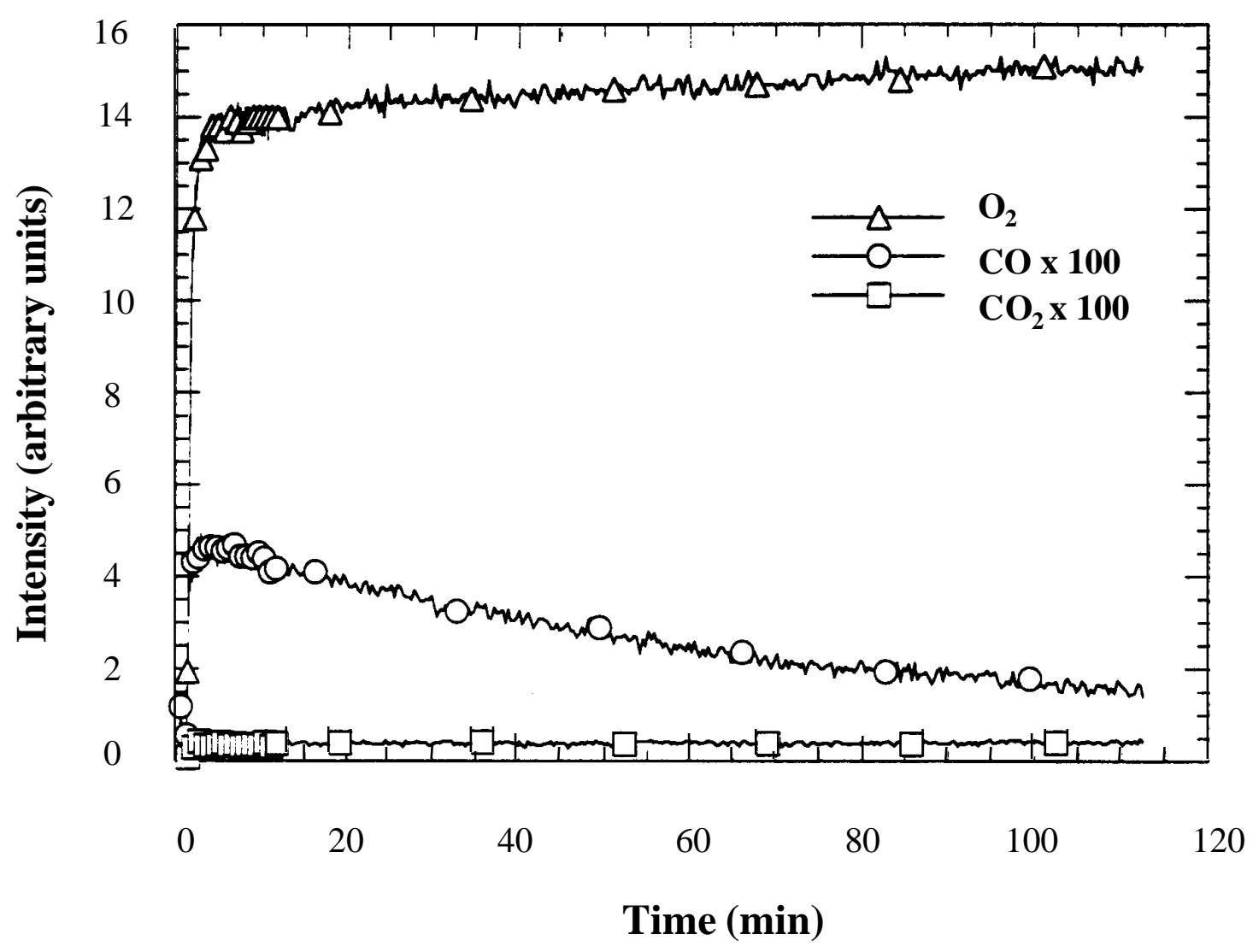

Figure 28. Mass spectrometric analysis of gases evolved upon in situ exposure of sample $\mathrm{N} 950$ to $\mathrm{O}_{2}$ at room temperature $\left(5 \% \mathrm{O}_{2}\right.$ in $\mathrm{He}$ at $\left.1 \mathrm{~atm}\right)$. 
(a)
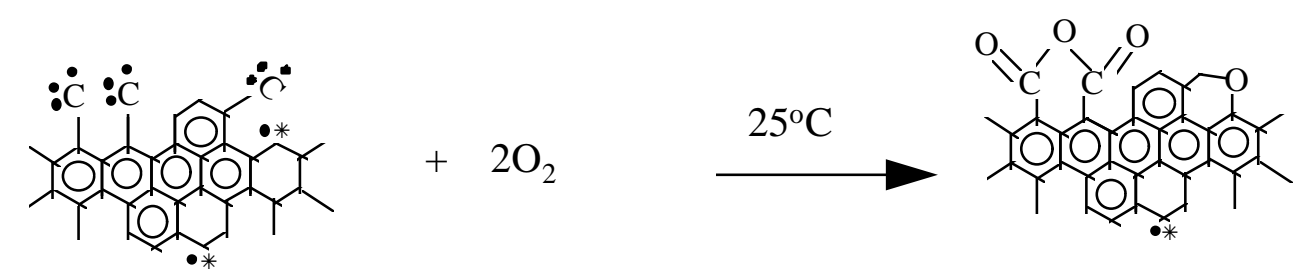

(b)
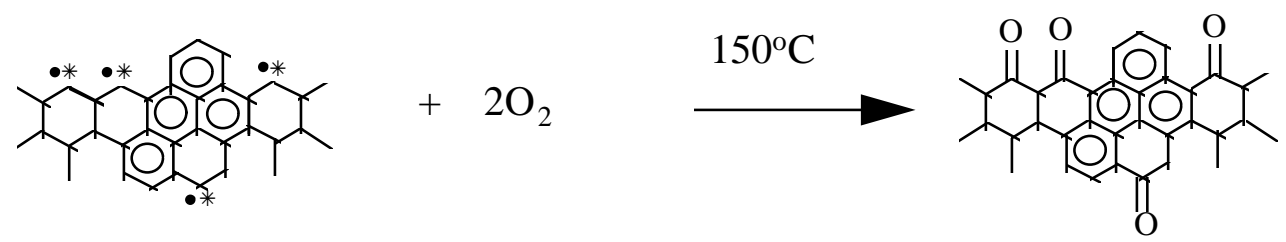

Figure 29. Proposed model for the adsorption of $\mathrm{O}_{2}$ at carbon active sites of different nature and stability: (a) low-temperature adsorption on highly energetic sites of type I ("dangling carbon"); (b) high-temperature adsorption on less energetic sites of type II (divalent in-plane $\sigma$ pairs). 


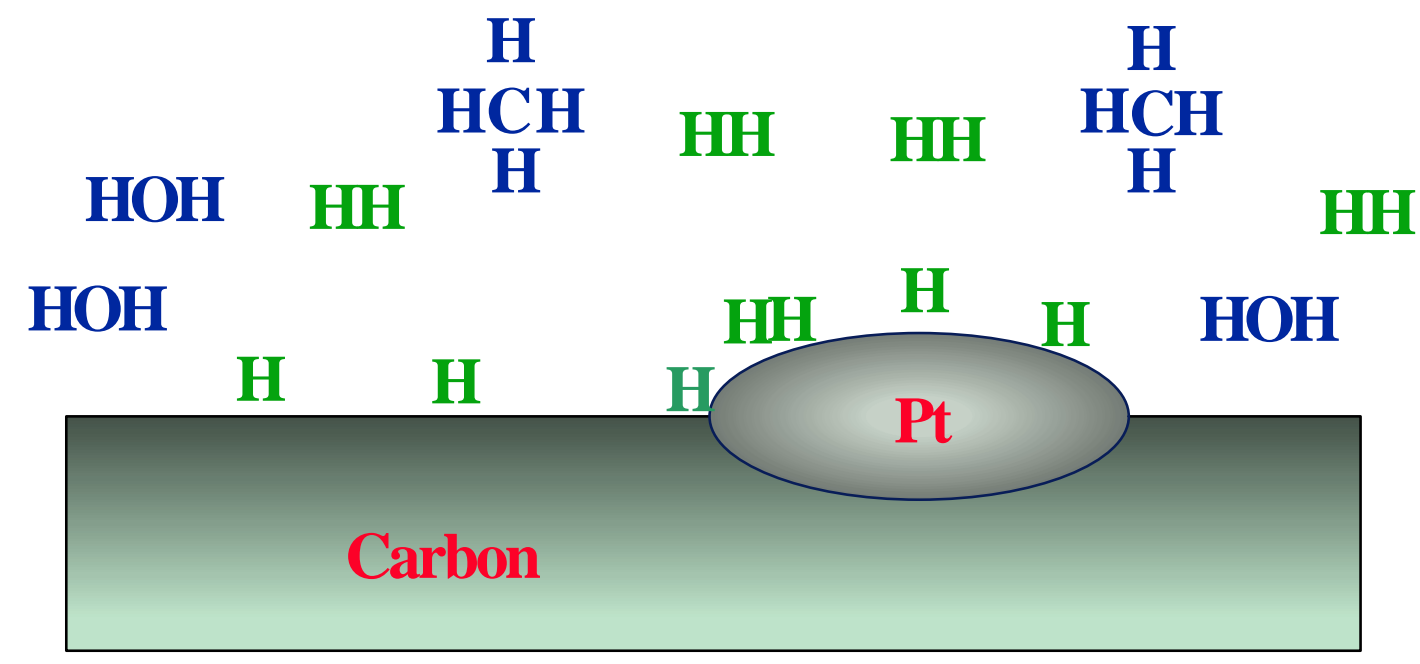

Figure 30. The graphical representation of hydrogen spill over model. 


\section{Chapter 5}

\section{CONCLUSIONS}

The influence of two treatment parameters, temperature and gas identity, on the surface chemistry of activated carbons was clarified with the help of a wide variety of analytical techniques. It is shown that both the nature and the number of active surface sites can be manipulated by adjusting these two parameters.

Below $1000^{\circ} \mathrm{C}$, gas identity was found to be crucial. Treatment in $\mathrm{N}_{2}$ at $950^{\circ} \mathrm{C}$ removes the oxygen functional groups, leaving the surface with at least two types of sites: (a) highly energetic "dangling carbon" sites, capable of adsorbing oxygen, and then $\mathrm{H}_{2} \mathrm{O}$ at room temperature and (b) graphene layer edge sites which only adsorb oxygen at elevated temperatures. Treatment in $\mathrm{H}_{2}$ at $950^{\circ} \mathrm{C}$ not only removes oxygen, but also remove "dangling carbons", leaving a stable basic surface nearly free of very active sites and thus uncapable of adsorbing $\mathrm{O}_{2}$ and $\mathrm{H}_{2} \mathrm{O}$ at ambient temperature.

The removal of oxygen in the form of $\mathrm{CO}$ and $\mathrm{CO}_{2}$ during high-temperature $\mathrm{N}_{2}$ treatment leaves unsaturated carbon atoms at crystallite edges; these sites are very active for subsequent oxygen adsorption. In contrast, high-temperature $\mathrm{H}_{\underline{z}}$ treatment accomplishes three tasks: (a) it also removes surface oxygen; (b) it stabilizes some of the (re)active sites by forming stable $\mathrm{C}-\mathrm{H}$ bonds; (c) it gasifies the most reactive unsaturated carbon atoms. The relative contributions of these three effects depend on the temperature of $\mathrm{H}_{2}$ treatment. 
Treatment at higher temperatures $\left(>1500^{\circ} \mathrm{C}\right)$ produced stable surfaces in either $\mathrm{N}_{2}$ or $\mathrm{H}_{2}$. Structural annealing takes place at these temperatures and the consequent growth in the size of graphene layers eliminates the highly energetic sites. Both PZC and XRD measurements indicate that this growth is only slightly more favorable in $\mathrm{H}_{2}$ than in $\mathrm{N}_{2}$. Curiously, however, the basicity of the surface goes through a maximum with increasing heat-treatment temperature. This finding suggests that, of the two types of Lewis base sites, the localized electron pairs at the edges of the graphene layers are more important than the delocalized $\pi$ electrons on the basal planes.

In the presence of platinum (and most likely other noble metals), capable of creating and spilling over hydrogen atoms, stable and highly basic surfaces can be produced at temperatures of $500^{\circ} \mathrm{C}$ or less.

In sum, an oxygen free, highly basic, hydrophobic and stable surface of activated carbon can be created at $950^{\circ} \mathrm{C}$ in $\mathrm{H}_{2}$, or at relatively low temperature treatment of carbon mixed with a noble metal. These carbons hold potential commercial value, not only because they can be shipped and stored without any concern for loss of properties ('aging effect'), but also because they have unique and tailorable adsorption properties, such as selective adsorption of NO in the presence of $\mathrm{O}_{2}$, or enhanced capacity for phenol adsorption from solution. Furthermore, they may contain an unusual energetic distribution of active sites, which may have new chemical and catalytic applications. 


\section{REFERENCES}

1. R. C. Bansal, J. B. Donnet and F. Stoeckli, Active Carbon, Marcel Dekker: New York (1988).

2. R. W. Coughlin, Ind. Eng. Chem, $\underline{8}, 12$ (1969).

3. L. R. Radovic and F. Rodriguez-Reinoso, in " Chemistry and Physics of Carbon",

P. A. Thrower, ed., Marcel Dekker: New York, 25, 243 (1996).

4. E. C. Akubuiro and N. J. Wagner, Ind. Eng. Chem. Res. $\underline{31}, 339$ (1992).

5. A. Derylo-Marczewska and M. Jaroniec, Surf. Colloid Sci., 14, 301 (1987).

6. S. D. Faust and O. M. Aly, Adsorption Processes for Water Treatment, Butterworths: Boston, MA (1987).

7. R. M. Taylor and R. W. Kuennen, Environ. Prog., $\underline{13}$, 65 (1994).

8. V. L. Snoeyink and W. J. Weber, Environ. Sci. Technol., 1 , 228 (1967).

9. S. S. Barton and B. H. Harrison, Carbon, 13, 283 (1975).

10. S. S. Barton, D. J. Gillespie, B. H. Harrison and W. Kemp, Carbon, 16, 363 (1978).

11. H. P. Boehm, Advances in Catalysis, Academic Press: New York, 16, 179 (1966).

12. M. Voll and H. P. Boehm, Carbon, $\underline{9}, 481$ (1971).

13. F. Rodriguez-Reinoso, M. Molina-Sabio and M. A. Muñecas, J. Phys. Chem., $\underline{96}$, 2707 (1992).

14. C. A. Leon y Leon, J. M. Solar, V. Calemma and L. R. Radovic, Carbon, $\underline{30}, 797$ (1992).

15. E. Papirer, S. Li and J. B. Donnet, Carbon, 25, 243 (1987). 
16. H. P. Boehm and M. Voll, Carbon, $\underline{8}, 227$ (1970).

17. C. Moreno-Castilla, J. Rivera-Utrilla, M. V. López-Ramón and F. Carrasco-Marí n, Carbon, $\underline{33}, 845$ (1995).

18. L. R. Radovic, J. I. Ume and A. W. Scaroni, in "Fundamentals of Adsorption", M.

D. Levan, ed., Kluwer: Boston, MA, p. 749 (1996).

19. H. Tamon and M. Okazaki, in "Fundamentals of Adsorption”, M. Suzuki, ed., Kodansha: Tokyo, p. 663 (1993).

20. P. Davini, Fuel, $\underline{68}, 145$ (1989).

21. P. Davini, Carbon, $\underline{28}, 565$ (1990).

22. L. B. Adams, C. R. Hall, R. J. Holmes and R. A. Newton, Carbon, 26, 451 (1988).

23. S. S. Barton, M. J. Evans and J. A. F. MacDonald, in "22nd Biennial Conference on Carbon", San Diego, CA, p. 438 (1995).

24. B. Stö hr, H. P. Boehm and R. Schlögl, Carbon, 29, 707 (1991).

25. R. C. Bansal, F. J. Vastola and P. L. Walker, Jr., Carbon, 12, 355 (1974).

26. S. K. Verma and P. L. Walker, Jr., Carbon, 30, 837 (1992).

27. H. P. Boehm, Carbon, $\underline{32}, 759$ (1994).

28. B.R. Puri, in “Chemistry and Physics of Carbon”, P. L. Jr. Walker, ed., Marcel Dekker: New York, $\underline{6}, 191$ (1970).

29. D. W. McKee and V. J. Mimeault, in "Chemistry and Physics of Carbon", P. L. Walker, Jr. , ed., Marcel Dekker: New York, $\underline{8}, 151$ (1973).

30. C. A. Leon y Leon and L. R. Radovic, in "Chemistry and Physics of Carbon", P. A. Thrower, ed., Marcel Dekker: New York, 24, 213 (1994).

31. J. S. Noh and J. A. Schwarz, Carbon, 28, 675 (1990). 
32. P. Pattabiraman, N. M. Rodriguez, B. Z. Jang and R. T. K. Baker, Carbon, $\underline{28}, 867$ (1990).

33. S. Hagiwara, K. Tsutsumi and H. Takahashi, Carbon, 16, 89 (1978).

34. Y. Xie and P. A. Sherwood, Appl. Spectros., $\underline{43}, 1153$ (1989).

35. K. Kinoshita, Carbon: Electrochemical and Physicochemical Properties, WileyInterscience: New York (1988).

36. G. M. K. Abotsi and A. W. Scaroni, Carbon, $\underline{28}, 79$ (1990).

37. P. Vinke, M. van der Eijk, M. Verbree, A. F. Voskamp and H. van Bekkum, Carbon, $\underline{32,} 675$ (1994).

38. C. R. Hall, and R. J. Holmes, Carbon, $\underline{30}, 173$ (1992).

39. C. R. Hall, and R. J. Holmes, Carbon, $\underline{31}, 881$ (1993).

40. D. W. McKee and C. L. Spiro, Carbon, 23 437 (1985).

41. H. F. Stoeckli and F. Kraehenbuehl, Carbon, $\underline{19}, 353$ (1981).

42. S. Brunauer, P. H. Emmett and E. Teller, J. Am. Chem. Soc., 60, 309 (1938).

43. M. M. Dubinin, Prog. Surf. Membrane Sci., $\underline{9}, 1$ (1975).

44. K. S. W. Sing, Chemistry and Industry, May, p. 829. (1967).

45. T. J. Fabish, M. L. Hair, J. Colloid Interface Sci., 62, 16 (1977).

46. W. V. Kotlensky, in Fourth Conference on Carbon: Pergamon Press: University of Buffalo, Buffalo, NY, P. 423 (1960).

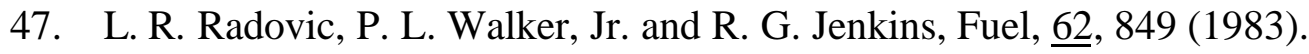

48. J. S. Noh and J. A. Schwarz, J. Colloid Interface Sci., $\underline{130,} 157$ (1989).

49. C. A. Leon y Leon, Ph.D. Thesis, The Pennsylvania State University (1993). 
50. J. M. Calo, D. Cazorla-Amorós, A. Linares-Solano, M. C. Roman-Martínez and C. Salinas-Martínez De Lecea, Carbon, $\underline{35}$, 543 (1997).

51. Y. Otake and R. G. Jenkins, Carbon, $\underline{31}, 109$ (1993).

52. U. Zielke, K. J. HÜttinger and W. P. Hoffman, Carbon, 34, 983 (1996).

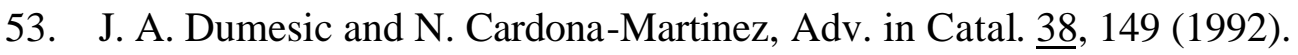

54. R. W. Wunder, and J. Phillips, J. Phys. Chem., 100, 14430 (1996).

55. M. O’Neil and J. Phillips, J. Phys. Chem., 91, 26867 (1987).

56. R. R. Gatte, J. Phillips, Langmuir, 프, 758 (1989).

57. A. S. Gow and J. Phillips, J. Energy Fuels, ㄱ, 674 (1993).

58. M. O’Neil, R. Lovrien and J. Phillips, Rev. Sci. Instrum., 56, 2312 (1985).

59. P. C. Gravelle, Adv. Catal., 22, 191 (1972).

60. A. S. Gow and J. Phillips, Ind. Eng. Chem. Res., $\underline{31}, 193$ (1992).

61. G. M. Jenkins and K. Kawamura, Polymeric Carbons-Carbon Fibre, Glass and Char, Cambridge University Press: Cambridge (1976).

62. R. C. Bansal, F. J. Vastola and P. L. Jr. Walker, J. Colloid Interface Sci., $\underline{32}, 187$ (1970).

63. R. C. Bansal, F. J. Vastola and P. L. Jr. Walker, Carbon, 9, 185 (1971).

64. A. G. W. Bradbury and F. Shafizadeh, Carbon, 18, 109 (1980).

65. A. Cheng and P. Harriott, Carbon, 24, 143 (1986).

66. I. M. K. Ismail and P. L. Walker, Jr., Carbon, 27, 549 (1989).

67. J. Lahaye, P. Soulard, J. Dentzer and P. Ehrburger, J. Chim. Phys., 90, 139 (1993).

68. P. H. Emmett and E. J. Brunauer, J. Am. Chem. Soc., 59, 310 (1937). 
69. H. F. Liu, R. S. Liu, K. Y. Liew, R. E. Johnson and J. H. Lunsford, J. Am. Chem. Soc., $\underline{106}, 4117$ (1984).

70. T. Kyotani, Z. G. Zhang, S. Hayashi and A. Tomita, Energy Fuels, 2, 136 (1988).

71. A. A. Lizzio, H. Jiang and L. R. Radovic, Carbon, 28, 7 (1990).

72. L. R. Radovic, A. A. Lizzio and H. Jiang, in "Fundamental Issues in Control of Carbon Gasification Reactivity", J. Lahaye, P. Ehrburger eds., Kluwer Academic Publishers: Dordrecht, The Netherlands, p. 235 (1991).

73. P. J. Hall and J. M. Calo, Energy Fuels, $\underline{3}$, 370 (1989).

74. N. R. Laine, F. J. Vastola, and P. L. Walker, Jr., J. Phys. Chem., 무, 2030 (1963).

75. A. C. Lau, D. N. Furlong, T. W. Healy and F. Grieser, Colloids Surf., $\underline{18}, 93$ (1986).

76. C. A. Coulson, in Fourth Conference on Carbon, Pergamon Press: University of Buffalo, Buffalo, NY, p. 215 (1960).

77. J. L. Johnson, in “Chemistry of Coal Utilization” (Second Suppl. Vol.), M. A. Elliott, ed., Wiley: New York, p. 1491 (1981).

78. R. H. Hurt, A. F. Sarofim and J. P. Longwell, Combust. Flame, 95, 430 (1993).

79. E. Papirer, J. Dentzer, S. Li and J. B. Donnet, Carbon, 29, 69 (1991).

80. Q. L. Zhuang, T. Kyotani and A. Tomita, Carbon, 32, 539 (1994).

81. Q. L. Zhuang, T. Kyotani and A. Tomita, Energy Fuels, $\underline{8}, 714$ (1994).

82. Q. L. Zhuang, T. Kyotani and A. Tomita, Energy Fuels, 10, 169 (1996).

83. Y. A. Zarifyanz, V. F. Kiselev, N. N. Lezhnev and O. V. Nikitina, Carbon, 5, 127 (1967). 
84. S. Ishihara, L. L. Pulido and T. Kajimoto, ACS Preprints (Div. Fuel Chem.), 41(1), 476 (1996).

85. G. A. Andreeva, N. S. Polyakov, M. M. Dubinin, K. M. Nikolaev, Izv. Akad. Nauk SSSR, Ser. Khim., 2193 (1981).

86. M. M. Dubinin, Carbon, $\underline{18}, 355$ (1980).

87. R. Sh. Vartapetyan and A. M. Voloshchuk, Russian Chem. Rev., $\underline{64}$, 985 (1995).

88. B. R. Puri, K. Murari and D. D. Singh, J. Phys. Chem. $\underline{65}, 37$ (1961).

89. B. R. Puri, Carbon, $\underline{4}, 391$ (1966).

90. K. Miura and T. Morimoto, Langmuir, $\underline{4}, 1283$ (1988).

91. E. A. Muller, L. F. Rull, L. F. Vega and K. E. Gubbins, J. Phys. Chem, $\underline{100}$, 1189 (1996).

92. M. M. Dubinin, Carbon, 21, 359 (1983).

93. M. M. Dubinin and V. V. Serpinski, Carbon, $\underline{19}$, 402 (1981).

94. C. Pierce, R. N. Smith, J. W. Wiley and H. Cordes, J. Am. Chem. Soc., 73, 4551 (1951).

95. W. C. Connor, Jr., G. M. Pajonk and J. Teichner, Adv. Catal., 34 , 1 (1986).

96. A. Ekstrom, G. E. Batley and D. A. Johnson, J. Catal., 34, 106 (1974).

97. J. M. Parera, E. M. Traffano, J. C. Musso and C. L. Pieck, in " Spillover of Adsorbed Species”, G. M. Pajonk, S. J. Teichner and J. E. Germain, eds., Elsevier: Amsterdam, p. 101 (1983).

98. A. J. Robell, E. V. Ballou and M. J. Boudart, J. Phys. Chem., 모, 2748 (1964). 


\section{Project DE-FG22-95PC95225}

\section{PUBLICATIONS}

\section{A. Refereed Publications in Journals}

Menéndez, J.A., Phillips, J., Xia, B. and Radovic, L.R., "On the Modification and Characterization of Chemical Surface Properties of Activated Carbon: In the Search of Carbons with Stable Basic Properties." Langmuir 12, 4404 (1996).

Menéndez, J.A., Xia, B., Phillips, J. and Radovic, L.R., "On the Modification and Characterization of Chemical Surface Properties of Activated Carbon: Microcalorimetric, Electrochemical, and Thermal Desorption Probes," Langmuir 13, 3414 (1997).

Xia, B., Phillips, J., Chen, C.-K., Radovic, L.R., Silva, I.F. and Menéndez, J.A., "Impact of Pretreatments on the Selectivity of Carbon for NOx Adsorption/Reduction," Energy \& Fuels 13, 903 (1999).

\section{B. Presentations at Conferences, Symposia, etc.}

Phillips, J., "Calorimetric Investigations of Carbon Catalyst Supports," Microcalorimetry Workshop, San Juan, Puerto Rico, July, 1996.

Phillips, J., Xia, B., Menendez, J.A. and Radovic, L.R., "Creation of Basic Carbon Surfaces with Unique Adsorption Properties," 1996 AIChE Fall Meeting, Chicago.

Menéndez, J.A., Illán-Gómez, M.J., Phillips, J. and Radovic, L.R., "Surface Chemical Effects During Treatment of an Activated Carbon in Hydrogen and Nitrogen", 1996 International Carbon Conference, Newcastle upon Tyne, United Kingdom.

Menéndez, J.A., Phillips, J. and Radovic, L.R., "Optimization of Surface Chemistry of Activated Carbons: Generation of Stable Basic Surfaces," American Carbon Society Workshop Carbon Materials for the Environment, Charleston, SC, June 1996.

Xia, B., Phillips, J., Menendez, J.A. and Radovic, L.R., "Selective Adsorption of NO on Activated Carbon Treated in Hydrogen," 23rd Biennial Conference on Carbon, State College, PA, 1997.

Radovic, L.R., "A Tale of Two Reactions: Char/O $\mathrm{O}_{2}$ and Char/NO," 21st Event of the Italian Section of the Combustion Institute, Ravello, Italy, May 1998. 